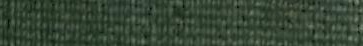

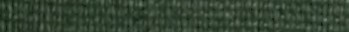
S20

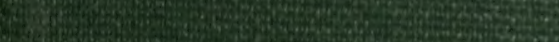
Hof Sy 65 Hin 39. 


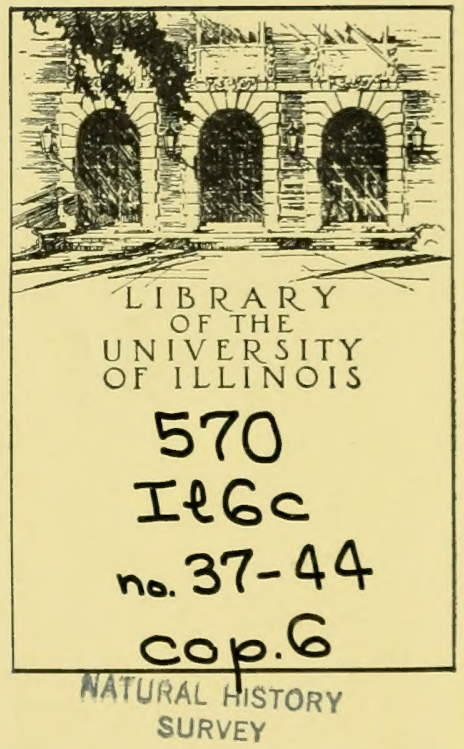


Digitized by the Internet Archive in 2010 with funding from University of Illinois Urbana-Champaign 




\author{
STATE OF ILLINOIS \\ DWIGHT H. GREEN, Governor \\ DEPARTMENT OF REGISTRATION AND EDUCATION \\ FRANK G. THOMPSON, Director
}

\title{
Bird Dogs in Sport and Conservation
}

\author{
RALPH E. YEATTER
}

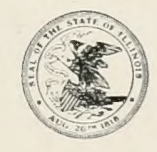

Printed by Authority of the State of Illinois

\section{NATURAL HISTORY SURVEY DIVISION} HARLOW B. MILLS, Chief

Circular 42

Urbana

December, 1948 
STATE OF ILLINOIS

Dwight H. Green, Governor

DEPARTMENT OF REGISTRATION AND EDUCATION

Frank G. Thompson, Director

BOARD OF NATURAL RESOURCES AND CONSERVATION

Frank G. Thompson, Chairman

A. E. Emerson, Ph.D., Biology

L. H. Tiffany, Ph.D., Forestry

L. R. Howson, B.S.C.E., C.E., Engineering
GEORge D. Stoddard, Ph.D., Litt.D., L.H. LL.D., President of the University of Illin Walter H. Newhouse, Ph.D., Geology Roger Adams, Ph.D., D.Sc., Chemistry

\section{NATURAL HISTORY SURVEY DIVISION Urbana, Illinois \\ Scientific and Technical StafF \\ Harlow B. Mills, Ph.D., Chief \\ Bessie B. Henderson, M.S., Assistant to the Chief}

\section{Section of Economic Entomology}

George C. Decker, Ph.D., Entomologist and Head

J. H. Bigger, M.S., Entomologist

L. L. English, Ph.D., Entomologist

C. J. Weinman, Ph.D., Entomologist

S. C. Chandler, B.S., Associate Entomologist

James W. Apple, M.S., Associate Entomologist

Willis N. Bruce, M.A., Assistant Entomologist

John M. Wright, B.A., Assistant Entomologist

H. B. Petty, M.A., Associate in Entomology Extension

George F. Ludvik, M.A., Special Research Assistant

John E. Porter, M.S., Laboratory Assistant

\section{Section of Faunistic Surveys and Insect Identification}

H. H. Ross, Ph.D., Systematic Entomologist and Head

Milton W. Sanderson, Ph.D., Associate Taxonomist

B. D. Burks, Ph.D., Associate Taxonomist

Lewis J. Stannard, Jr., M.S., Assistant Taxonomist

Leonora K. Gloyd, M.S., Laboratory Assistant

Philip W. Smith, B.S., Laboratory Assistant

Dorothy A. Moulton, Technical Assistant

\section{Section of Applied Botany and Plant Pa- thology}

Leo R. Tehon, Ph.D., Botanist and Head

J. Cedric Carter, Ph.D., Plant Pathologist

J. L. Forsberg, M.S., Associate Plant Pathologist

G. H. Boewe, M.S., Assistant Plant Pathologist

Robert A. Evers, M.S., Assistant Botanist
Section of Forestry

Willet N. WANdell, M.F., Forester a Head

Lawson B. Culver, B.S., Associate in F estry Extension

Section of Aquatic Biology

George W. Bennett, Ph.D., Aquatic ologist and Head

William C. Starrett, Ph. D., Associate Aqu ic Biologist

D. F. Hansen, Ph.D., Assistamt Aqua Biologist

R. Weldon Larimore, M.S., Research Ass. ant

Јасов H. Lemm, Field Assistant

Daniel Avery, Field Assistant

\section{Section of Game Research and Manag} ment

Ralph E. Yeatter, Ph.D., Game Specia.

Frank C. Bellrose, B.S., Associate Ga Specialist

Harold C. Hanson, M.S., Assistant Ga Specialist

Section of Publications and Public R lations

James S. Ayars, B.S., Technical Editor a Head

Blanche P. Young, B.A., Assistant Te nical Editor

Charles L. Scott, B.S., Assistant Techni Photographer

\section{Technical Library}

Marguerite Simmons, M.A., M.S., Te nical Librarian

\section{Cooperative Wildlife Research}

Paul J. Moore, B.S., Project Leader George C. Arthur, B.S., Project Leader Lysle R. Pietsch, M.F., Project Leader

A. B. Cowan, B.S.F., Assistant Project Lea

Consultant in Herpetology: Hobart M. Smith, Ph.D., Assistant Professor of Zoology, Univers of Illinois. 


\section{CONTENTS}

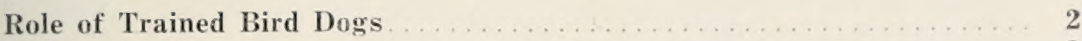

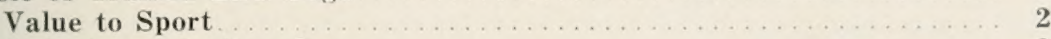

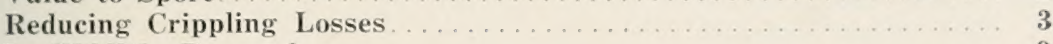

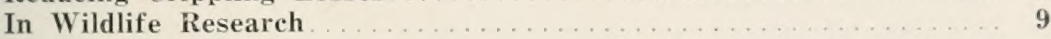

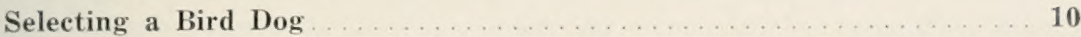

Breeds and Classes . . . . . . . . . . . . . . . . . . . . . . . 11

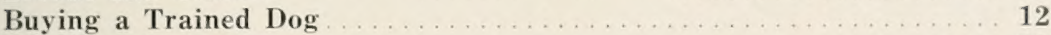

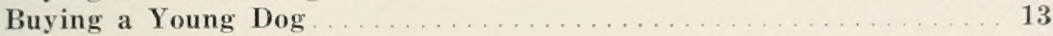

Desirable Characteristics. . . . . . . . . . . . . . . . . . 14

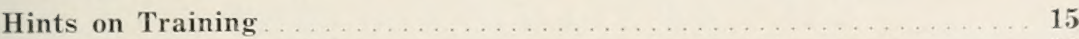

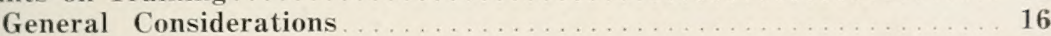

The Amateur Trainer. . . . . . . . . . . . . 16

Training Systems . . . . . . . . . . . . . . . . . . . . . . . . 19

Training Classes. . . . . . . . . . . . . . . . . . . . . . . 20

Planted Game . . . . . . . . . . . . . . . . . . . . $20 \ldots \ldots$

The Young Dog . . . . . . . . . . . . . . . . . . . . . . . . . . . . 20

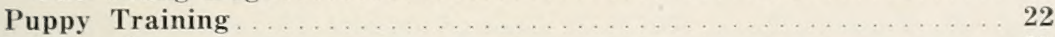

First Lessons . . . . . . . . . . . . . . . . . . . . . . 22

Name . . . . . . . . . . . . . . . . . . . . . . . . 22

Lead . . . . . . . . . . . . . . . . . . . . . . 23

"No" . . . . . . . . . . . . . . . . . . . . . . . . . 23

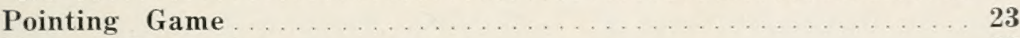

Natural Retrieving . . . . . . . . . . . . . . . . . . 23

Force Breaking to Retrieve . . . . . . . . . . . . . . . 25

Freedom in the Field . . . . . . . . . . . .

Accustoming to Firing of Gun . . . . . . . . . . . . . 27

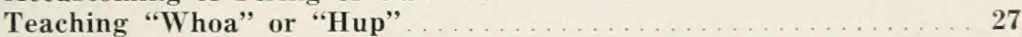

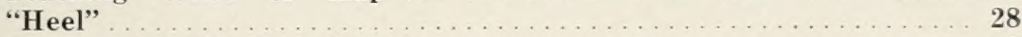

Review of "Whoa" or "Hup" . . . . . . . . . . . . . . . . . 29

Coming Promptly to Call ... . . . . . . . . . . . . . . . . . . . 29

Hand Signals . . . . . . . . . . . . . . . . . . . . . 29

Advanced Yard Training . . . . . . . . . . . . . . . . . . . . . 29

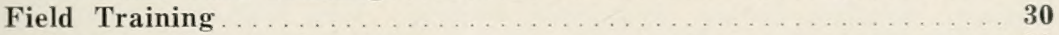

Teaching Dog to Quarter...................... 30

Steadiness on Point and to Wing and Shot. . . . . . . . . 32

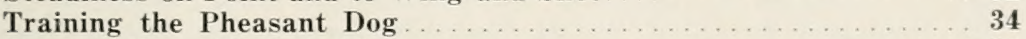

Overhandling Undesirable . . . . . . . . . . . . . . . 36

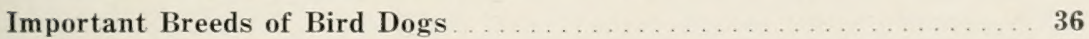

The Pointing Breeds . . . . . . . . . . . . . . . . 37

Brittany Spaniel . . . . . . . . . . . . . . . . . . . . . 37

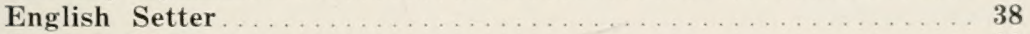

Gordon Setter .............................. 39

Irish Setter . . . . . . . . . . . . . 41

Pointer . . . . . . . . . . . . . . . . . . . . 42

German Shorthaired Pointer...................... 44

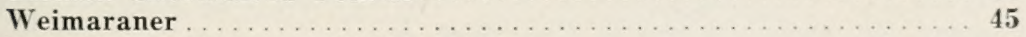

Wire-Haired Pointing Griffon.................... 47

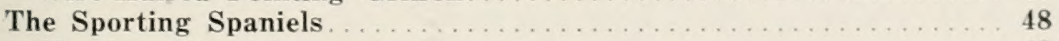

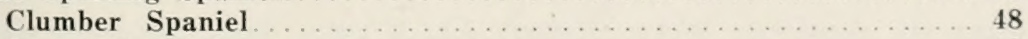

Cocker Spaniel . . . . . . . . . . . . . . . . . . . . . . . . 49 
Sussex Spaniel

The Retrievers

American Water Spaniel

Chesapeake Bay Retriever

Curly-Coated Retriever

Flat-Coated Retriever

Golden Retriever

Irish Water Spaniel

Labrador Retriever

\section{LIST OF. ILLUSTRATIONS}

Frontispiece. English Springer Spaniel, F. T. Ch. Bing of Roe. Winner in various field trials and third in First National Amateur Field Trials for English Springer Spaniels at Craborchard Lake, Illinois, December 12-14, 1947. Mr. and Mrs. Joseph C. Quirk, Greenwich, Conn., owners. Photo by Evelyn Shafer.

Page 3. Pointer, Sport. Dr. E. F. Greer, Vandalia, Ill., owner. Photo from Bob Becker.

Page 4. Chesapeake Bay Retriever, F. T. Ch. Tiger of Clipper City. Dr. George H. Gardner, Evanston, Ill, owner. Photo by Evelyn Shafer.

Page 5. Golden Retriever, F. T. Ch. King Midas of Woodend. Winner of First National Championship, held in 1941. E. N. Dodge, Wayzata, Minn.. owner. Photo from Bob Becker.

Page 5. Cocker Spaniel, F. T. Ch. Cinar Spot of Earlsmoor. Connecticut Spaniel Field Trial, Saybrook, Conn., November 17-18, 1944. Dr. Samuel Milbank, owner-handler. Photo from Bob Becker.

Page 6. Black Labrador Retriever. Photo from Bob Becker.

Page 7. Yellow Labrador Retriever, Mac of Greencroft. Russell Wilcox, Horicon, Wis., owner. Photo from Bob Becker.

Page 8. English Setter, Huntstone Felicia. Bob Becker, Chicago, Ill.. owner. Photo from owner.

Page 9. Labrador Retrievers, F. T. Ch. Glenairlie Rocket, right, and F. T. Ch. Glenairlie Rover. F. T. Ch. Glenairlie Rocket (Mrs. Frances Morgan Garlock, Brockport, N. Y., present owner; Glenairlie Kennels, Barrington, Ill., former owner) is said to have won more points in field trials up to 1948 than any other Labrador. F. T. Ch. Glenairlie Rover, his sire, was formerly a widely known field trial winner. F. F. Garlock, owner. Photo from owner.

Page 10. English Setters, F. T. Ch. Susie, left, and Sal. Susie was champion in puppy class in northern Illinois field trials held at Downers Grove, March, 1948, and placed second in derby at Asa B. Wallace Memorial Field Trials at Weldon Springs, Mo., November 1, 1948. Paul Sabo, Jr., Champaign, Ill., owner. Photo by Paul Sabo, Jr.

Page 12. Pointers. Photo from Bob Becker.

Page 13. American Water Spaniel, Ch. Grant's Red. Theodore Grant, Downers Grove, Ill., owner. Photo from Bob Becker. 
Page 15. Britany Spaniel, ('h. Iromo IIappy. Judged best in breed at 1916 National Brittany Spaniel Specialty Show, and winner in various field trials. Jack L. Whitworth, Avon, Ohio, owner. Photo from owner.

Page 16. Irish Water Spanicl, Boges Jiggs. Thomas (C. Marshall, Fairfield, Conn., owner. Photo from liob Becker.

Page 18. English Setter. Photo by Evelyn Shafer.

Page 21. Irish Setter in araing by clifford Wallace. Ihoto from boh Becker.

l'age 26. Labrator Retriever, Shot of Barrington, being trained to retrieve by Martin Hogan. V. Me:kle, Chicago, Ill., owner. Photo from Bob Bectier.

Page 28. Engish Springer Spaniel and traners. I'hoto from Bob becker.

Page 31. Weimaraner. Photo from Bob Becker.

Page 32. German Shorthaired Pointer. Photo from Bob Becker.

l'age 35. Brittany Spaniel, Gwennes' Passy the Second. Tommy Thompson. Ferndale, Mich.. owner. Photo from Bob Becker.

l'age 37. Brittany Spaniel, Ch. Nac of Paradise. Judged best in breed at 19.17 National Brittany Specialty Show, and best in breed at Chicago International, 1918. W. S. Oberlin, De Kalb, Ill., owner. Photo by George IF. Bennett.

Page 39. English Setter. Int. Ch. Silvermine Wagabond. Mr. and Mrs. Davis II. Tuck, Redding Ridge, Conn., owners. Photo by R. W. Tauskey.

l'age 10. Gordon Setter, Ch. Blakeen Saegryte. George W. Thompsom. Baltimore, Md., owner. Photo by William Brown.

Page 41. Irish Setter, Bryan of Tyronne. Edward H. Brown, Waltham. Mass., owner. Photo by Evelyn Shafer.

Page 43. Pointer. Photo by Evelyn Shafer.

Page 4. German Shorthaired Pointer, Ch. Sue von Schwarenberg. Jack Shattuck, Jr., Minneapolis, Minn., owner. Photo from G. D. Goodwin.

Page 46. Weimaraner, Ch. Silver Blue Luke. Charles S. Hartung, Chery Chase, Md., owner. Photo by Brooks Studio, Washington, D. C.

Page 48. Wire-Haired Pointing Griffon. Max MeGraw, Fin'n Feather Farm. Dundee, Ill., owner. Photo from owner.

Page 49. Clumber Spaniel, Squirrel Run Ree. Hallock Du Pont. Wilmington, Del., owner. Photo by Evelyn Shafer.

Page 50. American Cocker Spaniel. Photo by Evelyn Shafer.

Page 51. English Cocker Spaniel. Photo by Evelyn Shafer.

Page 52. English Springer Spaniel, F. T. Ch. Russet of Middlefield. Champion at First National Imateur Trials for English Springer Spaniels at Craborchard Lake, Ill., December 12-14, 19.17. Dr. C. G. Sabin. Portland. Ore., owner. Photo by Evelyn Shafer.

Page 54. Sussex Spaniel. Hornshill Russet. Mrs. Brewster Sewall, New Hartford, Conn., owner. Photo by Evelyn Shafer.

Page 55. American Water Spaniel. Photo by Evelyn Shafer.

Page 57. Chesapeake Bay Retriever. Ch. The Second Cocoa. F. 1. Bunte. Chicago, Ill., owner. Photo by Allison-Lighthall, Chicago, Ill.

Page 58. Curly-Coated Retriever, Sarona Jacob of Marvadel. J. Gould Remick, Cedarhurst, N. Y., owner. Photo by Evelyn Shafer. 
Page 59. Flat-Coated Retriever, Black Royal. Mrs. Robert Boggs. New York, N. Y., owner. Photo by Evelyn Shafer.

Page 60. Golden Retriever. Photo by Evelyn Shafer.

Page 61. Irish Water Spaniel, Ch. Handsome Mahoney. Sire of numerous champion Irish Water Spaniels. R. G. Lindsay, Milwaukee, Wis.. owner. Photo from owner.

Page 63. Labrador Retriever. Photo by Evelyn Shafer.

Note.-The author regrets that names or winnings of some dogs piciured in this circular have been necessarily omitted because of inability to obtain full identifica. tions. 


\section{ACKNOWLEDGMENTS}

The writer is indebted to numerous persons and organizations for assistance in preparation of this circular. Special thanks are due to Charles S. Goodall for advice on training and for critical reading of the manuscript; to Bob Becker for permission to quote from his publications and for the loan of a number of photographs used in this circular; and to Robert Cary, artist, for the crayon drawing used on the cover.

The writer wishes to thank members of the Natural History Survey staff for their cooperation, especially Dr. Harlow B. Mills, Chief, for advice and interest; Dr. Leo R. Tehon, who proposed this circular and encouraged its writing; Dr. George W. Bennett for constructive eriticisms and photography; Willet N. Wandell for making available unpublished material; and James S. Ayar's for counsel on numerous occasions during the writing of the manuscript.

Appreciation is expressed to the American Kennel Club for permission to use material from its publications. The Complete Dog Book (1947) is the source of much of the material on breeds.

The writer is grateful to the late Professor Howard M. Wight for pointing out the value of bird dogs in game studies, and to Dean S. T. Dana of the University of Michigan School of Forestry and Conservation for permission to quote from Professor. Wight's unpublished manuscript on the pheasant dog.

Thanks are due many others who cooperated with the writer in various ways. Unfortunately the list is too long to be published in full. The following assisted in obtaining material for the text or furnished photographs:

F. A. Bunte, Chicago, Ill.; Rune Clark, Champaign, Ill.; H. B. Conover, Chicago, Ill.; Dean H. Ecke, Denver, Colo.; F. Fletcher Garlock, Chicago, Ill.; G. D. Goodwin, Secretary, German Shorthaired Pointer Club of America, Inc., Minneapolis, Minn.; Mrs. H. W. Glassen, Secretary, the English Setter Association, Lansing, Mich.; Rober't E. Hesselschwerdt, Urbana, Ill.; Roland Kilbon, Editorial Department, Sun, New York, N. Y.; R. G. Lindsay, Milwaukee, Wis.; Max McGraw, Dundee, Ill.; Beatrice E. Peterson, Librarian, American Kennel Club, New York, N. Y.; Darwin Morse, Secretary-Treasurer, the Weimaraner Club of America, Richmond, Mass.; Dr. Charles G. Sabin, President, Northwest English Springer Spaniel Club, Inc., Portland, Ore.; Miriam L. Steyer, Secretary, Gordon Setter Club of America, Bronx, N. Y.; Joseph C. Quirk, Secretary-Treasurer, English Springer Spaniel Field Trial Association, Inc., New York, N. Y.; and Jack L. Whitworth, Secretary, American Brittany Club, Avon, Ohio. 


\section{BIRD DOGS}

RALPHE. YEATTER

RIRD DOGS have enjoyed wide popularity among Illinois huntB er's for many years. During the period of settlement, the open prairies proved well adapted to dog work, and even then hunters imported and bred pointers and setters to aid in hunting upland game birds. Later, retrievers became well known in the extensive waterfowl hunting areas of the Illinois and Mississippi river valleys. Since the ring-necked pheasant was added to the list of Illinois game birds about 30 years ago, spaniels have become popular as upland game dogs. The recent marked increase in hunting as a recreation has brought an increase in the numbers of bird dogs of all kinds, and today one or more breeds can be seen in nearly every community in the state.

Indicative of the interest in bird dogs shown by sportsmen and other outdoor enthusiasts of Illinois is the number of major field trials held in the state annually. Other organized efforts that indicate an interest in bird-dog breeds and help to advance them include the activities of specialty clubs. Many of these clubs have good-sized membership lists. Howerer, in Illinois, as elsewhere, by far the largest number of backers of bird dogs is found in the host of unorganized owners who value these dogs for their services afield, as well as for their friendliness. intelligence, and beauty, qualities that make them. as a class. excellent family dogs.

This circular discusses pointing dogs, spaniels, and retrierers, referred to collectively here as bird dogs, in relation to hunting and wildlife conservation in Illinois. Although it was witten chiefly with a view to giving information for the benefit of prospective owners and owners who plan to train their own dogs. it is hoped that it will be of some value to everyone who likes to hunt and is interested in the welfare of Illinois wildlife.

A suggestion made to the Illinois Natural History Survey by Bob Becker was in large measure responsible for the writing of this circular. Mr. Becker, as one of the directors of the Illinois: State MIuseum, urged the Surver to undertake a study of the 
place of bird dogs in Illinois conservation, particularly from the standpoint of reducing crippling losses of upland game and waterfowl. The following discussion of the important values of there hunting $\log s$ is based on studies in Illinois and elsewhere.

\section{ROLE OF TRAINED BIRD DOGS}

At the present time, trained bird dogs in Illinois serre in three important capacities. Not only do they continue in their historic role as companions of the hunt; they also help to conserve dwindling game resources by reducing crippling losses and they aid in wildlife research.

\section{Value to Sport}

Illinois ranks high among states in the proportion of land devoted to agriculture. In the northern half of Illinois. where the great bulk of the state's 8,000,000 inhabitants live, intensive farming and pasturing make upland game cover very scarce.

Illinois hunters include about 400,000 residents who buy hunting licenses annually and, in addition, many farm owners. tenants, and farm boys who hunt on their home acres without being required to purchase licenses. The total number of hunter: in the state each year is undoubtedly well orer a half million.

Although the cottontail rabbit, in point of numbers taken. is by far the most important game species in Illinois, the game birds, particularly quails and pheasants, provide the farorite sport of many hunters. In bird hunting, trained dogs play an especially important role. Well-trained bird dogs increase materially the opportunities of bagging game. They are especially important to the average bird hunter, whose time in the field is limited to a few trips or a few hours annually, and whose annual game bag is relatively small. Many hunters who do not own dogs hunt with friends who do. Thus, the thousands of trained bird dogs in the state help to distribute the opportunities of harresting game among a large number of hunter's.

The fact that trained hunting dogs tend to increase hunting success often orershadows other important values of these dogs. Not the least of these ralues is that. for most people. hunting with a dog greatly increases the enjoyment of the sport. The use of bird dogs frequently diverts emphasis from large game hags to enjoyment of hunting as a recreation. Toluntary limiting of 
the kill is commendable, since most kinds of game birds are no longer numerous enough to meet the heavy and growing demands of hunters.

The value of the trained bird dog to the arerage hunter is well expressed by Bob Becker (1945): "In our estimation, the

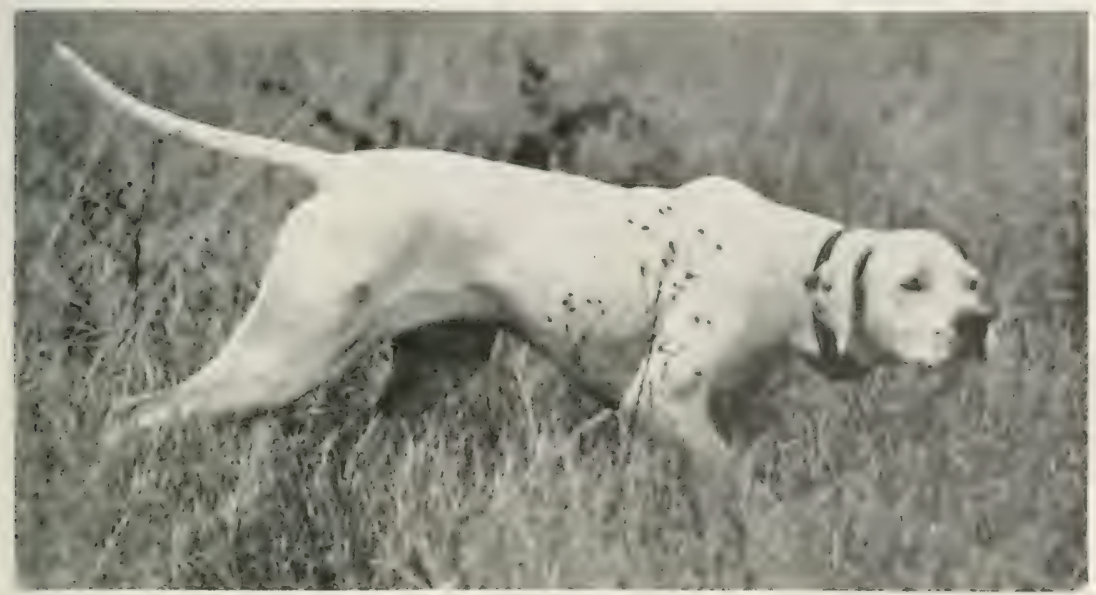

The rigid point and tense expression of this pointer mean quails just ahead. Skillful handling and retrieving of birds by well-trained dogs add much to the enjoyment of any hunt.

most potent reason for using a hunting dog, aside from the humane angle of finding wounded birds, is the FUN of getting your game with the aid of a devoted canine partner. And he doesn't have to be a purebred with a pedigree a mile long to give the owner a lot of fun in the hunting field. If the pooch has a nose and will get those cripples he can't help but add a lot of fun to any hunt. In fact, a hunter who doesn't use a dog misses about 80 per cent of the fun of a hunt."

\section{Reducing Crippling Losses}

It is now recognized that retrievers and other hunting dogs: that ale trained to retrieve have an important place in game management. By capturing wounded birds and mammals that would otherwise escape the hunter, these dogs reduce materially a serious wastage of wildlife. A high percentage of game partially or wholly disabled by shot will eventually die of wounds or be killed by natural enemies. Game lost by crippling means more 
game killed or crippled by hunter's in an effort to complete the hunting bag.

Crippling losses of upland game and waterfowl have become a cause of grave concern on the part of conservation officials and thoughtful sportsmen. The extent of these losses is indicated

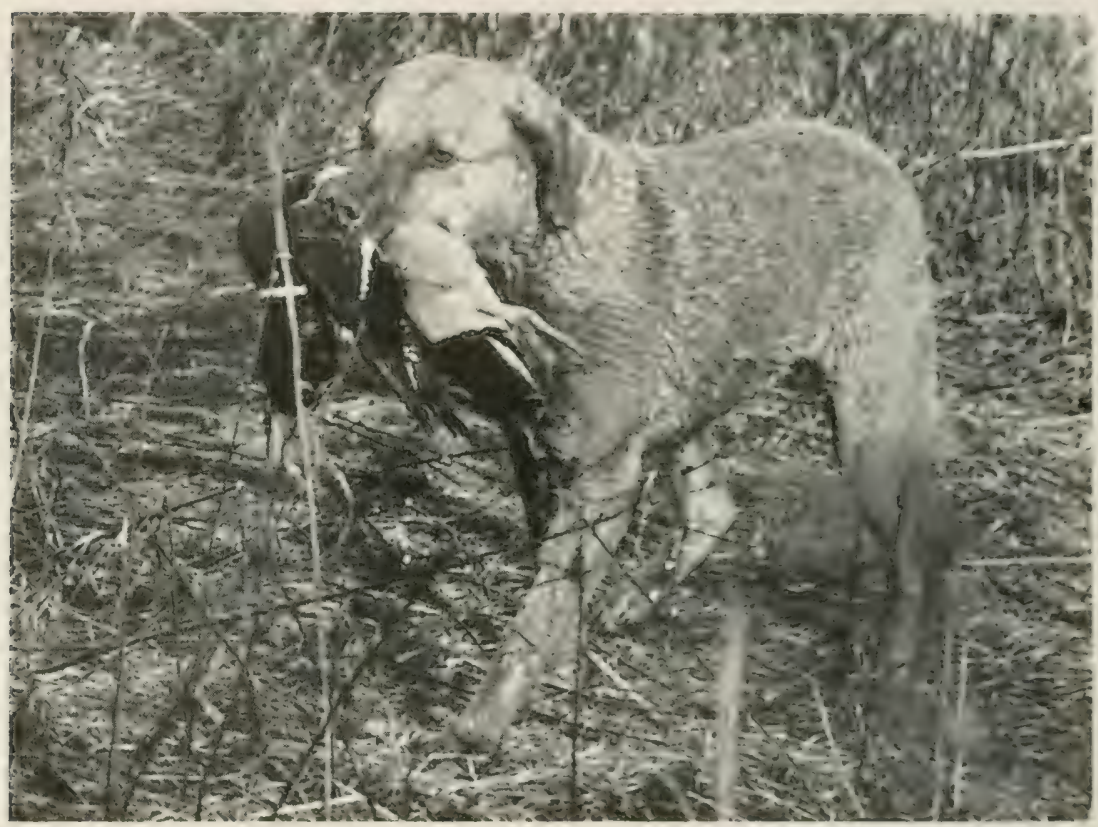

The Chesapeake Bay Retriever breed originated on the eastern seaboard. Dogs of this breed, for several years numerically strong in the Mississippi River valley, have retrieved many ducks annually.

by studies in various states. In Minnesota, for example. crippling losses of ducks were found to vary from 11 to 54 per cent of the total number bagged plus birds known to be crippled, and the losses by pheasant hunters to vary from 6 to 48 per cent (Nelson \& Swanson 1941). The percentage of crippling was influenced by the type of shooting and the experience of the hunters. In a detailed study in Pennsylvania, the crippling losses of pheasants averaged 30.4 per cent of the number bagged and crippled (Randall 1939). Hawkins \& Bellose (1939) estimated the criplling losses of dabbling ducks on the Illinois River to be at least onethird of the annual bag, and of diving ducks more than one-half the bag.

The effectiveness of retrierer's in reducing crippling losses 


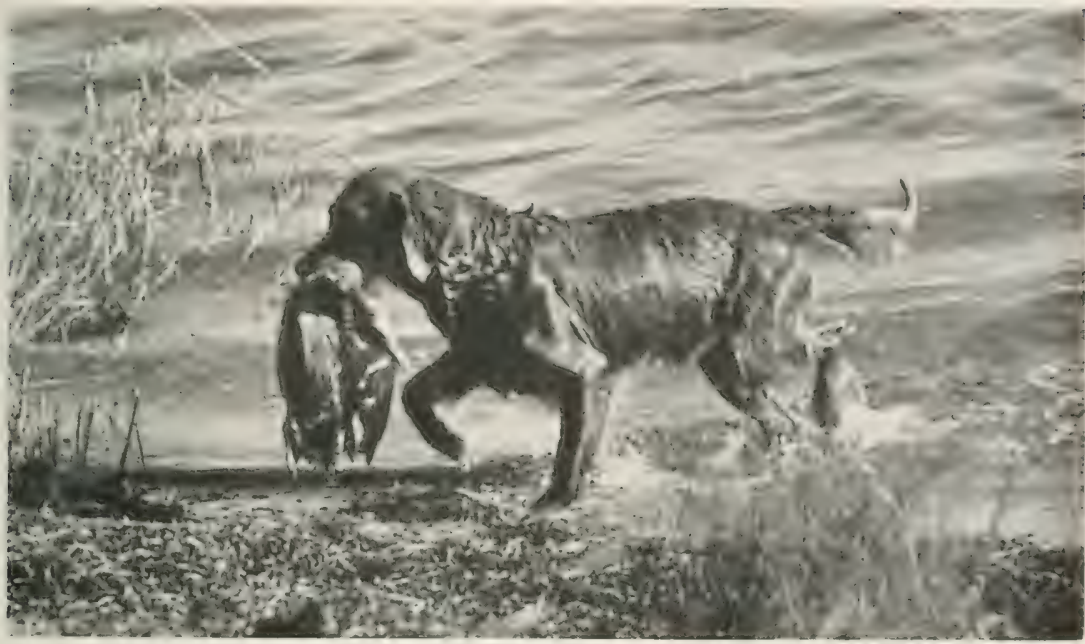

A Golden Retriever brings in a duck. Estimates of the number of ducks wounded or killed and not recovered in Illinois range from one-third to onehalf the number bagged. Greater use of trained retrievers could materially reduce this loss.

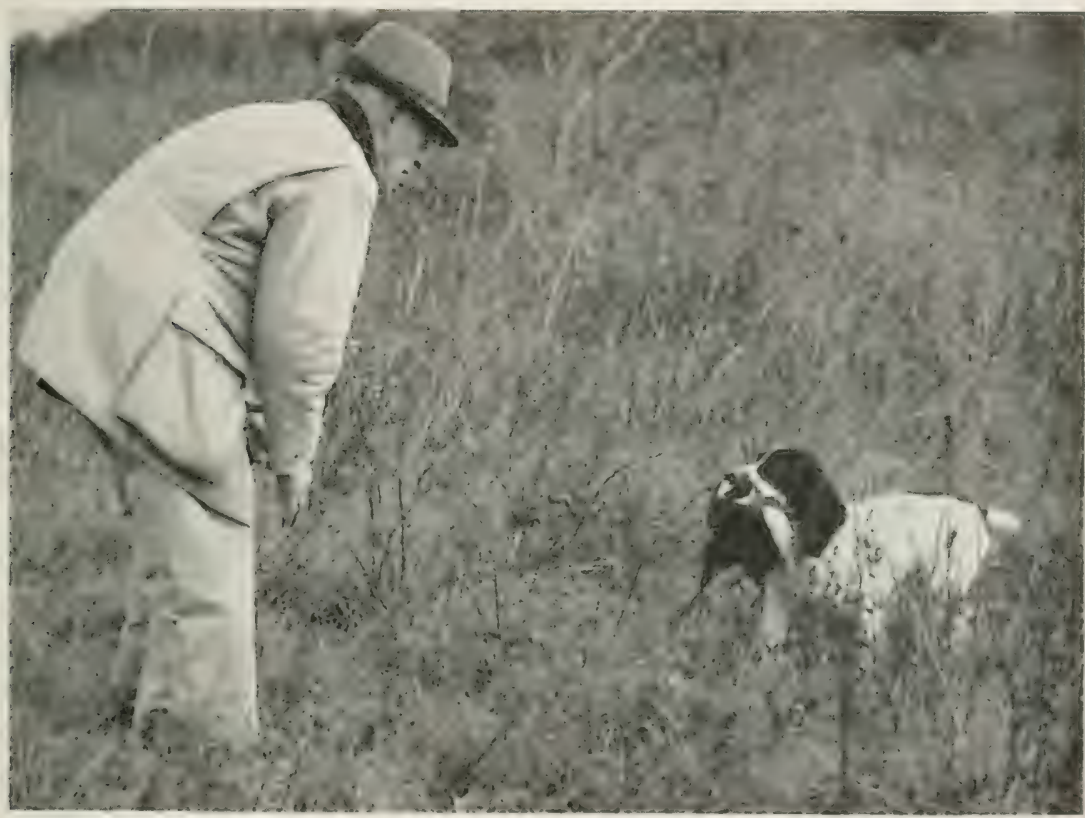

A Cocker Spaniel retrieves a wounded pheasant. Despite small size, the hunting strains of Cockers are splendid field dogs. 
is illustrated graphically by a tally of hunters' bags carried on throughout the 1946 hunting season on two check areas in northern Illinois, one in Kendall County and one in Winnebago County.

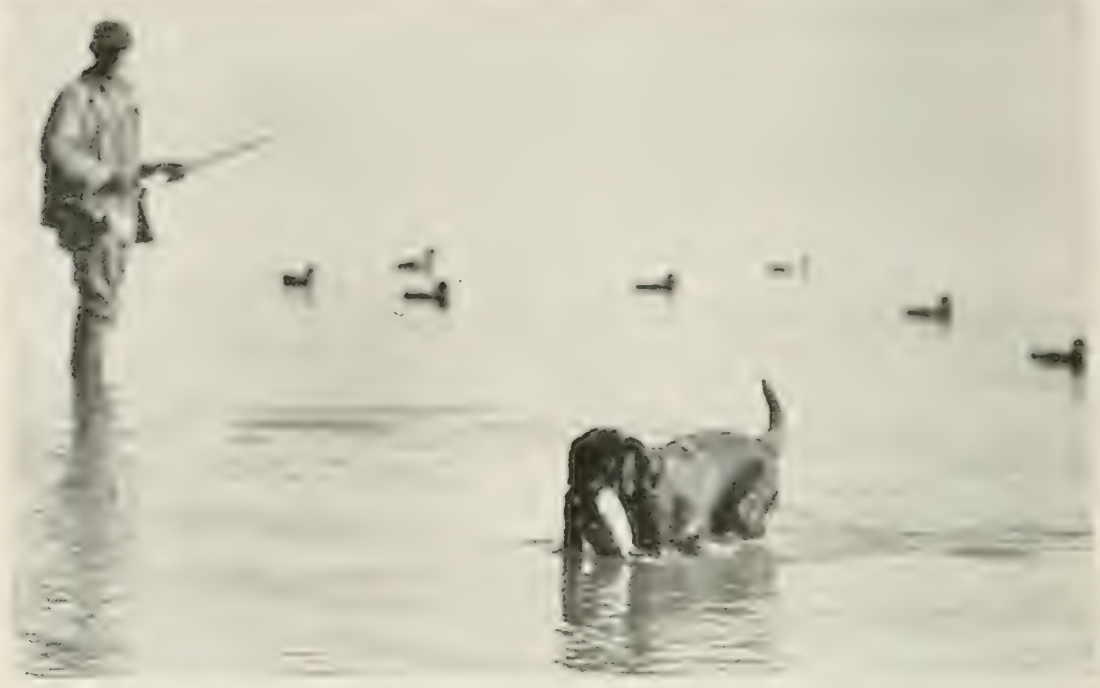

Several kinds of retrievers are well known in the Illingis waterfowl flyways. Here a black Labrador retrieves a duck shot by a hunter from a nearby blind.

On these areas the hunters who hunted without dogs shot 88 pheasants, of which 19, or 21.6 per cent, were crippled birds that were able to escape. Hunters with dogs shot 81 birds. of which only 8 , or 9.9 per cent, were so lost.*

Similar reductions of crippling losses when dogs were used were found in the previously mentioned Pennsylrania pheasant study (Randall 1939). Here it was found that hunters of all classes who hunted without dogs had an arerage crippling loss of 39.8 per cent, while those who hunted with dogs lost only 20.1 per cent of their birds. The losses reported by all the Pennsylvania hunters were high, but the number of birds lost by crippling was reduced to approximately half by retrieving dogs, as was the case in Illinois.

In the Pennsylvania study, the hunters were classified in three groups, novice, average, and reteran. Novice hunters were

\footnotetext{
*Unpublished data contributed by Illinois Pheasant Research Project $($ PR-30) conducted cooperatively by the Illinois Natural History Survey, the Illinois Department of Conservation, and the U. S. Fish and Wildife service.
} 
found to have higher arppling losses than arerage or veteran hunters, owing partly to such caluses as shooting at bircls that were out of range and using too smatl or too large shot. Nevertheless, the losses of even veteran hunters were reduced by more than 40 per cent by the use of retrieving dogs.

The true retriever breeds, such as the Chesalpeake. Labliatdor, Golden, and the water spaniels, were developed prinarily as waterfowl retrievers, but today many of these dogs are being used on upland game. In upland game hunting they have been teamed frecuently with pointing dogs as "non-slip" retrievers (that is, kept at heel except when retrieving). However, their services are not confined to retrieving; often they can be trained to hunt pheasants and other game ahead of the gun. The American Water Spaniel is a notable example of a retriever that can easily be trained to hunt upland game. Labrador's, Chesapeakes, and doubtless other retriever breeds seem to possess considerable ability as hunters.

Speaking of Labradors, Becker (1947b) says: "Another point about the Labrador which the average duck and pheasant hunter will be interested in is the breed's ability to be trained something

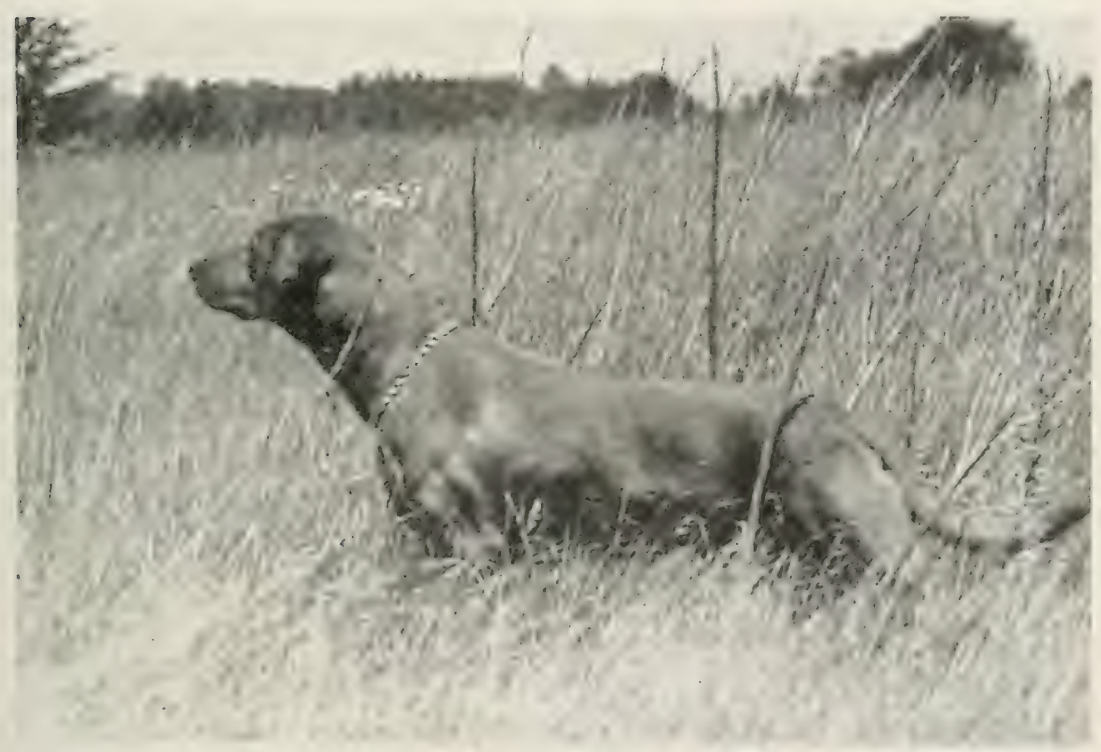

Retrievers are becoming more popular in upland game hunting. where they are often teamed with pointing dogs or sporting spaniels. In some cases, retrievers, like this pointing yellow Labrador, are trained to quest for pheasants. 
like a spaniel and work ahead of the gun to flush game. It's qui.e possible that not all Labradors will do this. We owned one Labrador (Dawn of Kezar) who, after being broken as a retriever. was taught in a few weeks tr take hand signals and quarter her ground back and forth ahead of the gun. No one watching her valuable work would pretend that she crashed the weed thickets with the speed and dash of a Springer... . But this Lab loved to quest for game. To the 'hunt 'em up' command and at ware of the hand she would bang into the brush and tall weeds to find pheasants for us, always staying within easy gun range."

Most upland bird hunting is, of course, done with the pointing and sporting spaniel breeds, and in these dogs ability to retrieve is especially important from the standpoint of reducing crippling losses of upland game. Many of the pointing dogs and sporting spaniels owned by Illinois hunters are trained for the dual purpose of finding and retrieving. In the case of the spaniels. training to retrieve is doubtless given considerable impetus by the fact that they are expected to retriere in field trials. Retriering is not included in field trials for the pointing breeds. In reg:trd to trials for pointing dogs, the late Professor Howard M. Wight

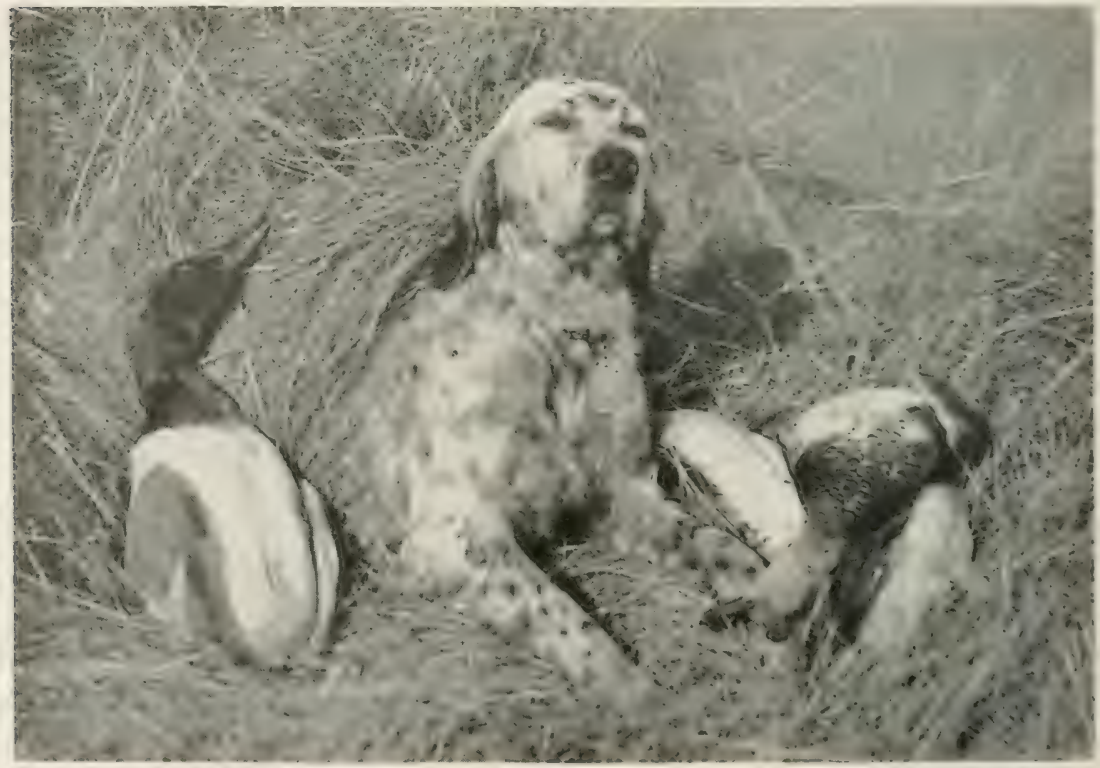

Although trained on upland game birds, setters occasionally fill in as waterfowl retrievers. This English Setter served as pick-up dog during a shoot on a duck pass in North Dakota pheasant country. 
of the University of Michigan School of Forestry and Conservattion (unpublished) wrote:

"It seems to me that field trials emphasize both speed and range too much, for while both are worthy of attention, they are

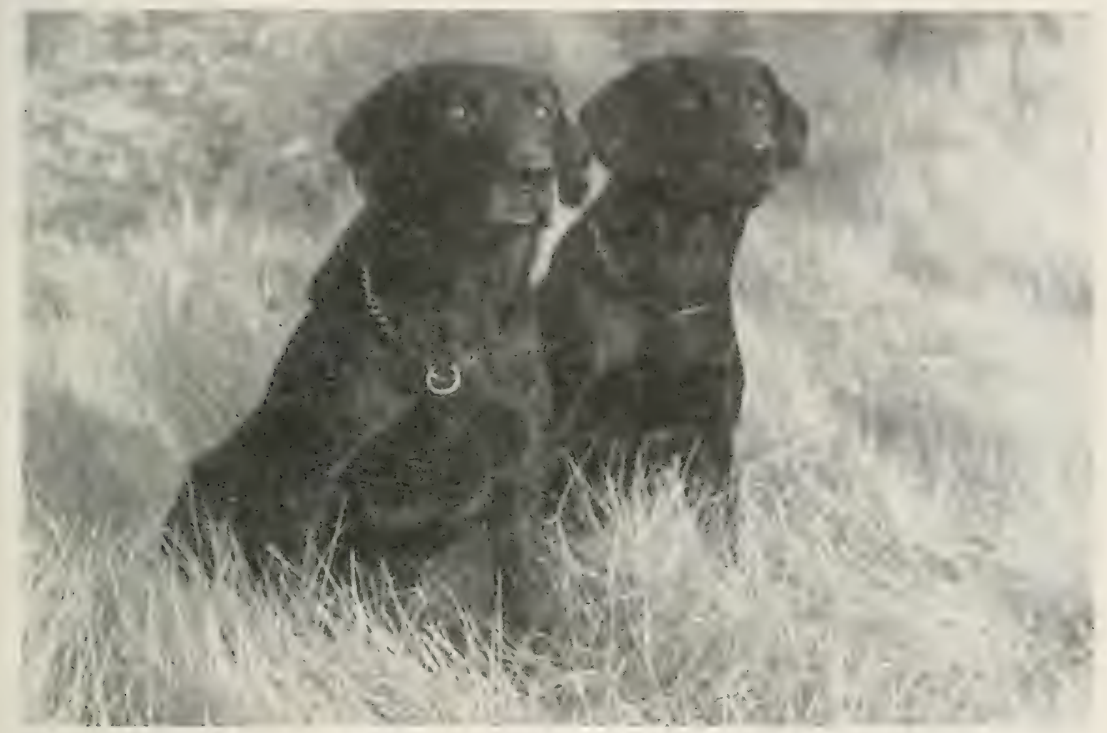

A pair of champion Labrador Retrievers owned by an Illinois sportsman. Field trials stimulate the improvement of the bird-dog breeds.

now quite well beyond any particularly practical use, and such factor's as the ability to retrieve may well be given a more pronounced place in trials designed to improve the bird dog."

\section{In Wildlife Research}

Increasingly stringent legal restrictions on hunting seasons, game bags, and other improvised conservation measures have, in most instances, failed to halt the downward trend of upland game, waterfowl, furbearers, and other wildlife. This failure has brought a tardy recognition of the importance of preserving and restoring wildlife habitats. Unfortunately, Wasteful land management practices. including a general intensification of farming and grazing, regardless of land types, and wholesale draining. have already caused tremendous losses of soil. Water. forests. and wildlife. 
The past two decades have seen a remarkable growth of research in the field of wildlife conservation. Throughout the country, biologists in colleges, in universities, and in state and federal conservation agencies are gathering facts on the basic requirements and behavior of game and other wildlife. This

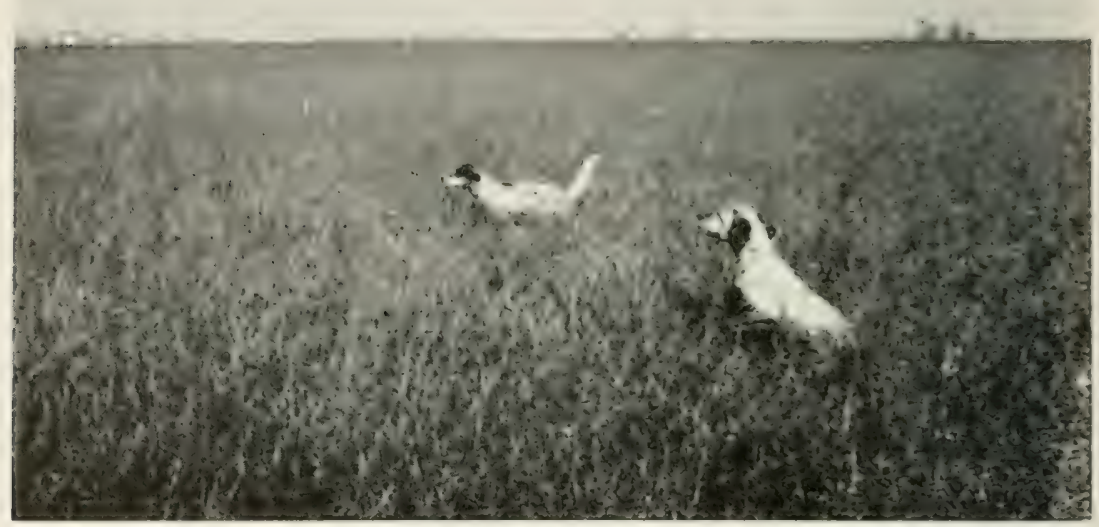

Two English Setters spot a pheasant in a central Illinois stubble field. The rear dog has stopped short to honor the other's point. Trained bird dogs such as these are of much value in game studies.

information is necessary before wildlife management can find and maintain its proper place in the whole conservation morement.

Game research has created a new field of usefulness for the talents of various breeds of hunting dogs in the United States. Several years ago, Professor Wight conducted extensive studies of pheasant populations in Michigan with the aid of his setters. Max and Max Barry, and thus drew attention to the ralue of trained dogs in wildlife investigations. Since then, hunting dogs: have given valuable aid to field men engaged in game population studies, in life history studies, and in other kinds of game research and management work.

\section{SELECTING A BIRD DOG}

Picking the right dog for a hunting companion depends in large measure on the sportsman's hunting preferences, on his knowledge of the work of the different breeds. and on the sound- 
ness of his appraisal of the hunting potentialities of the particular dog or dogs in which he is interested.

\section{Breeds and Classes}

The bird dogs may be conveniently classified into three groups: (1) the pointing breeds, (2) the sporting spaniels, and (3) the retrievers. The chief breeds are given in the following list.

The Brittany Spaniel, the only spaniel that points game, is here listed with the pointing dogs. Two spaniels, the American Water Spaniel and the Irish Water Spaniel, are well-known retrievers and compete with the other retrievers in field trials. All of the breeds of sporting spaniels and pointing dogs can, of course, be trained to retrieve.

\section{BREEDS AND CLASSES OF BIRD DOGS}

ClassifiCATION

Pointing Dogs

Sporting Spaniels

Retrievers
BREED

Brittany Spaniel

English Setter

German Shorthaired Pointer

Gordon Setter

Irish Setter

Pointer

Weimaraner

Wire-Haired Pointing Griffon

Clumber Spaniel

Cocker Spaniel

English Springer Spaniel

Field Spaniel

Sussex Spaniel

American Water Spaniel

Chesapeake Bay Retriever

Curly-Coated Retriever

Flat-Coated Retriever

Golden Retriever

Irish Water Spaniel

Labrador Retriever

The hunting breeds in the above list that are best known in Illinois are probably the Pointer, English Setter, English Springer. 


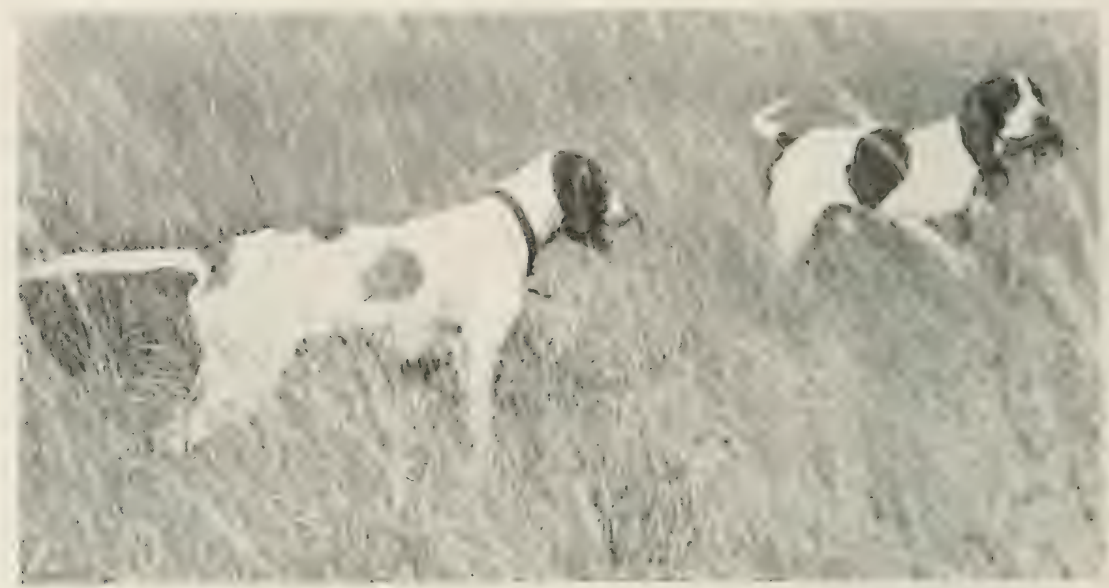

The leading Pointer has just retrieved a quail and is holding it in his mouth while he points another hird. The well-trained companion is honoring his brace mate's point.

Spaniel, Irish Setter, Chesapeake Bay, Labrador, and Golden retrievers. The Brittany Spaniel, Gordon Setter, German Shorthaired Pointer, and American Water Spaniel are fairly well known. The Cocker Spaniel is probably the most popular of all family $\operatorname{dogs}$, but is used much less for hunting in Illinois than the Springer Spaniel. Although most people know the Irish Water Spaniel, it is overshadowed by some of the better known breeds of retrievers and ranks as one of the rarer hunting dogs in this state. The other bird dogs are rare or known to but few Illinois hunters. The rarity of these breeds in no way detracts from their merit.

\section{Buying a Trained Dog}

The prospective purchaser of a hunting dog may be faced with the problem of training his dog for work in the field. The sportsman who is able to buy a fully trained dog does not have this problem, but he should remember that training methods differ. For best results he should know how the dog has heen worked in the past. This statement applies also to the owner who has had his dog trained by a professional. Although dissatisfaction between a dog buyer and a reputable dealer or trainer is usually due to differences in handling and knowledge, the buyer should not lose sight of the fact that there is a certain number of 
dishonest dealers who adrertise "trained" dogs that are of little or no value as hunting dogs. He should make sure that he is dealing with a reputable seller (Stringer 1946).

\section{Buying a Young Dog}

A 3-months-old puppy will probably give little evidence of his potential ability as a hunting dog. Hence, it is to the advantage of the purchaser to learn as much as possible of the ancestry of the prospect. The buyer of a registered puppy has the advantage of records kept over a number of years. Familiarity with the families of the breed that have produced outstanding field trial dogs is helpful in making a choice. Although there are many bird dogs of uncertain ancestry that do good work in the field, buying a purebred puppy of proved hunting ancestry increases considerably the probability of getting a good performer.

A puppy should not be taken from its mother before the age of 2 months. If it is to be shipped far, it should be at least

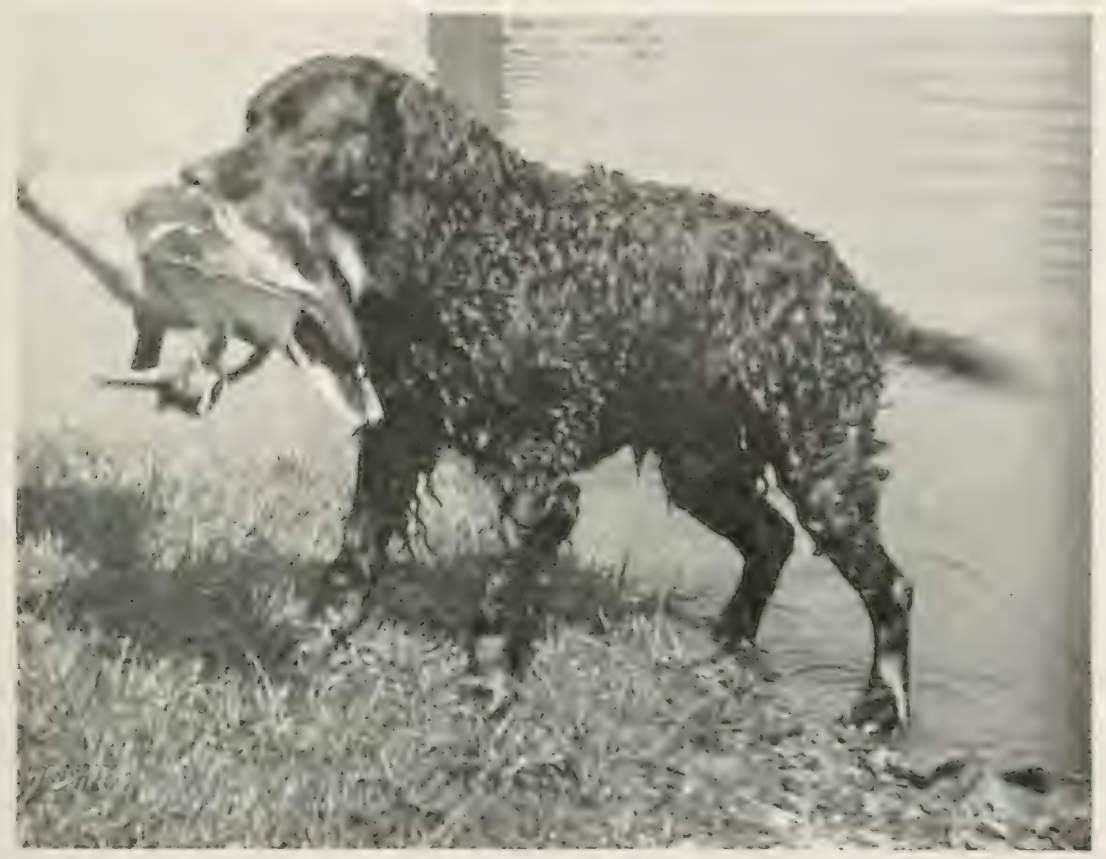

A sturdy and eager retriever despite his small size, the Imerican Water Spaniel continues to win friends among Illinois sportsmen. It is at home in upland as well as marsh hunting. 
3 to 4 months old, and preferably 4 to 6 months. The strain of shipping may give a younger puppy a sethack from which it will recover slowly, if ever (Lytle 1934).

Dogs can now be shipped by plane from New York to California in about 16 hours. It will usually be well to investigate the possibility of air transportation for the newly purchased puppy or grown dog to reduce the time and strain of shipping. Air express rates on dogs, as a rule, compare favorably with railroad express rates.

The breeder of good hunting dogs must charge prices for puppies commensurate with their breeding and potential hunting ability, and the care they have been given. This fact does not mean, however, that a sportsman must pay an exorbitant price to obtain a good bird dog.

\section{Desirable Characteristics}

Perhaps the leading qualifications of the potentially good hunting dog are hunting instinct, intelligence, health. vigor. amenability to training, and a good nose. Since for the great majority of sportsmen the hunting dog will be the family dog. good disposition also is desirable.

The nose of the bird dog has been dereloped by many generations of breeding to a high degree of efficiency in detecting even faint scents. Nevertheless, individuals. whaterer their breeding, show considerable variation in the keenness of their scenting powers. If his nose is faulty, a dog will be handicapped in the field regardless of his other natural qualifications and his training.

Well-trained bird dogs hunt while running at full speed. with head held high, and seek the scent of game birds in the air. This habit is in contrast to the ground trailing of the hound working on rabbits or other "fur"; the hound follows the scent left on the soil and vegetation in the path of the quarry. As discussed later. ground trailing is a fault in bird dogs.

The behavior of the bird dog working on game will doubtless be made more understandable by a brief discussion of scent emission by game animals. Stoddard (1932) has aptly described game scent by comparing it to a smoke or a vapor that is visible to the eye. When a bird moves about or shakes its feathers, it gires off a heary cloud of scent, or "smoke." If a breeze is blowing. the "smoke" is constantly carried downwind. If the atmosphere 
is still and moist, the "smoke" spreads out in all direcetions, but lies close to the ground.

If a quail, for example, is flushed, it flies away swiftly, leaving an air-borne "smoke trail" behind it, which terminates where the guail alights and crouches. The bind can be located easily by the bird dog that arrives before the "smoke trail" is dissipated. If the bird remains motionless for some time, the trail of scent disappears and its "body scent" is largely withheld by the tightly compressed feathers. Then the dog will probably have difficulty in finding the bird.

The scenting ability of the dog and scent emission by game are affected by a number of conditions that are only partially understood. It remains something of a mystery why dogs with keen scenting powers can sometimes locate game birds with ease and at other times fail to find them. Doubtless the conficting odor's giren off by moldy regetation, the different degrees of moisture and temperature of the air and soil, the physical condition of the dog, and other factors play an important part.

\section{HINTS ON TRAINING}

Undoubtediy one of the most valuable assets of the successful dog trainer is his understanding, usually acquired by experi-

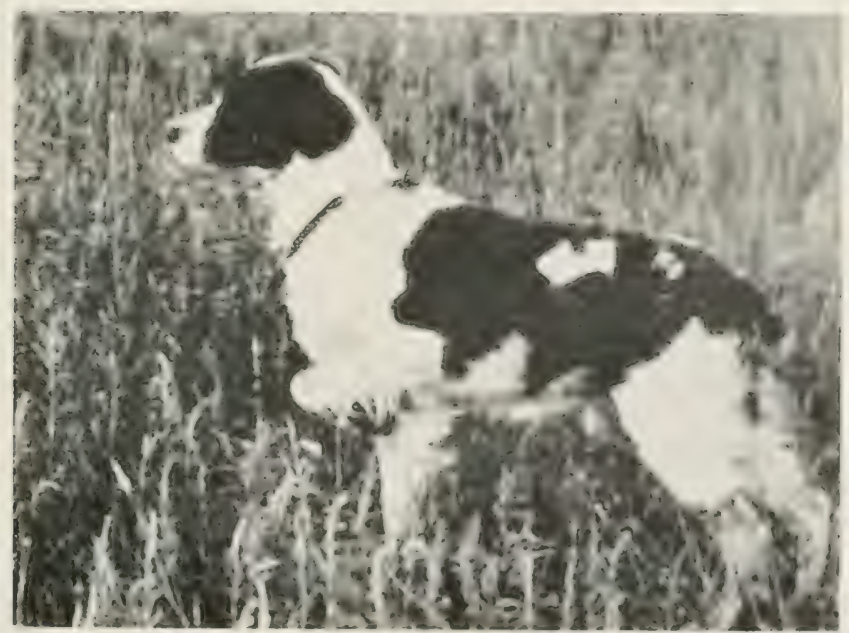

In a bird dog, the nose counts. Field-trial champions, such as this male Brittany Spanie!, excel in scenting ability as well as in other hunting qualities, and their offspring is in demand as hunting and breeding stock. 
ence, of the nature of a dog's mental equipment and mental processes. Lack of space precludes enlargement on this subject here. but an informative discussion, in understandable terms, of the

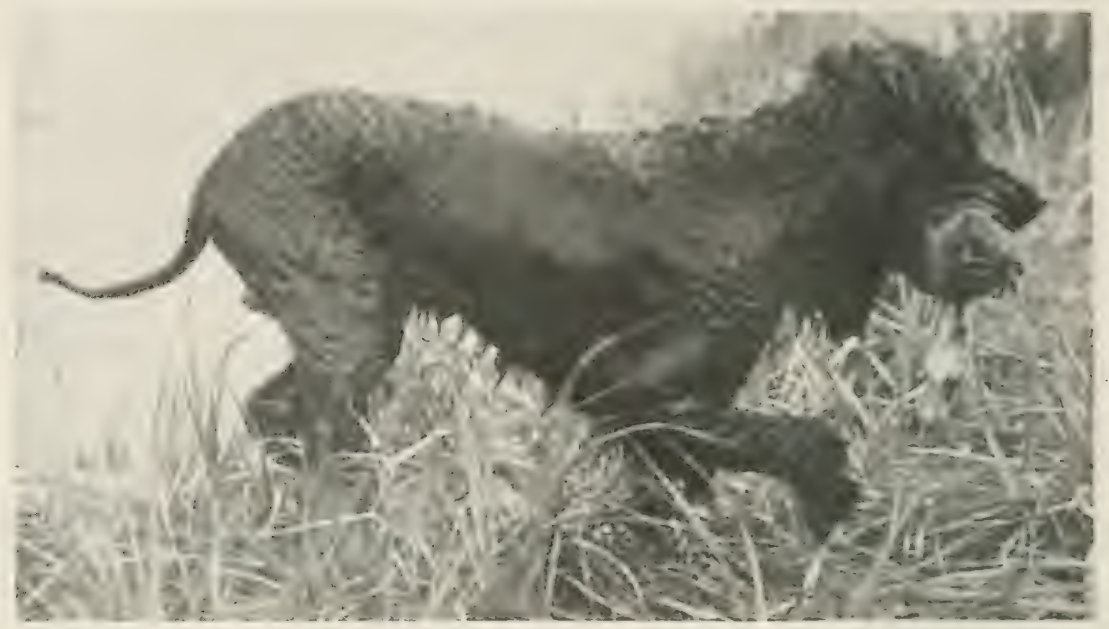

Formerly, Illinois market hunters used Irish Water Spaniels extensively on waterfowl to conserve powder and shot. Less numerous now. these dogs still rank high in ability as retrievers.

mental reactions and behavior of dogs can be found in $\mathrm{H}$. W. Carlton's book, Spaniels: Their Breaking for Sport and Field Trials, Chapter XI, "Psychology and Dog-Breaking." This book is listed under "Literature Cited," page 64.

\section{General Considerations}

The Amateur Trainer.-Sportsmen who buy trained dogs or have young dogs fully trained by professionals are relatively few compared with those who buy young dogs and train them during spare time. That numerous capable hunting dogs in the state have been trained by their owners speaks well, on the whole. for amateur trainers. Nevertheless, many dogs derelop bad hunting habits that might have been aroided or minimized if the owners had been better informed on training.

There are numerous books on the subject of training hunting dogs. Unfortunately for the average reader, authors sometimes fail to bridge the wide gap between the professional trainer and the amateur and they outline rough training methods which. in the hands of the beginner. may ruin the dog as a hunter. 
In the section "Literature Cited" are listed some publication, on training that, in our opinion, are especially helpful to the amateur trainer. A considerable number of other books might have been listed: the reader's own interests will guide him to other sources of material suited to his needs. The publications mentioned have been drawn on in writing this section on training.

It is obvious that the subject of training camnot be presented fully in a publication of this kind. We have attempted to give only a brief outline of some of the more important steps in training, in the hope that as training problems arise the reader will turn to authoritative books and articles on this subject.

Most dogs are by nature anxious to please their masters. but they cannot do things they do not understand. Lessons need to be repeated until they are thoroughly mastered. Patience on the part of the trainer, whether natural or acquired, is the first requisite in successful training (Moffit 1937).

Obedience training is an essential part of the education of the dog, whatever his breed. In hunting dogs, this is especially important, since the disobedient dog hunts mostly for himself and takes most of the owner's time in trying to keep up with him or to find him. The obedient dog, which responds to directions and hunts for his owner, stands a good chance to find as many birds within gun range as the wild, disobedient dog will find for himself a mile away (Becker 1945).

The successful amateur trainer develops a knack of teaching obedience without cowing or alienating his hunting companion. The following quotation from a widely known English authority on spaniels (Carlton 1945) can well serve as a guide when the puppy's obedience training is begun:

"One should no doubt teach the puppy his name, which may be done by calling his name and patting him or giving him a piece of biscuit. One should also, no doubt, make the puppy gallop up to one on his name being called-which may be done in much the same way. And one should make him go to his kemnel when desired. This presents more difficulty. Personally. if a puppy is recalcitrant in this respect. I generally get him to me, and either pick him up and carry him in or put on him a collar with a short light cord attached and make him comply by an admixture of cajolery and gentle force, and end up with a reward.

"In these early lessons, as with all other lessons during early" puppyhood, the four cardinal principles are: 
"(1) Never give an order without seeing that the pupuy complies with it; he has got to learn to obey you always. not sometimes.

"(2) Always be absolutely gentle, both in voice and action -when you come to work in the field, you want a bold, keen dog. not a cowed and listless wreck.

"(3) Never give an order with which you cannot secure compliance without a display of harshness.

"(4) Never persist in any lesson which is becoming a brre to the puppy.

"The nearer these early lessons can be approximated to a game, in the puppy's eyeš, the better."

As the puppy develops and learns to take directions. you should become accustomed to giving them in a firm. distinct voice, making sure that each command is understood and carried out. The commands should be short, and the same words should

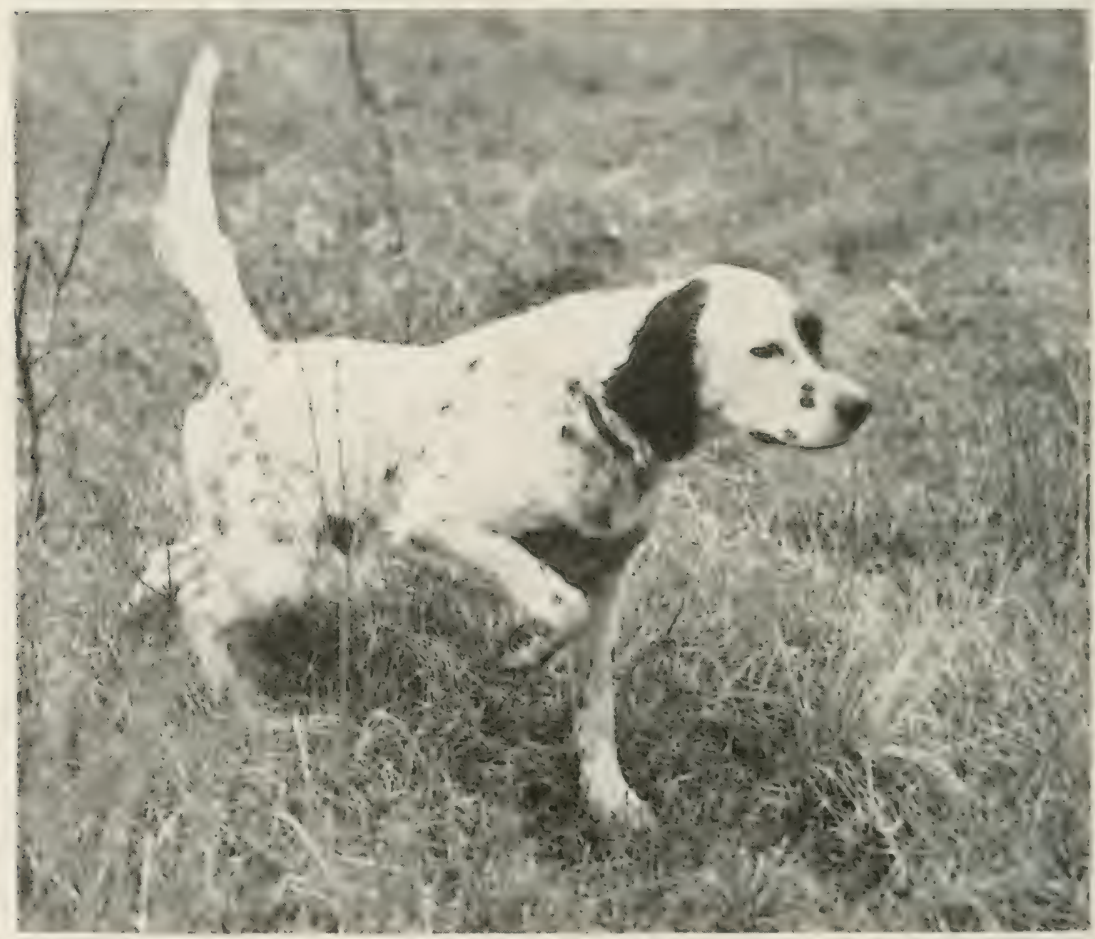

An English Setter points a covey of quails. The many setters. pointers. and spaniels trained to retrieve game help to reduce crippling losses among upland game birds. 
always be used for each response expected. Be sure each command is audible, but do not get into the habit of raising your voice, or the pupil will probably think he does not need to mind unless you shout.

Teach a few basic things well lather than attempt a large number, which may be only half learned.

At each step of training, make every effort to see that the dog understands what you want, and, whenerer possible, why you want it. When the lesson is learned, it should be practiced until response becomes habitual. This is the background of obedience training. Such training calls for ingenuity, common sense, and much patience in getting the lessons over to the $\log$. Harsh treatment and punishment not understood have permanently intimidated many promising hunting dogs. The dog's span of attention is short. Lessons should be only 4 or 5 minutes long for the young dog. They should not be prolonged until the dog becomes bored or sour, and the trainer loses patience.

Dogs vary in intelligence and temperament just as do humans. This variation calls for study of the individual characteristics of the pupil and adaptation as far as possible of the training program to his needs. Some dogs need more rehearsals of each step than others. Some must be praised and encouraged more than others (Becker 1947a).

Although considerable emphasis has been laid on the preparation of the trainer, there is no need to orerrate the difficulties of training a hunting dog. Most boys can teach their dogs any number of tricks by the simple method of showing the pupil what is wanted, practicing it until well learned, and rewarding the dog's progress with praise. The amateur trainer who stresses the derelopment of companionship with his dog, and encourages his inborn desire to do things to please his master, pares the way for progress in training.

The man who likes hunting dogs and dog work and who is willing to acquaint himself with the fundamentals of training can usually do at least a fairly good job of training his own dog. The development of a good hunting companion will amply reward him for his work. Moreover, the skill in handling acquired during the training period will serve the hunter well in the field. Obriously, good dog work is in large measure dependent on good handling.

Training Systems.-Tarious systems are used in training birt dogs. Some owners do little yard training and confine their 
programs largely to a few field trips before the hunting season, and then take the dog along on hunting trips. If the owner works frequently with his dog, the animal can erentually become a useful hunting companion, but he will make mistakes, some of which might have been avoided with more yard work and other preliminary training.

A program that combines yard training and field training over an extended period of time seems to give best results.

Training Classes.-A program that combined yard training and field training over an extended period was used successfully by a group of spaniel owners in northern Illinois. They began a training class in April and continued until October. Yard (obedience) training was given first. When this was thoroughly mastered, the dogs were taken to the field and put through an intensive course of quartering, finding and flushing game, remaining steady to flush and shot, and retrieving. During the summer months the dogs were trained in water retriering, and in the autumn a field trial was held.

Observation of the methods of a successful trainer was particularly helpful to the beginners, who had a good spaniel man to act as instructor and coach. A class met for instruction erery other Sunday. At each meeting progress was checked, mistakes were straightened out, and questions were answered. Then each amateur trainer was given a mimeographed sheet of the lesson and told to work at home (Becker 1945, Goodall 1946).

Sound instruction of this kind is helpful in all phases of dog training, particularly in the more difficult tasks, such as training to retrieve.

Planted Game.-The use of planted birds is of great assistance in training dogs for hunting and retriering. Barn-loft or pen-reared pigeons, game-farm pheasants. guineas. and domestic ducks are used for this purpose.

Planting or hiding a dizzied bird in cover, where its exact location is known, enables the trainer to control his dog on the approach or on point.

Flushing and shooting planted birds in flight provides the means of training a dog to retrieve under conditions that anproximate actual hunting.

The Young Dog.-The dog makes most of his physical and mental growth during the first year of life. At 6 months most dogs have developed only to the stage of simple yard training. finding and chasing game. and other relatively easy tasks. To 
adapt training to the mental development of the young dog. most trainers delay the start of intensive yard training until the puppy is at least 8 months old or even a year or more. Some trainer's, however, believe it does no harm, and may be beneficial, to do a limited amount of hunting with a puppy 5 or 6 months old before he has had advanced yard training. However, Martin Hogan

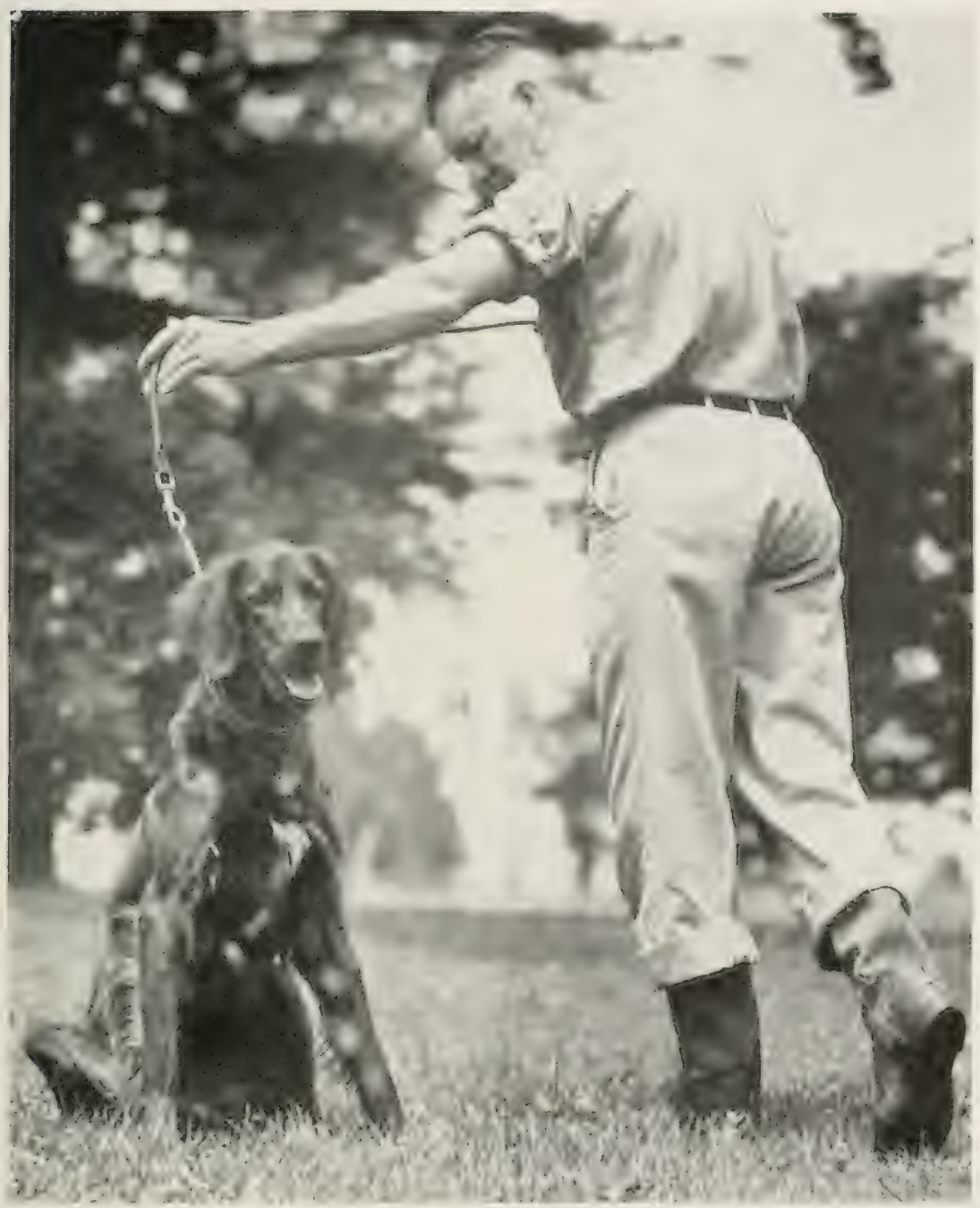

Clifford Wallace, trainer of hunting dogs, tests an Irish Setter on the command, "Sit." The trainer walks around the dog and then moves some distance away to see if he will stay in position. 
(Becker 1947b) warns that a young dog, even one that has been trained to the firing of a gun, can easily be made gun-shy if several hunters shoot at once when the dog is in the immediate vicinity. A young dog that seems fully trained to field hunting can be ruined by being taken into a duck blind where there is heavy shooting just overhead.

The steps in training pointing dogs and spaniels for hunting are similar in many respects. However, there are obrious differences in the work of the two classes of dogs and in methods of handling. For example, spaniels are usually taught to sit dorm when they spring game and to remain steady in this position until they are sent to retrieve or to resume hunting. Also, when given the signal to halt ("Hup") they take the sitting position. Pointing dogs are trained to remain steady to wing and shot in standing position, and also to "Whoa" in the same position. Publications mentioned later deal with specific training methods for each class.

The following brief training outline, based on steps followed and methods recommended by well-known professional trainer's and authorities on hunting dogs, may be helpful to the amateur trainer in planning his program. Numerous rariations in the sequence of steps of training are employed successfully by different trainers.

\section{Puppy Training}

First Lessons.-The puppy from the age of about 3 to 8 months can be taught a few simple lessons. In addition to being housebroken, he can be taught to know his name well and the meaning of "No" and he can be given simple yard training. for" example, to lead, to stand (pointing dogs), to sit (spaniels). to "Fetch" and a few other easy lessons such as those outlined below. During this period, like a child, he learns how to learn. and how to mind. He learns the meaning of a number of words (sounds to him). This preliminary training, based largely on the desire of the puppy to do things with his master, pares the way for future progress.

During this time, the young dog is usually given a period of freedom in the field, which is continued until he learns to recognize game and to handle himself well afield.

Name.-Whenerer you call the puppy or speak to him. make a point of using his name. He should learn always to associate 
the sound of his name with himself. Later, when you teach him to stand or sit, you should be able to call him by a dozen different names, without having him move from position. He should not move until you use his own name (Moffit 1937).

Lead.-Hogan (Becker 1947b) advises that the puppy be taught to lead early and that the owner exercise care in this training. He says: "As you know, any good dog of any breed can be cowed by an owner who handles it too roughly on a leash. You can make pups leash shy by being too rough with them at first. At the age of 4 months or so, a pup should have at short leash snapped on his collar so he can trail it around. Then you gradually exert pressure on that leash and guide him." He can then be taught to follow readily at the pull of the leash.

"No."-When the puppy does something wrong, give the command "No" in a firm tone, and make every effort to show him what he has done wrong. His knowledge of the meaning of "No" will be very useful throughout his training.

Pointing Game.-As a means of introducing the pointing breeds to game, one professional trainer (Bufkin 1946) uses the following device. A squirrel skin is tied to a piece of twine about 10 feet long attached to a long stick. The skin is placed on the lawn close to the puppy's nose, where he will get the scent. As the puppy tries to pick up the skin, it is pulled along, just out of his reach. When he learns that he cannot quite catch the quarry he will usually begin to point instead of chase. This pastime derelops pointing at an early age, but it should not be continued more than a month or it may form the habit of "false pointing" of moving objects.

Natural Retrieving.-Most bird dog puppies possess a natural tendency to retrieve that can be developed by practice. Carlton (1945), speaking of spaniels, adrises that training be started as soon as the puppy is weaned and his confidence in his master is firmly established. This is probably sound advice for puppies of any bird dog breed, especially if they are to be trained as natural retrievers. Carlton points out that the puppy's inclination to pick up and carry things is present much earlier than his desire to hunt. Similar stages of development are evident in young foxes: for example, around the entrance of a fox den will usually be found dead ground squirrels or other prey animals, which serre as playthings for the young. Female foxes have been observed to give to their young parts of prey animals to carry during their first hunting trips. 
Carlton's adrice on early training of puppies in retrieving is partially summarized below:

1. Do not begin until you have gained the puppy's confidence so that he is eager to race up to you whenever he sees you.

2. When you begin his retriering lessons, take him to a place where he will not be distracted by dogs, other animals. traffic, or people. This may be on the lawn, if it is not his regular playground, or it may be in some area where the grass is not close cut, but where he will have no difficulty seeing a thrown object.

3. Get him interested in a knotted handkerchief or a similar easily seen, soft object that is to be used as a dummy. When he is watching the movement of your hand and moring in the same direction, throw the dummy underhand a yard or two away. at the same time telling him to "Fetch."

4. If he has seen the dummy leave your hand, the chances are he will race out to it, pick it up, and run back to you. If he does not go to it, he probably has not seen it leave your hand. in which case pick it up and throw it again.

5. If the puppy does not come directly back to you, try to get him to do so by sitting down, or by turning your back. or by walking away from him. When he comes to you with the dummy, your object is to get it directly back in your hand. However, do not snatch it or engage in a tug-of-war with the puppy. To do so tends to develop a "hard mouth," that is, a habit of biting down hard on what is being retrieved. Place your hand under the puppy's lower jaw (so that he will not duck his head or drop the dummy) and press the dummy up and toward the back of his mouth as you remove it. If necessary, place your fingers in his mouth and open it gently.

6. When the dummy is back in your hand, reward the puppy with a bit of food or by making much of him. Probably food is the best reward for the first two or three lessons. Following these lessons, rely on praise, reserving the food until he shows a disinclination to return to you after he picks up the dummy.

While the puppy is very young, limit the practice periods to 4 or 5 minutes at a time, and once or twice a day. He should always consider these lessons play: whenever his interest wanes. take away the dummy and discontinue the lesson.

After a week or two of practice, begin to substitute larger dummies, such as a stuffed canvas glove, a short piece of garden hose, or some other soft object that the puppy likes to pick up. 
For later lessons, a good practice dummy is one made of a piece of soft wood, $8 \mathrm{or}^{\circ} 10$ inches long, rounded off to a diameter of about 2 inches, with a number of pigeon, pheasant, or other bircl wings attached to it.

As your puppy grows and becomes proficient at picking up and returning the dummy, you must vary lessons gradually in the direction of retrieving in the field. As early in his schorling as possible, begin to throw the dummy where he will have to use his nose to find it, but not, at first, in thick cover. He should return it to you in the same way as in the earlier lessons.

Another variation is to get the puppy to find the dummy without having seen you throw it. When you are walking downwind with him, drop the dummy when he is not looking. After you have gone 50 feet or so, turn and walk back into the wind toward the dummy, encouraging him to hunt for it. If he is familiar enough with it to recognize the scent, he should be able to draw up to it from a distance of several yards. He will thus learn to look for and retrieve something he has not seen fall.

Later, under hunting conditions, the training of natural retrievers must be extended to include retrieving of shot birds. Methods of field training vary among trainers. One of the most useful methods of teaching the dog to retrieve birds is by releasing domestic pigeons to be shot in flight and retrieved by the dog.

If the puppy will not retrieve in play, the practice should be discontinued, and he can be force broken to retrieve after he has had some hunting experience (Bufkin 1946).

Force Breaking to Retrieve.-There is some difference of opinion as to the merits of natural and force-broken retrievers. It is generally agreed, however, that if the dog has been thoroughly force broken he can be depended on to retrieve, while a natural retriever may refuse to retrieve and the owner will be unable to enforce the command. Nevertheless, force breaking is one of the most difficult and time-consuming tasks of training, especially for the amateur. Unless the job is done thoroughly, it is better not attempted. If the dog shows indications of being at least a fair natural retriever, it may be questioned whether it is worth while for the nonprofessional to attempt force breaking. The amateur trainer who plans to force break his hunting dog to retrieve can find descriptions of methods in the books on training listed under "Literature Cited."

Freedom in the Field.-Getting your young dog into the field and allowing him to learn to hunt by himself is an important 
part of his training. By the time the puppy is 5 or 6 months old you will probably find it profitable to get him into the field to gain experience in finding wild things as often as possible. Although some trainers faror delaying this period of freedom in

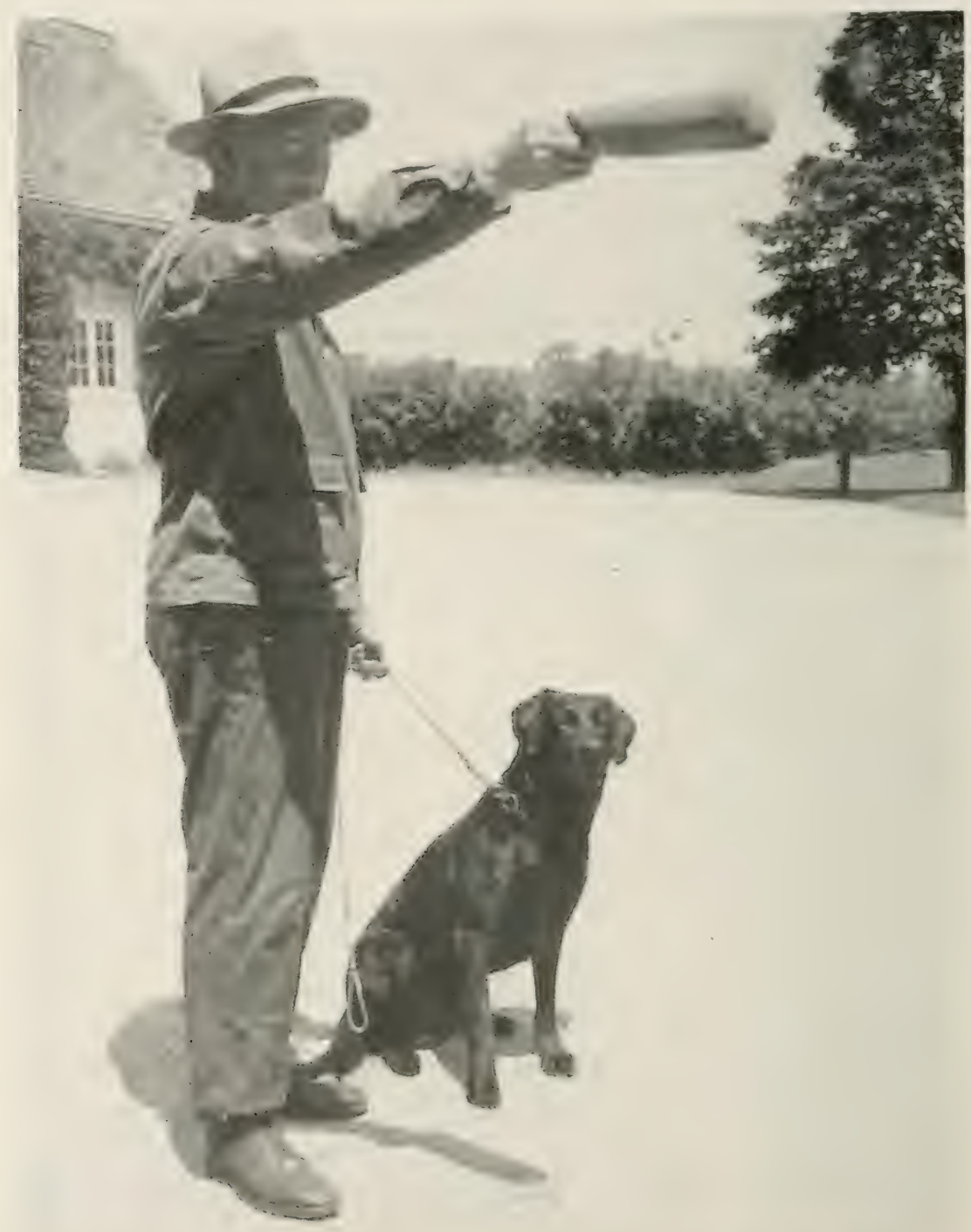

Martin Hogan, professional trainer of Barrington. Illinois, uses a padded and weighted dummy in training a Labrador to retrieve. The dog is taught to remain in sitting position until sent to fetch. 
the field until advanced yard training is begrum (8 months to at year), it seems better in most cases for amateur trainers io begin to take their dogs to the field at an earlier age. Gencrally, the more preliminary field training and experience on garne your puppy receives, the better hunter he will become.

On these trips allow him to find and chase rabbits, suluirels, birds, anything he finds, to his heart's content. Four or five ficld trips a week where he will have a chance to find game provide excellent training. This is his time to get acquainted with the field and to develop independence in finding likely spots for game.

The dog should be allowed plenty of freedom to learn things for himself. His early attempts at hunting may be supervised, but not too obviously. Frequent directions may take array his initiative, or give him the idea he is doing something wrong, which is likely to lead to disobedience later (Moffit 1937).

Clifford Wallace (Becker 1947b) emphasizes that usually a good shooting dog can be made from one that likes to hunt. The period of freedom in the field is his time to learn to thoroughly enjoy hunting. He can be got under control with obedience training after his hunting instinct is developed.

Since he needs to gain self-confidence, it is well for him to be without canine company on at least most trips; many successful trainer's believe a young dog will learn to hunt faster if taken out a few times with an older, experienced dog. If he is one of the pointing breeds and shows a tendency to point, he should be encouraged, but no attempt should be made to enforce pointing at this time. Sooner or later he will start making points.

Accustoming to Firing of Gun.-Field trips offer you good opportunities to accustom the young dog to the report of a gun. Previously you may have introduced him to a report by firing a cap pistol (not close at first) as you approach him with his food. He will thus come to associate a report pleasurably with food. In the field, begin by occasionally firing .22 blanks, at first when the dog is some distance away and only when he is intent on chasing something he has flushed. He will probably pay no attention to the report. Gradually you may fire the gun nearer to him, always when he is chasing. If he shows no nerrousness, you may use a .410 or larger gauge, firing it only when he is chasing, and at first when he is some distance away.

Teaching "Whoa" or "Hup."-Another lesson that you can give a dog of the pointing breeds during field trips is the meaning of "Whoa." When the dog is ready to start his romp in the 
fields, but before you have unsnapped the leash, grasp him by the collar and tail, putting him in pointing position, at the same time giving the command "Whoa." Since he will be anxious to be off, he will probably stiffen to a point. Repeat this procedure at the start of each trip until he has learned to remain quiet in

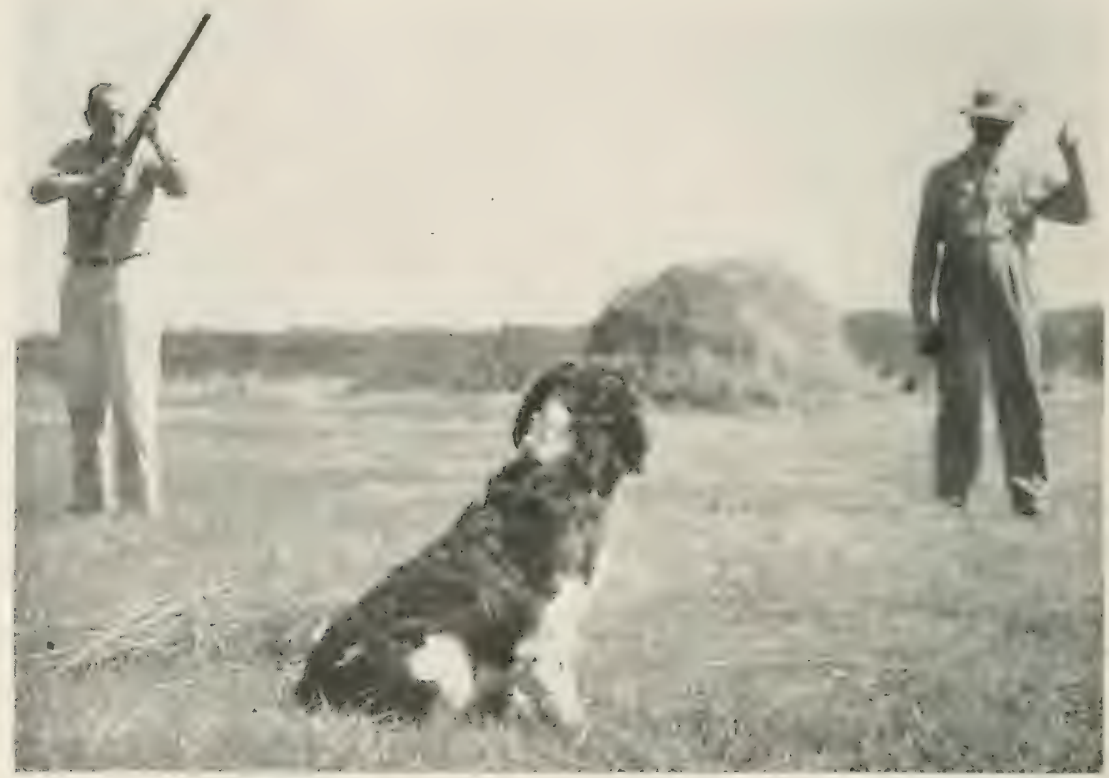

Teaching a Springer Spaniel steadiness to shot. Spaniels are trained to sit when they spring game and to remain in this position until sent to retrieve or resume hunting.

this position; then try stepping back a few paces, restraining him with the leash. Whenever he moves, go back and straighten him to a point. Soon he will stop on point at "Whoa" with only occasional restraint by the leash (Bufkin 1946).

The meaning of "Hup," or sit, can be taught to the sllaniel in about the same way.

"Heel."- In teaching a dog to heel, carry a very light, willowy switch. When you start to walk with the dog on leash give the command "Heel" and a hand signal to indicate he is to stay behind. He will not know what is wanted and will probably try to go ahead. Call him back, giving the command and hand signal, and repeat these until he understands he is to walk behind. If he is still hard to keep back. flick (not whip) him lightly with 
the switch, repeating the command. This will cause him to get back in position quickly. Practice with this method will teach him to walk in position at command.

Review of "Whoa" or "Hup."-If the period of freedom in the field has begun before the start of the yard training, the dog will probably have learned the meaning of "Whoa" (pointing (logs) or "Hup" (spaniels), but will need further practice.

As previously mentioned, the spaniel is usually taught to sit after flushing game and to come to a sitting position when stopped in the field. You can teach the spaniel to "Hup" (sit) when you are walking with him on leash. When you stop, give this command and show him what you want by placing your hand on his rump, pushing him gently but firmly to a sitting position, at the same time drawing up the leash to keep his head erect. Practice until he will sit without command when you stop. An occasional pulling up of the leash may be needed as a reminder. Eventually you should be able to move away some clistance while your dog remains motionless in "Hup" position.

Coming Prompily to Cail.-One of the most important lessons involves teaching the young dog to come to you when you call him. If you are having difficulty in this respect, you may use a 25-foot clothesline rope as a lead. If the dog does not come at once when you call, use the lead to start him to you. When he comes promptly, praise him. After he learns to come promptly when called, mistakes in other phases of his training can be corrected at once. It may be questioned seriously, howerer. whether it is ever good handling, or fair to a dog, to call him to you to punish him. If punishment is necessary for willful infraction of rules (when your dog is old enough and well enough trained to know the rules and to know that he must obey them) you should go to him. He should not have the idea he is likely to be punished when he comes to you (Lytle 1934).

Hand Signals.-Dogs learn the meaning of hand signals more readily than they learn words. During yard training, use hand signals along with commands as often as possible. For example. when you give the command to "Whoa," "Hup," or "Heel," also give an appropriate hand signal. The dog should learn to respond to hand signals in the field whether he hears the command or not.

Advanced Yard Training.-By the time your dog is 8 to 12 months old he will probably have developed mentally to the point where he is ready for advanced yard training. We will assume that he has had preliminary lessons in most phases of yard work. 
and thai the series of lessons has progressed gradually from the easier to the more difficult tasks.

The adranced yard training program should jerfect by degrees his performance of the earlier yard lessons, or any new ones given him. Later, when further freedom in the field wi!l do no good and teaching control will do no harm, these les:ons: may be applied to initiate control of your dog in the field.

\section{Field Training}

Teaching Dog to Quarter.-Eventually, in the field. you will bring your hunting dog's yard lessons into play in teaching him to remain steady to flush and shot, and in bringing him under: control while working ahead of you. Do not be in a hurry to enforce control, however, until he has gained field experience. You should teach him to quarter the ground ahead of you, but he will have to learn for himself to work the birdy spots and to skirt the unlikely places. Proper working of the corer requires experience on his part.

Spaniels should quarter the ground, windshield-wiper fashion ahead of you, to flush the game within gun range. Preferences vary among hunters as to what distance the spaniel should work ahead of the gun. In thick cover, you will often find it an advantage if you are able to hold your spaniel in where he can be kept in view. On open ground some hunters prefer not to hare the dog work very close. On this point Charles S. Goodall (letter) writes:

"A dog that finds and flushes game 50 yards ahead gives little chance for a killing shot. A pheasant will be at least 60 and perhaps 70 yards away before it is safe to shoot (because of the $\operatorname{dog}$ ). From 25 years' hunting experience, I know that most game is shot under 30 yards. It is my opinion that most hunters and even top wing shots can't even cripple a bird at 70 yards, much less kill one. Also, a dog 50 yards in front of the gun will flush a moving bird far out of range if it is necessary to follow the line any distance before flushing. A dog ranging or quartering over a 70 - to 80-rard front with the gun in the middle of that front is covering enough ground, eren though he is crossing in front of the gun at a distance of 5 yards. Incidentally, that is exactly where I want my Springers to cross in front of me most of the time; wide on the sides but close to the gun when they cross." 


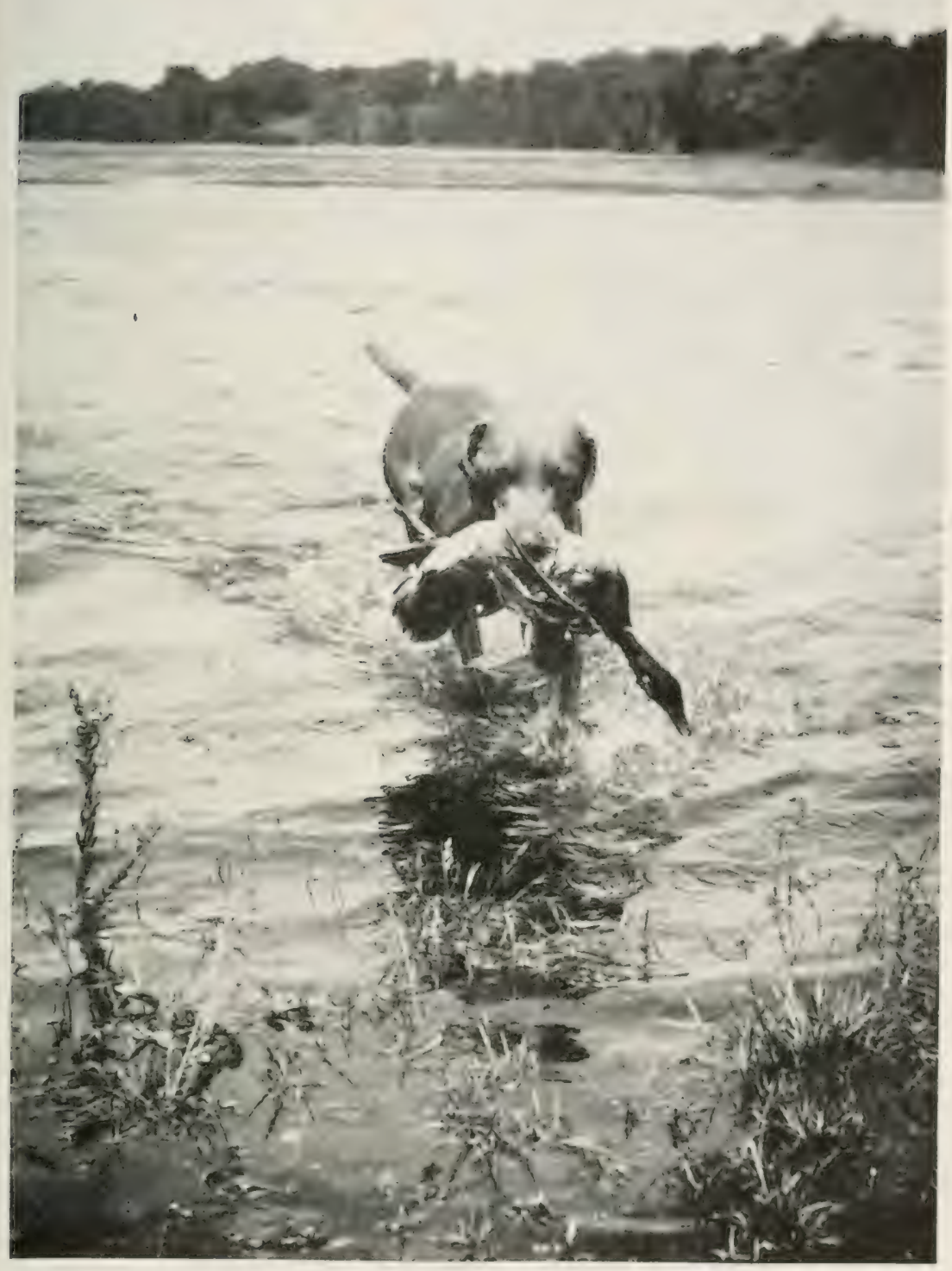

Patient labor is required to produce a fully trained retriever or hunter: the age of attaining maximum working powers varies with breeds and individuals. This Weimaraner is classed as a finished retriever and hunter at only 2 years. 


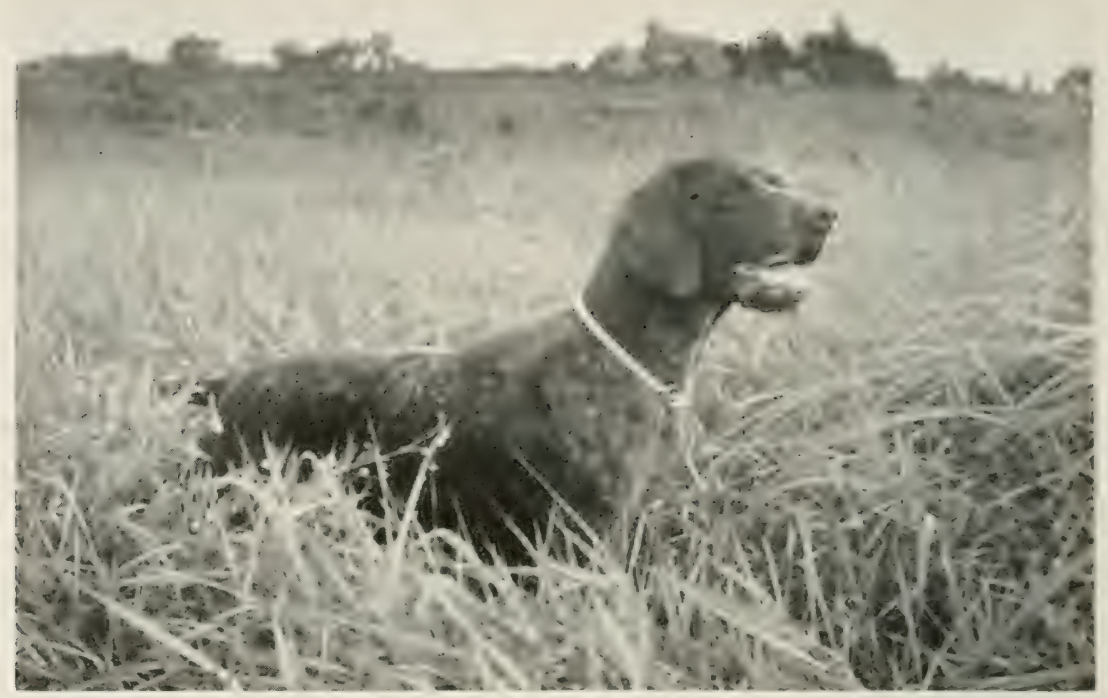

This young German Shorthaired Pointer shows the staunch pointing qualities that are characteristic of the breed.

In training the spaniel to quarter, you may use hand signals to advantage to indicate that he is to turn and quarter in the opposite direction. Some trainers use their dog whistles for no other purpose than to turn the dogs. Perhaps the most useful device you can use in training your young dog to quarter properly is to follow a zigzag course over the field, always working into the wind in early lessons. When the puppy sees you change your course he will usually swing back to keep ahead. Occasionally you may find it necessary to start to run to arouse his interest in what lies ahead of you. After the dog has learned to quarter properly, you may reserve whistle signals or roice signals for special occasions when it is necessary to get his attention.

Pointing dogs should quarter ahead of the hunter while working the likely spots, but at a greater distance than in the case of the spaniels.

Steadiness on Point and to Wing and Shot.-The well-trained pointing dog should hold in pointing position until the hunter flushes the game and shoots: then remain steady in this position until sent to retrieve or to resume hunting. The spaniel should flush the game within gun range; then sit and hold steady in this position until sent to retrieve or to continue hunting. 
Achiering steadiness in the young dog requires pationce on the part of the trainer as well as frequent rehearsals of the lesson. It is probably better not to strive for complete steadiness early in the dog's hunting experience. The first impulse of the dog when game is flushed seems to be to leap after the quarry. The strong tendency found in all breeds of dogs to chase moving objects is undoubtedly inherited from their wild hunting ancestors (Becker 1947a).

Some dogs learn with experience that it is useless to chase birds, but most dogs, if not given careful training, repeated when necessary, are likely to develop persistent habits of breaking and chasing.

When the pointer or setter begins to point game, make a special effort to get to him when he is on point. Hold him there for 5 minutes or more, stroking him and straightening him to a good pointing position; let him know you are well pleased with him. Repeat "Whoa" several times to associate this command with pointing game. Pushing the dog gently toward the pointed game tends to make him lean back. This is a good way to make some dogs more staunch.

Methods of teaching steadiness to wing and shot vary among trainers. Many trainers rely on a check cord (25 to 50 feet of clothesline attached to collar) to steady the dog on point or to wing or shot. Stopping the dog with enough force to cause him to turn end-for-end after he has broken point and started to chase is frequently recommended to cure these faults. Nevertheless, in most cases it seems better for the amateur to teach steadiness without the use of a check cord if possible. Goodall (letter) states: "The check cord ruins more spaniels than any other thing; it makes blinkers or pointers out of them. Many bird-shy spaniels are caused by a check cord, even in the hands of a good trainer."

The following method of teaching steadiness without a check cord is recommended by one nationally known professional trainer (Moffit 1937): When the dog has been taught to "Whoa" or "Hup," is accustomed to the firing of a gun, and is undergoing advanced training in the field, the trainer begins the steadiness training by firing a gun at an opportune time. The dog is probably accustomed to associate the report with the fun of chasing. and his impulse will be to be off, but in this lesson the command "Whoa" or "Hup" is given immediately after the report. If the dog has been sufficiently trained. and all goes well. he will 
stop and hold the standing (pointing dogs) or sitting (spaniels) position.

If the dog does not obey the command, the trainer usually (under some circumstances it may be preferable to let the dog get his chase out) goes to nim and carries him back to the exact spot where he should have stopped. The dog is put in crrrect position, kept there a few minutes, and allowed to think orer his mistake. This procedure is repeated until the dog learns to strij, at the shot and command, and finally to the shot alone r.Moffit 1937).

Training the Pheasant Dog.-Training a bird dog to hunt pheasants presents special problems because of the cock pheasant's habit of running ahead of the hunter and dog. Pointing. dogs must learn by experience to follow the pheasant, rather than keep on pointing while the bird runs away. Occasionally. one of these dogs learns by himself to circle the pheasant. thus probably causing it to lie to a point between the dog and hunter. The following quotation from Wight (unpublished) presents some original ideas on training the pointing dog to work on pheasants:

"A good census dog must be fast, rangy, heady, and not too staunch on points. The good hunting dog should be les: rangy, more readily controlled, and fairly staunch on points, but it must not be permitted to hold its point long after the cock has run far out of the area, as so frequently occurs. In other words. the behavior of the cock pheasant is quite different from that of the quail or grouse. It may lie to the dog, or it may not. It is safe to expect that it will move out when the dog approaches. A dog which holds long points, and finally is sent on only to point and repoint, is not a pheasant dog. and probably it nerer can become a pheasant dog. It indicates that it lacks proper training. After watching many well-trained dogs hunt pheasants. it is the author's opinion that the old. well-established methods are used too frequently and that it is better to forget practically everything that is known about training the grouse or quail dog before starting in to train a dog for pheasant hunting. Lots of bird sense which the dog alone can derelop if he possesses the natural ability is the first essential in a good pheasant dog. and the dog can develop bird sense only when he is given the onportunity. Many good dogs are spoiled by too much attention by the trainer.

"Instead of pursuing the cock from the rear (trailing) it is best for the dog to move out and around the bird. thereby either 
changing its course or causing it to lie to a point or to flush within shot of the gun. There are several methods for training the dog to handle the wily cock in this manner.

"1. Keep the dog's head ofl from the ground; never let him develop into a trailer. The best method found by the author has

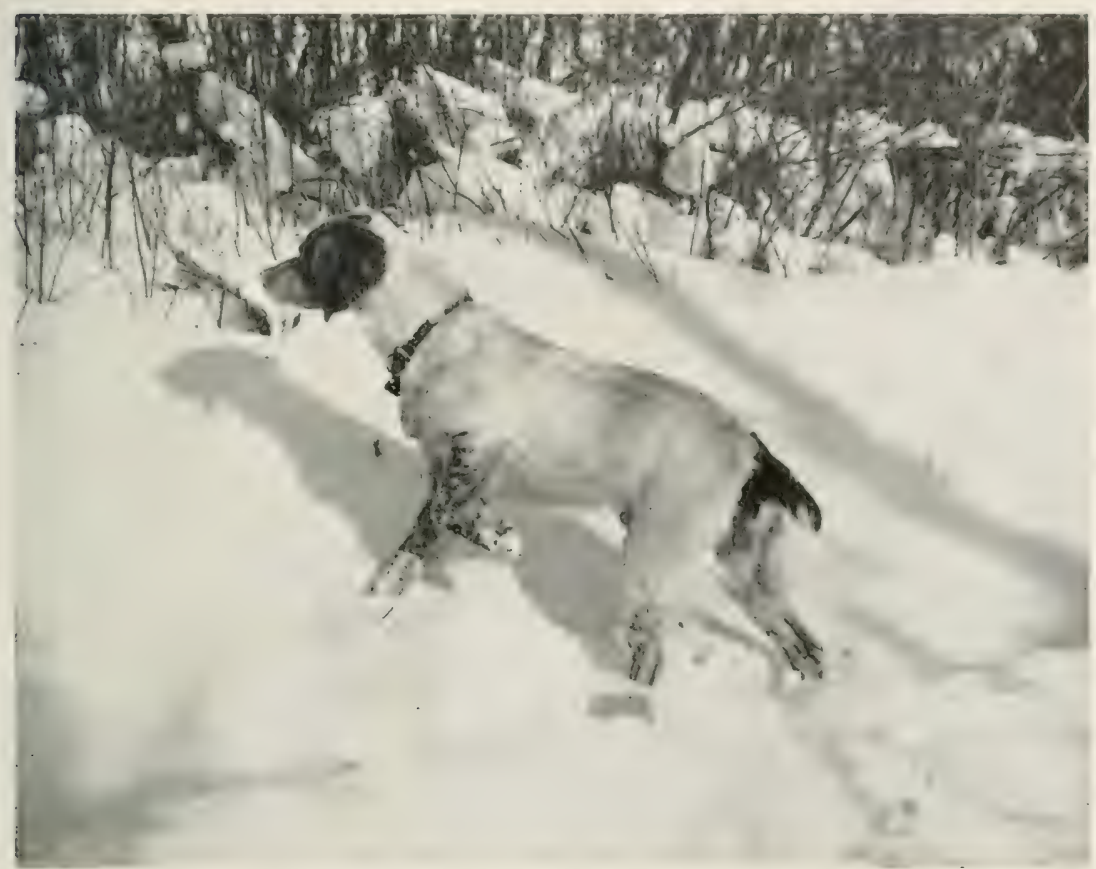

This Brittany Spaniel's tense point marks the hiding place of a pheasant in a snow-covered thicket.

been to take the dog out of short cover at the first indication of ground trailing and put him down in a dense regetation that he can best traverse with his head held high.

"2. Never permit the young dog to trail the bird from behind. Train him to more around the bird. This may be done by teaching him to respond to a command. I personally like to locate a flock of pheasants in a narrow draw with but two normal escapes. one at either end; then when it is known that the birds are there the dog is put down so that he has the advantage of the wind. When he has his birds well located. force him to leare them completely and circle around, approaching the birds from the opposite side. After he has learned to do this efficiently from command, he may 
be encouraged to make the same move without command. Time and much patience will eventually result in an automatic response which seems to increase with age.

"3. By tethering a cock bird in dense cover, or by attaching to it a light clog, one has almost a complete control orer the training. By time and again controlling the dog's movements when the exact location of the bird is known, the approach and the point can be steadied. This is probably the best method of training the pheasant dog.

"4. Once the idea takes hold, it is advisable to give the dog plenty of opportunity to develop all of the fine technique which the particular dog is capable of developing through plenty of self-hunting, or better still through loose control when the trainer is present.

"This seems to be about the only way the dog has of learning the characteristic behavior of pheasants in flocks and singly under varying conditions."

Overhandling Undesirable.-It should be the objective of the hunter to train his dog thoroughly in the essential points of working to the gun; then to allow him to work with a minimum of direction. Frequent directions will distract the dog and retard the development of initiative in finding and skill in handling game, both marks of the good hunting dog.

\section{IMPORTANT BREEDS OF BIRD DOGS}

In the following pages are given brief histories of the chief breeds of pointing dogs, spaniels, and retrievers, as well as partial summaries of the bench standards approred by the American Kennel Club. For full descriptions of the breeds and complete breed standards, the reader should consult the latest issue of The Complete Dog Book, official publication of the American Kennel Club.

Hunters are usually more interested in the field performance of their hunting dogs than in bench-show points. While there is justification for this attitude, hunters should remember, nerertheless, that, if hunting ability is not given a subordinate role in breeding, bench standards can have an important role in maintaining high quality in the hunting breeds.

*Principal source of material in this section is The Complete Dog Book (1947) and other publications of the American Kennel Club. Spelling of names of breeds included in this circular follows the style of that book. 


\section{The Pointing Breeds}

Brittany Spaniel.-Although only recently introduced into the United States, the Brittany Spaniel is probably one of the oldest of the spaniel breeds. The naturally short-tailed character of the modern Brittany is credited officially to the mating, about

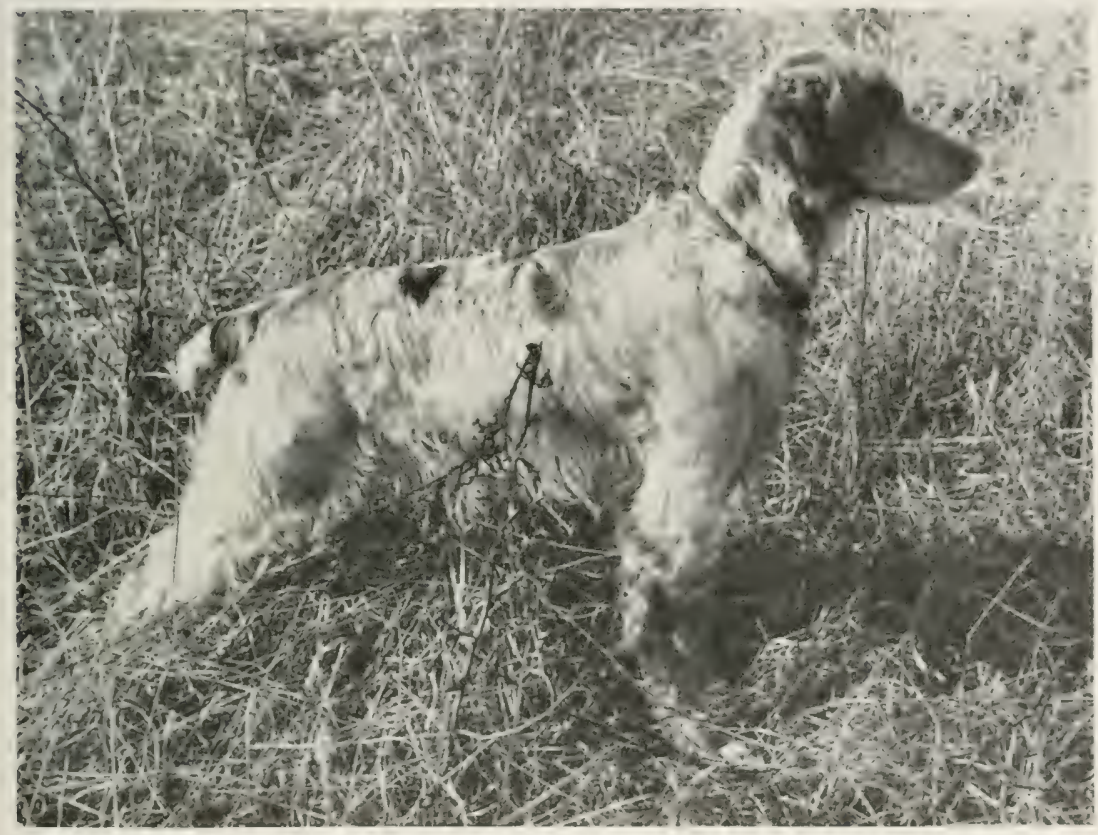

The Brittany Spaniel points his game like a setter or pointer. Recently introduced into the Lnited States from France, the Brittany, a mediumsized, naturally bob-tailed spaniel is gaining in popularity.

a century ago, of a bitch owned by an old hunter living in the Valley of Douron in Brittany with the dog of a risiting English hunter. In the litter were two tailless puppies, one of which was reared as a hunting dog. This dog, which is described as a splendid animal and an excellent hunter, became a popular stud. Among his progeny were numerous puppies either without tails or with short stubs. At the beginning of the present century. when the Brittany was said to be badly degenerated owing to inbreeding, a French breeder introduced crosses with pointer's and other hunting breeds. The Brittany type, howerer, seems to have been faithfully preserved, and the modern breed dates from this period. In 1931, the Brittany Spaniel was introduced 
into the United States, where it has gained steadily in popularity.

In general appearance, the Brittany Spaniel is a small. strong, closely knit dog of intelligent appearance and graceful bearing. It is energetic of movement and possesses rigor and stamina. It is longer legged and more rangy than the Crocker and Springer spaniels, and, unlike any other spaniel, it points game. Its work on pheasants and quails resembles that of a setter; it can be trained easily to retrieve.

Coat colors under the standard include dark orange and white, and liver and white. Some ticking is desirable but not so much as to produce belton patterns. The coat should be dense and flat or wavy, but not silky. Shoulder heights of the mature Brittany should be $171 \%$ to $201 \%$ inches, weights 30 to 40 pounds.

English Setter.-English Setters probably have been trained as hunting dogs in England for centuries. A popular theory based on old records is that this breed is an offshoot of the spaniel family. Another theory is that the setters and spaniels are descendants of the same ancestral type of dog. Still another theory is that the English Setter breed was dereloped from crosses between spaniels and old Spanish pointers.

Numerous strains* of English Setters have originated in the British Isles and several of these have been imported to America. The most famous of the British strains are the Lareracks and the Llewellins, both of which were brought to this country subsequent to 1870 . About 75 years ago, R. L. PurcellLlewellin, in Wales, made outcrosses of a strain of setters from northern England with outstanding dogs of the strain dereloped by his friend, Edward Laverack. The progeny proved to be remarkable field dogs, which became well-known on both sides of the Atlantic. The Laveracks became the foundation of the present bench show type of English Setter, while the Llewellins proved to be outstanding field trial dogs. Both the bench show and field trial types have their staunch supporters (Speelman of Williams 1928).

The English Setter is an exceedingly attractire, intelligent. active dog possessing speed, stamina, and hunting instinct. A lithe, muscular, well-balanced conformation enables it to more with ease and grace. An eminent breed characteristic is the long

* The term strain refers to a subrivision of the breeds of clomestic animals, that is, a zroup having a common lineage but not distinguishing characteristics sulficient to constitute a separate ireed. 


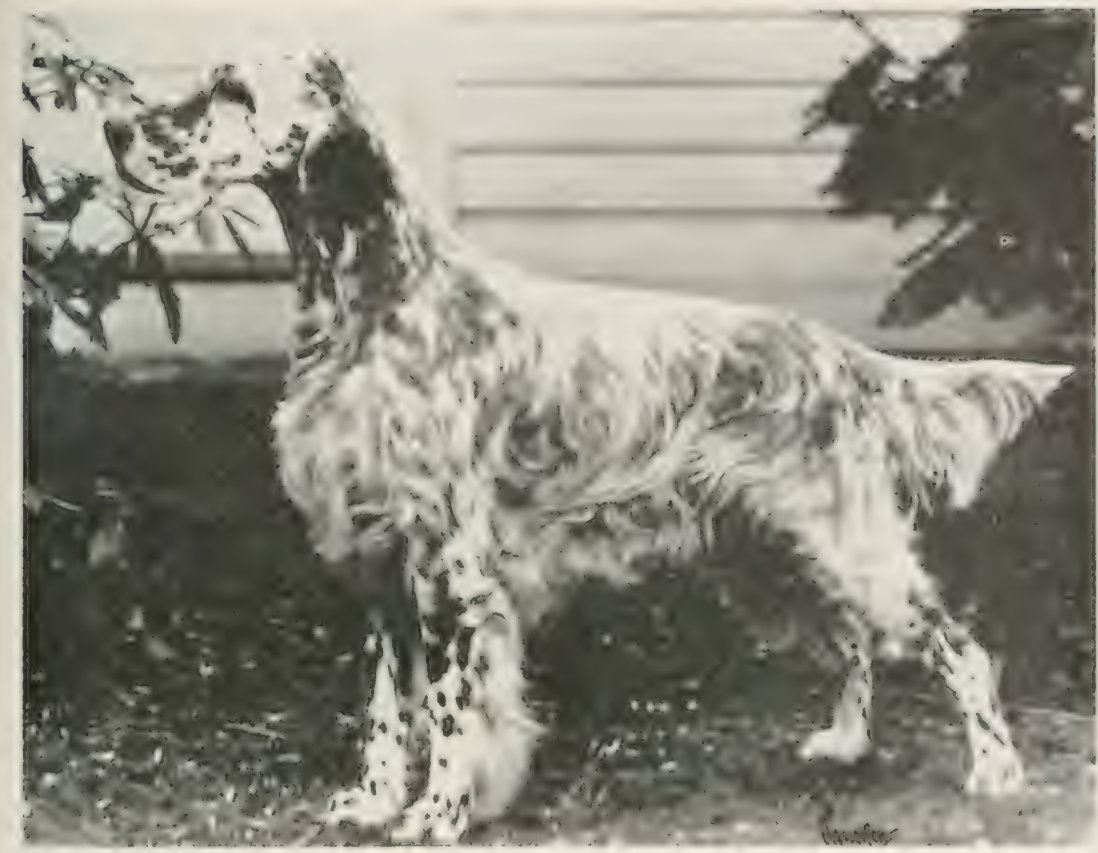

The English Setter is a popular hunting dog on every continent. Ancestors of the modern dogs of this breed aided in the medieval sport of netting. The better known strains of modern English Setters include the Llewellins and the Laveracks. A blue belton English Setter is pictured here.

skull with its moderate dome. The coat is straight, flat, and of medium texture.

In Illinois, English Setters and Pointers share popularity as leading all-round quail and pheasant dogs. English Setters make good companions and family dogs.

Strains are not recognized under the breed specialty organization standards; bench standards apply to all English Setters. Acceptable colors under the standard are black, white, and tan: black and white; blue belton; lemon and white; orange belton: lemon belton; orange and white; liver and white; liver belton: and solid white. Dogs without heary patches of color on the body but flecked all orel are preferred. Dogs should stand about 23 to 25 inches and bitches 22 to 24 inches at the shoulder. Mature dogs should weigh about 55 to 70 pounds and bitches 50 to 65 pounds.

Gordon Setter.-The "black and tan Setter" is an old breed. probably antedating the Irish Setter. A native of Scotland. where 
it gained wide popularity among titled sportsmen of the eighteenth century, it was named for the Duke of Gordon, who was one of its foremost breeders. Although the Gordon is a handsome dog and its owners are invariably enthusiastic in their

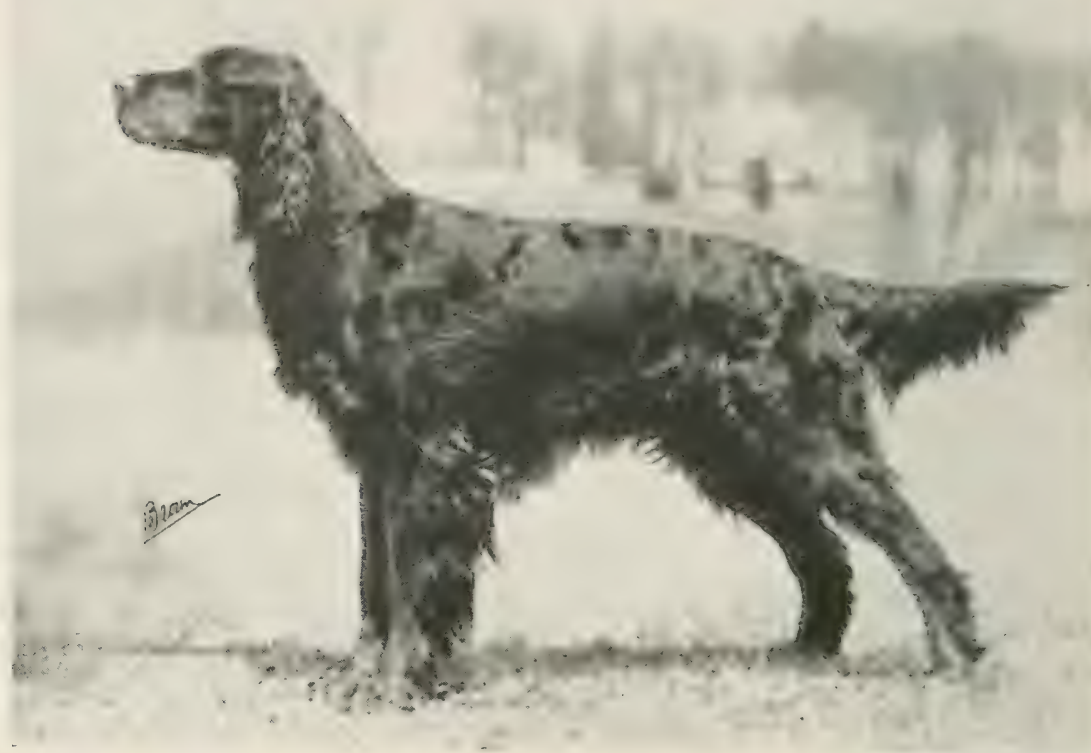

The handsome black and tan Gordon Setter is not so well known in Illinois as the English and Irish setters. Gordons are intelligent and capable hunting dogs.

praise of the breed, it remains one of the least-known setters in the United States.

The Gordon Setter Club of America points out that the numerical weakness of the breed in this country is due chiefly to the fact that the Gordon is a one-man dog and. therefore. does not train easily to work for a handler he is unaccustomed to in field trials. Field trial handlers naturally prefer a dog that develops early, has speed and independence, and is adapted to kennel routine without requiring close companionship of his handler or trainer. On the other hand, the Gordon makes an ideal family dog and is one of the most intelligent hunting dogs. Its friends claim that it has no equal for cover shooting and that its trait of covering the ground thoroughly and at a somewhat slower pace than the English Setter is often a decided asset. 
The Gordon is not common in Illinois, hut a few dogs of this handsome breed can be found here and there in the state.

The coat of the Gordon Setter should be straight or slightly wary, silky, and deep, lustrous black in color. Tan markings oecur above the eyes, on the sides of the muzzle, on the throat and chest. on the forelegs up to the elbows, and inside the hind legs and thighs. Present bench standards call for shoulder heights of 24 to 27 inches for mature males, 23 to 26 inches for females: weights should be 55 to 75 pounds for males and 45 to 65 poundis for females.

Irish Setrer.-The Irish Setter was a popular hunting dog in his native Ireland more than 2 centuries ago and. as early as the first decades of the nineteenth century, it had become established throughout the British Isles. There is no certainty as to the origin of this hunting dog, but officials of the Irish Setter Club of America believe that a combination of English Setter. slaniel and Pointer blood, with a trace of the Gordon Setter.

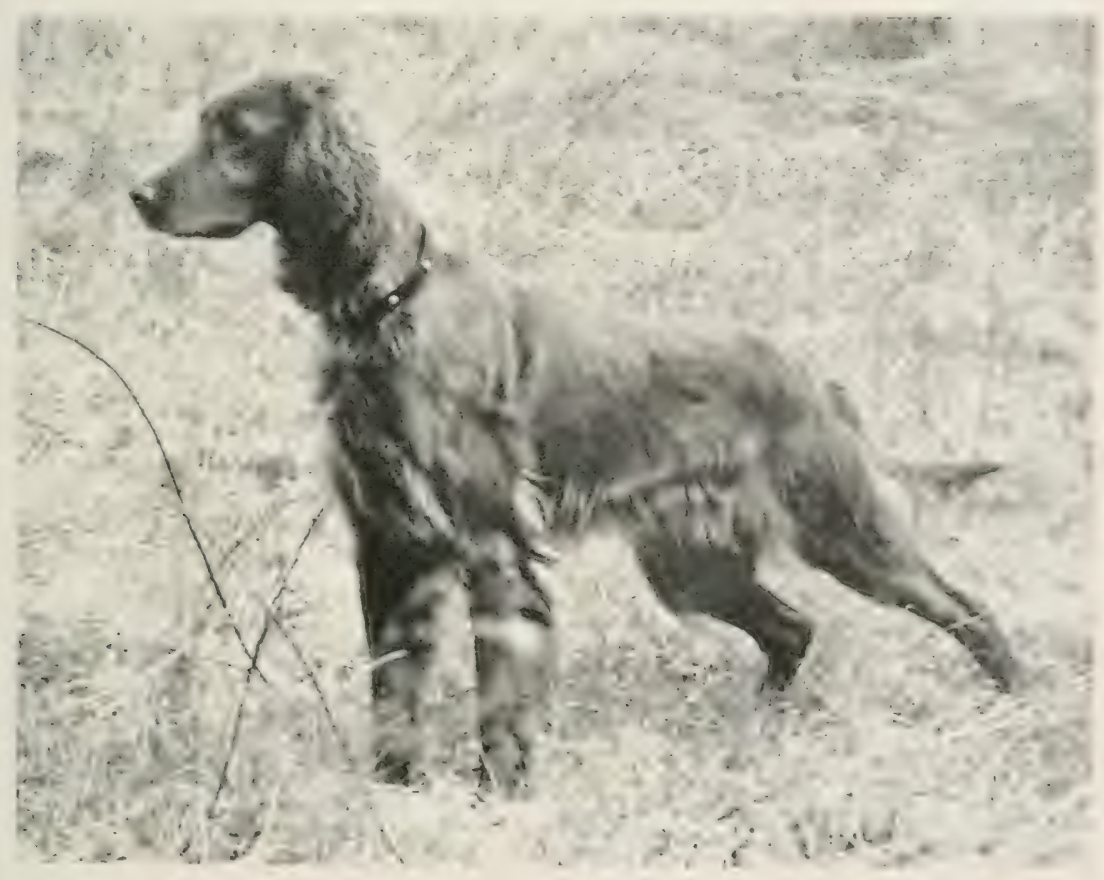

The rangy build and rich red coat of the Irish Setter are distinctive. This is an old hunting breed whose field ability was for a time neglected for bench show points. 
may have been the foundation of the breed. The Irish Setter has been generally known in the United S'ates since about 1875.

Until the solid red setter appeared in Ireland eary in the nine' eenth century, the usial color was red and white. with ihe white often predominating. Even today, in Great Britain. raiticolors are not uncommon. In America, any sizable white area on the coat is considered undesirable, although smail and incromspicuous white markings are accepted.

The Irish Setter throughout most of its history has ljeen a tough and efficient hunting dog. For a time, in America, emphasis: on bench show points brought the criticism that the natural field ability of the breed was being neglected. Howerer. the revival of interest among breeders in its role as a field dog seens: to have overcome to a great extent any such grounds for crisicisn.

Bred somewhat on race-horse lines, the Irish Setter is slightly longer of leg than the English and Gordon seiters. Irish Setter: are active, companionable, and attractive dogs possesing intelligence, keen nose, and sporting instinct. The bench stanclard calls for a rich golden chestnut or mahogany red coat. with no trace of black. White on the chest, throat, or toes, a small star on the forehead, or a small streak or blaze on the nose or face do not disqualify. Shoulder heights of mature dogs are usually 24 to 26 inches; weights 50 to 65 pounds.

Poinfer.-Trained hunting dogs of the Pointer trye are known to have been in existence for at least 3 centuries. and many authorities believe the Pointer is the oldest of our modern breeds of pointing gun dogs. The Pointer seems to hare been closely associated with sporting firearms through their successive stages of development. For a time after guns came into use in hunting, the selters, or setting spaniels. continued to be auxiliaries to netting, which was considered a more aristocratic form of sport than gunning. Apparently. at this time Pointers were used to locate game that was shot on the ground. It is interesting, however, that the earliest dependable record of hunting with Pointers, in England about 1650. was in the then popular sport of coursing hares. The Pointers served to find and point the quary, after which Greyhounds were brought up and unleashed for the chase.

It was formerly believed that Pointers were first imported to England from Spain, but it now seems probable that the modern breed was developed largely in the British Isles. It may be sumised that the setting spaniel played a prominent part 
in the founding of this breed, and there is good evidence of early crosses with Foxhounds, Greyhounds, and probably Bloodhounds. Early in the eighteenth century, Spanish Pointers were imported and crossed with the native Pointers. The heary and slow Span-

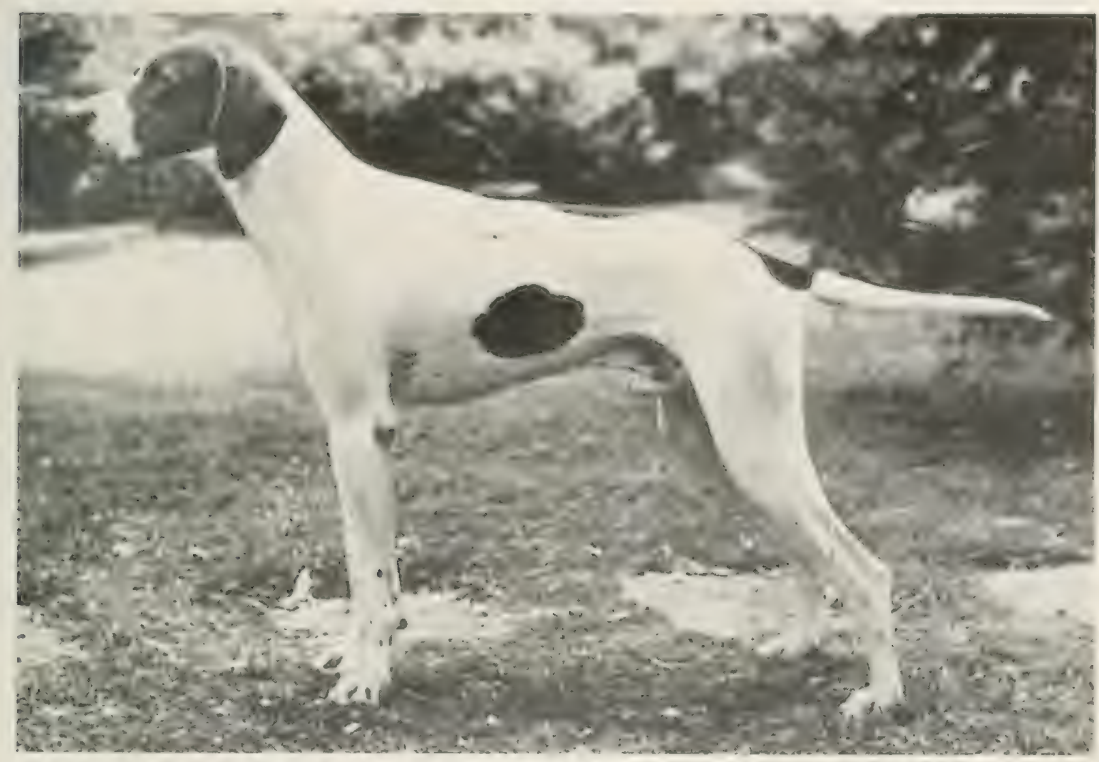

The Pointer shares honors with the English Setter as the leading birdhunting $\operatorname{dogs}$ in Illinois. The Pointer's short coat affords cleanliness and comfort in working, but it gives less protection from thorns than the long coat of the setter.

ish strain proved unpopular, and breeders discontinued this practice, but Spanish blood is credited with intensifying the pointing tendency.

During the eighteenth century, crossing with various setter strains was in rogue. This, no doubt, was partly to improve the Pointer's disposition, which seems to have been on the ferocious side and made him difficult to handle. The Pointer of today is usually a good-natured and friendly dog, but he has retained his independence and strongly competitive spirit, qualities which make him a fine field trial performer.

Emphasis on working qualities by many generations of Pointer breeders has produced a dog that is popular among birct hunters everywhere. The typical Pointer is a very intelligent. active, and attractive dog. The breed as a whole is probalbly a trifle sturdier and rangier than its chief competitors. the setters. 
The Pointer's short coat is something of an advantage from the standpoint of cleanliness, but it affords somewhat less protection from thorns than the longer hair of the setter.

Desirable Pointer characteristics include a deep chest with deep, well-sprung ribs, strong, moderately long legs, and a short, flat, and firm coat. Quality, general symmetry of outline, and smoothness of motion are emphasized by the standard.

The Pointer color is usually rich liver and white. Lemon and white, orange and white, black and white, and sometime: solid black are other markings.

Pointers vary in heights and weights; for mature males. shoulder heights of $241 / 2$ or 25 inches and weights from 50 to 55 pounds are often considered desirable.

German Shorthaired Pointer.-S p a n is h P o in ters were brought to Germany in the seventeenth century and crossed at various times with Bloodhounds. From this crossbred stock came the German Pointer, a heavy-bodied dog with highly dereloped scenting powers, staunch on point but slow afoot. About 50 rears

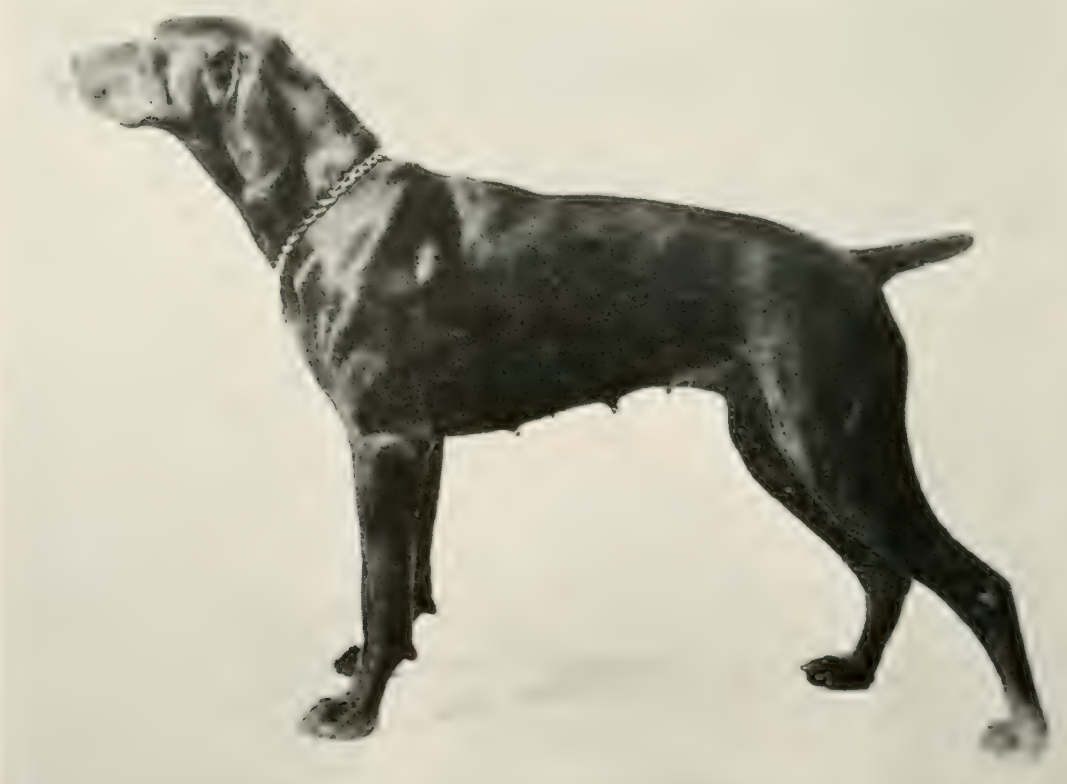

The German Shorthaired Pointer possesses a keen nose and is staunch on point. Unlike the American Pointer, it has a docked tail. Popularity of this breed is increasing in Illinois. 
ago, German and Austrian breeders began crossing their dogs with American Pointers, whose speed and energy they greatly admired. From these crosses, through careful selection, arose a new breed, the German Shorthaired Pointer, a smaller, faster log, which nevertheless retained its keen nose and staunchness.

German Shorthaired Pointer's were first imported into the United States in the early 1920 's. Although they have not yet become widely distributed here, they have gained the reputation among sportsmen who know them of being among the most versatile hunting dogs. Backers of these dogs say they are proficient hunters and pointer's on birds, good retrievers on land or water, and that they can be trained for hunting coon, possum, and other fur, where they serve as keen-nosed night trailers.

The coat of the German Shorthaired Pointer is short, flat, and firm. Acceptable color's under the standard are solid liver, liver and white spotted, liver and white spotted and ticked, liver and white ticked, liver roan. Any other color's than liver and white (gray white) are discriminated against. Dogs should stand 23 to 25 inches at the shoulder and weigh 55 to 70 pounds; bitches should stand 21 to 23 inches and weigh 45 to 60 pounds. Symmetry and field quality are emphasized by the breed standard. The tail of the German Shorthaired Pointer is customarily docked.

Weimaraner.-Jack Baird (Becker 1947b) says of the Weimaraner: "As might be expected, the breed was developed in Weimar, Germany, and, unlike most breeds, the history and tradition of the Weimaraner are not lost in the maze of antiquity. About 1810 the nobles of the court of Weimar were searching for a highly personalized hunting dog that could be used on all types of game. The Weimaraner was the result-and it fulfilled all their requirements.

"There is a reason why the Weimaraner is an all 'round hunting dog and still accomplished in other fields. The nobles of the old German court wanted their dogs to do everything well and also be personal companions. Consequently the breed was not kennel-raised but home dereloped, which gave the dogs the chance to reflect their owners. Too, there was a system of 'breed wardens' and all breeding was done through their selection of eligible stock. The wardens' authority included the telling of breeders which puppies they could keep. The net result was the production of a working-hunting strain that was completely companionable and instinctively alert to the wishes of the master. 


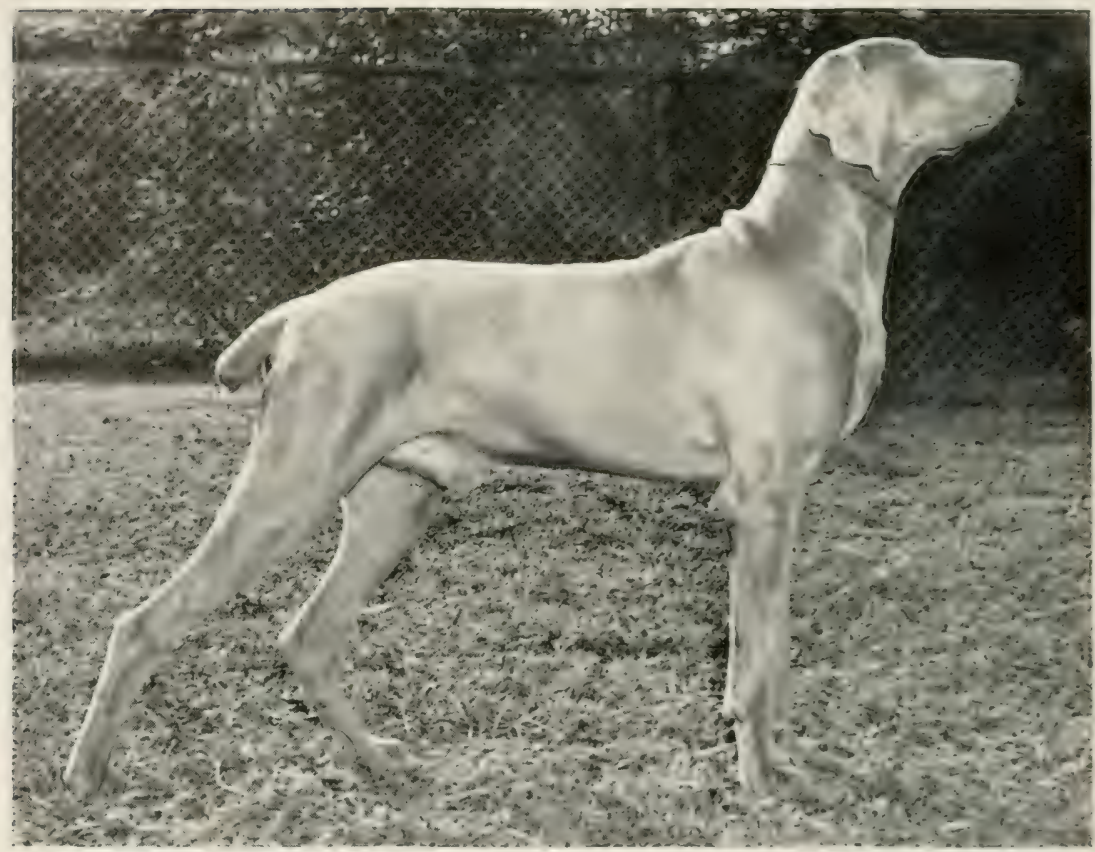

The Weimaraner was developed by German nobles as an all-around hunting $d o g$ and as a companion. Weimaraners serve as hunters, retrievers, and trailers, and they excel in obedience tests.

It is little wonder, then, that the selected stock that was finally permitted to come to the United States was able to produce youngsters that have made good in all fields in which they were introduced.

"In general, the same breeding and guardianship of the breed established in Germany has been continued in America," Baird writes. "There were never over 1,500 Weimaraners in all of Germany because of this strict breeding program. According to a report in 1947 at the annual meeting of the Weimaraner Club of America, there were only 200 of the breed scattered from coast to coast. And this strict-breeding policy pays off in that those permitted to buy any of the stock can be sure of getting a dog who will fulfill their needs."

In 1929, Howard Knight, a sportsman from Providence. Rhode Island, was admitted into the Weimaraner Club in Germany and brought orer the first two Weimaraners to be seen in the United States. Subsecuently he imported six other top specimens, which, with the first two, became the foundation stock here. 
The Red Schweisshunde, a solid-color Bloodhound, is thought to be the foundation of the breed. Originally, Weimaraners were used for hunting wolves, mountain lions, deer, and wild boars, when they distinguished themselves as trailers. Later, they proved to be capable hunters and retriever's of upland game birds and waterfowl. Although the Weimaraner can trail, point, and retrieve, he is usually classed with the pointing dogs.

In this country, as in Germany, only a few favored hunter's seem destined to own Weimaraners. Only those roted membership in the Weimaraner Club of America are eligible to ownership.

Kilbon (1947) gives an unusually good description of the physical characteristics of the Weimaraner. He compares its short coat of solid gray to fine velour. Acceptable shades of gray are silver, bright, dark (ash or blue), and yellow.

The eyes are blue-gray or amber; when the pupils are dilated, they appear almost black. The tail is cropped within 3 days after the puppy is whelped; it is approximately 6 inches long in a mature animal.

Mature dogs weigh 65 to 85 pounds and stand 24 to 26 inches at the withers; bitches weigh 55 to 75 pounds and stand 22 to 25 inches. In spite of its large size the Weimaraner is said to possess exceptional speed and smoothness of gait.

Wire-Haired Pointing Griffon.-The history of this breed dates from about 1875 , when a Dutch sportsman and dog fancier began to breed selected hunting dogs for the definite purpose of establishing a new sporting breed. The ancestry of the dogs used is unknown, but it is believed that they carried English Setter and Otterhound blood, and probably blood of the Pointer and some of the spaniels. Although the breed was founded in Holland, much of its later development took place in France.

First records of a Wire-Haired Pointing Griffon class in a major English dog show are those in 1888. A dozen years later the breed was introduced into the United States, where it has since gained considerable popularity as an upland bird hunter and as a retriever. Its distribution still is not extensive and comparatively few Illinois sportsmen are acquainted with the breed.

Griffon owners praise its versatility, although there is general agreement that it is slower in the field than the better known pointing breeds. It possesses an excellent nose, and its hard. wiry coat adapts it to work in swamps and dense upland cover. It is said to be an excellent water retriever. Adherents of this breed say that it can be trained for any kind of small game. 
The Wire-Haired Pointing Griffon is a dog of medium size; it is rather short backed and strong limbed. Its appearance suggests strength and vigor. The harsh coat gives a tousled, un-

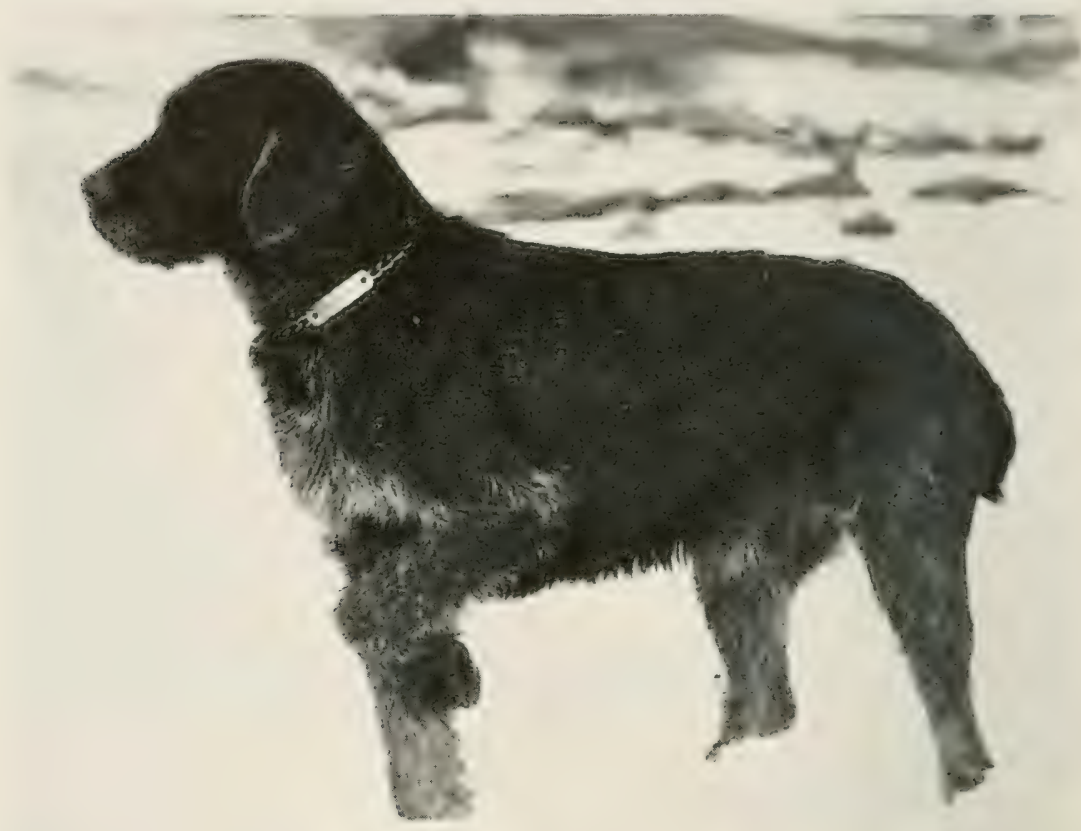

The Wire-Haired Pointing Griffon originated in Holland about 187.5. The Griffon is a versatile hunting $\operatorname{dog}$ but it lacks the speed of a pointer or setter. It is rare in Illinois.

kempt appearance. Nevertheless, the dog carries itself with a very intelligent air.

Acceptable colors under the bench standard are steel-gray with chestnut splashes, gray-white with chestnut splashes, chestnut, or dirty-white mixed with chestnut. Black is considered ohjectionable. Males stand approximately 211ㄹ to 231 inches at the shoulder; females $191 / 2$ to 211 @ 2 inches.

\section{The Sporting Spaniels}

Clumber Spaniel.-The Clumber, the largest of the spaniels. is rather slow moving, and for that reason is not so well adapted to American hunting conditions as the Springer or Cocker. On 
English estates where game is abundant, Clumber's are used, often in teams, for upland game hunting. They are said to be sure finders of all kinds of game and excellent retrievers.

These dogs have been introduced into Canada (Lloyd 1937) and the United States, but only in small numbers, and they are known to comparatively few American sportsmen.

The Clumber is a handsome, powerful-looking dog, with a white coat marked with orange or lemon. According to the stand-

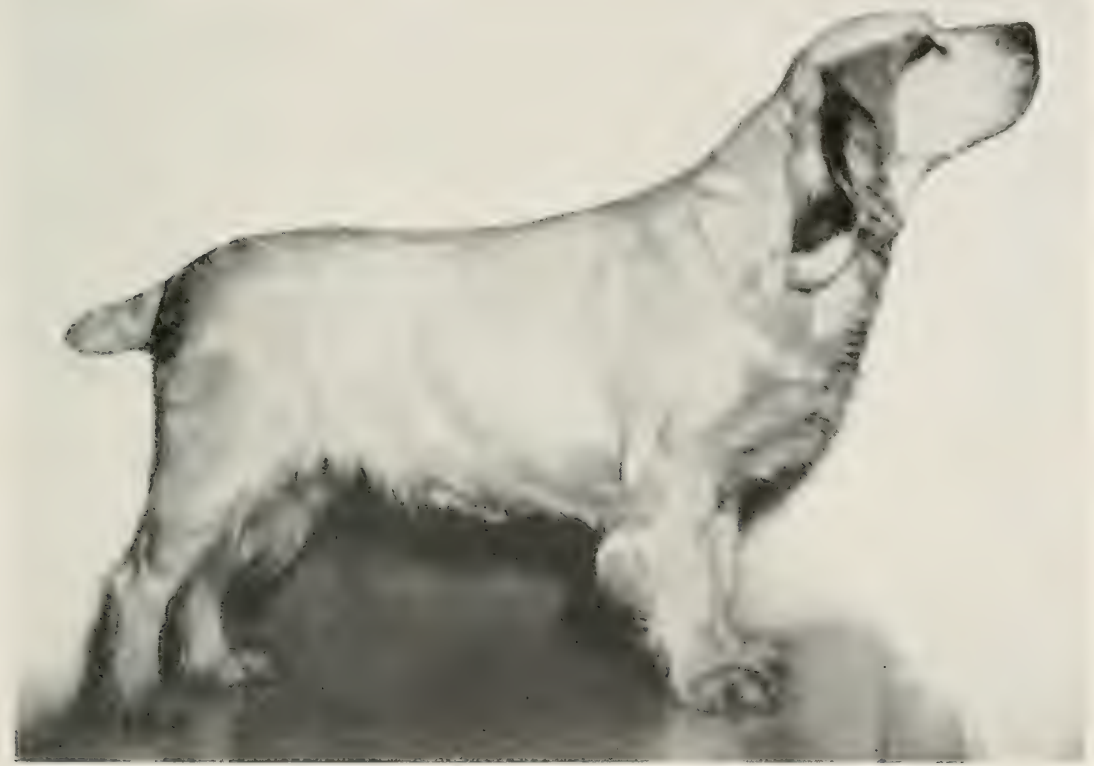

The Clumber Spaniel is a large, handsome, powerful-looking dog with a white coat marked with orange or lemon. In England, Clumbers are used for hunting all kinds of small game.

ard, the fewer markings on the body, the better is the color. Perfection of markings consists of solid orange or lemon ears, erenly marked head and eyes, and ticked muzzle and legs. Nature males average 55 to 65 pounds and females 35 to 50 pounds in weight.

Cocker Spaniel.-The Cocker Spaniel has long been numerically strong in England where, eren in the days of the flintlock fowling piece, "Cocking Spaniels" were bred extensively for hunting woodcocks and similar game.

In the United States, the first field trials for Cocker's were held in 1924. In recent rears, the breed has gained wide popu- 


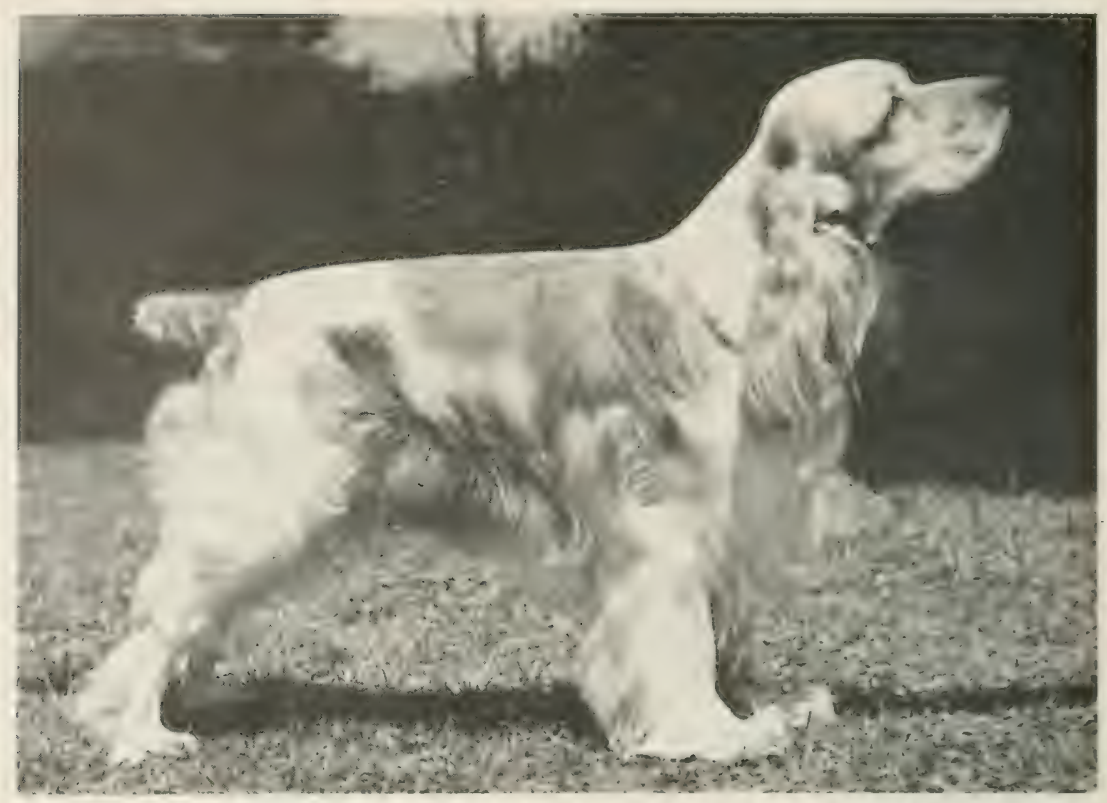

The Cocker Spaniel is one of our oldest hunting breeds. American Cockers are very popular as family dogs. Hunting strains produce firstclass field $\operatorname{dogs}$ used for hunting pheasants and other small game.

larity in this country and today it stands close to the top in numbers registered among dogs of all breeds. The companionable nature and merry actions of the Cocker, which make it a popular family dog, have to some extent overshadowed its real merit as a hunter.

A. M. Lewis (Becker 1947b) points out that emphasis on bench show points in recent year's has made it difficult to obtain Cockers with good field breeding. The Cocker that is to be a hunter must be selected with care. The attention of a number of breeders is again being turned to the inherent hunting abilities of this breed.

The American Cocker is a wide-awake, intelligent, serriceable-looking little dog having a rather short, firmly knit. muscular body, a deep chest, and strong. well-muscled legs. It possesses a naturally keen nose and under proper training is quick to learn what is required in the field. Perhaps as a natural outgrowth of its small size, the Cocker is often temperamental and is one of the most sensitive of bird dogs. This characteristic calls for understanding on the part of the trainer who should. at all times. 
maintain a proper mixture of firmness and gentleness. The Cocker responds to good training methods with excellent performance in the field (Moffit 1937).

Under the bench standard, the coat of the American Cocker should be flat or slightly waved, soft and dense. Solid colors,

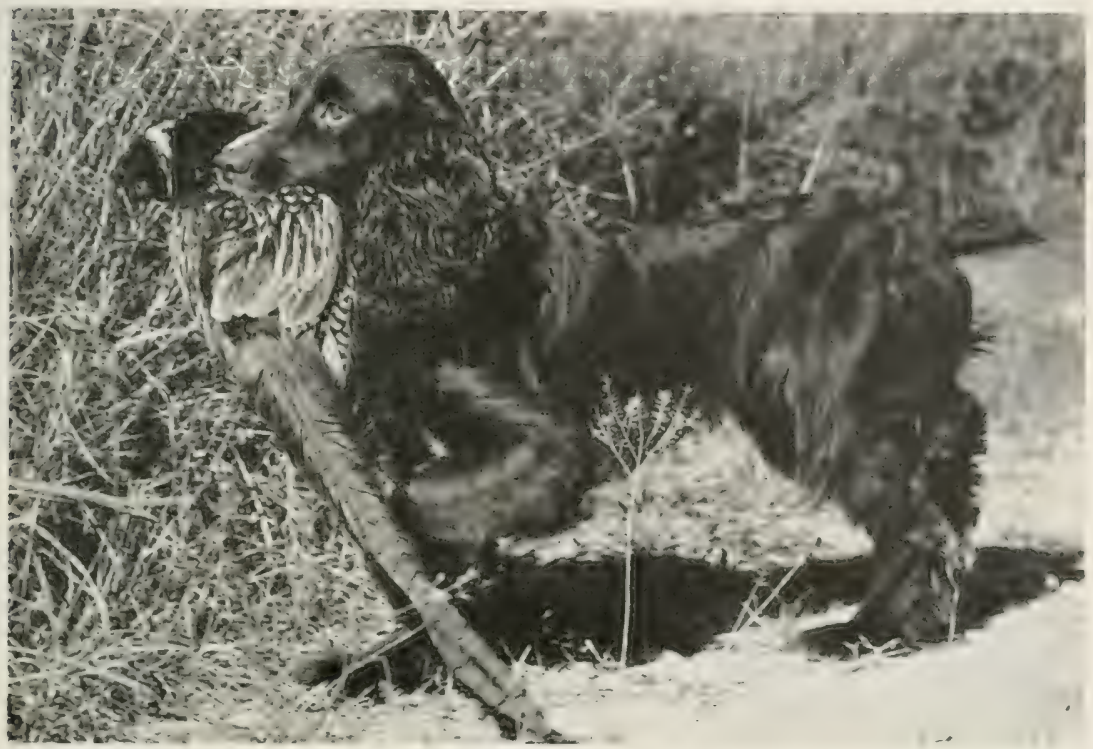

The English Cocker Spaniel is larger than the American Cocker and it has a long muzzle that facilitates retrieving of large game birds. This is a typical English Cocker.

which are common, include jet black, red, tan, cream, and liver. The standard specifies that these colors should be sound throughout and not faded or "washy." White on the chest of otherwise solid-colored animals is considered objectionable, but does not disqualify. Color combinations, such as black and white, black and tan, occasionally liver and white, and tricolors, or black and tan and white, also occur. Accepted weights of the American Cocker range from 22 to 28 pounds.

The English Cocker, relatively uncommon in the United States, differs from the American Cocker in both type and size. Primarily a sporting dog, it is somewhat larger and has longer legs and an elongated, setter-like dome and muzzle. Desirable weights are for males 28 to 34 pounds and for females 26 to 32 pounds. 
English Springer Spaniel--As their name indicates, the ancestral stock of this and most other spaniel breeds is leclieved to have been native to Spain. Development of the modern sporting spaniels took place largely in the British Isles and western Europe, where some types have been popular huning dogs for centuries.

Hunting dogs much like the modern English Springer Suaniel are shown in the illustrations of sporing books that date back to the fourteenth century. The early "Springing Spaniei" flushed partridges and other game for the falconer.

The Kennel Club of England recognized the English Springer. as a distinct breed in 1902 and adopted a stanclard as a guide to breeders. This breed became quite well known in the Lnited States after 1920. Field trials were held as early as 1921. and. in 1927, the English Springer Spaniel Field Trial Association was founded. It became the official sponsor of the breed on this side of the Atlantic.

The English Springer Spaniel is an attractive, compactly built, upstanding, and active spaniel of medium size. possessing

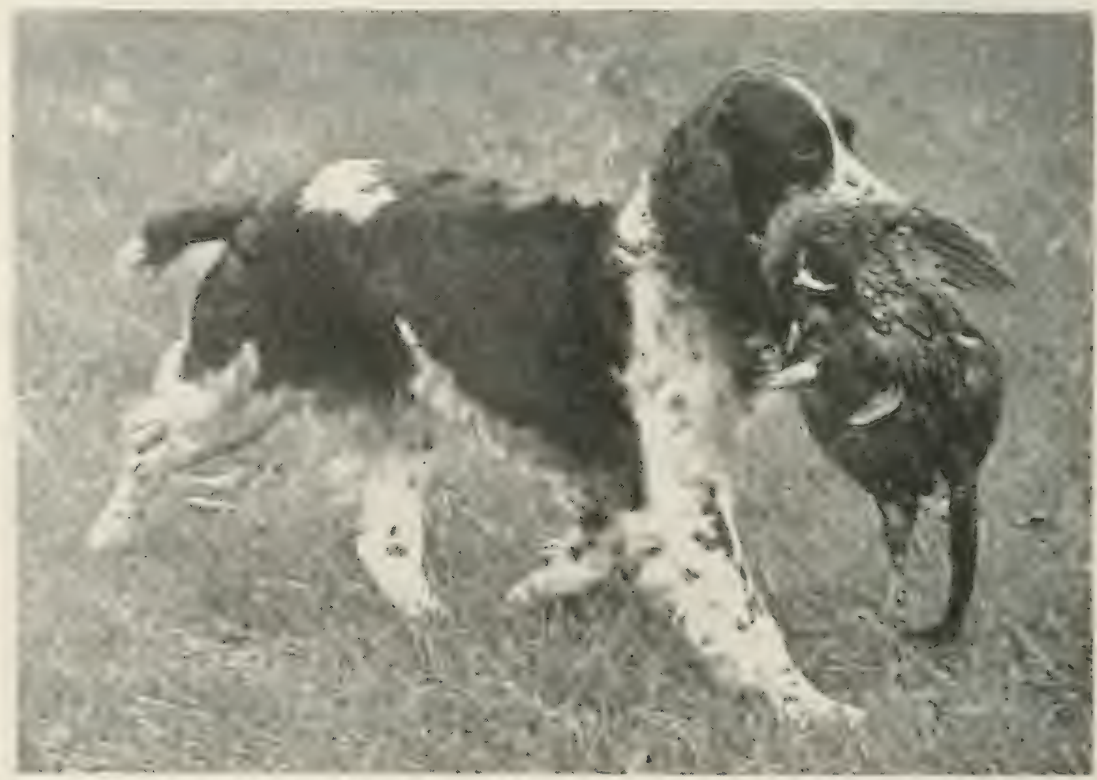

The English Springer Spaniel is now one of the popular hunting breeds in Illinois. Springers are good pheasant dogs and hunt well on other small game. They are widely used as waterfowl retrievers. 
intelligence, a keen nose, and sporting instinct. it is al huntis.s dog of all work. Its whole makeup is suggestive of strength. endurance, and considerable speed.

In Illinois, the Springer ranks as one of the leading pheasant hunting dogs; also it is often trained for rabbit hunting. Its value as a retriever on land and water is widely known. In spite of the fact that the Springer"s coat lacks the repuisite density for continuous work in icy water, this dog is probably surpassed in popularity as a waterfowl retriever along the Illinois River flywy only by the Chesapeake Bay and Labrador retrievers.

The Springer's intelligent and friendly nature make it very popular as a family dog; few breeds surpass it as a companion for children.

Among the colors and color combinations acceptable under the standard are liver and white; black and white; tan and white; black, white, and tan; liver; black; and roan. Only red and white and lemon and white are subject to discrimination. The favored shoulder height for dogs is 181.2 inches, with an allowable variation of one-half inch either way, and for bitches 18 inches, also with an acceptable variation of one-half inch. Mature dogs should weigh about 45 pounds, with 50 pounds as the upper limit of desirable weight. Bitches should weigh about 42 pounds and should not exceed 47 pounds. Proper balance and proportion in contour are considered highly desirable. Orersize is held prefelable to bad proportions.

Field Spaniel.-The Field Spaniel type was established by repeated crosses between the "Welch Cocker" and the Sussex Spaniel, resulting in a very long-bodied, low-set dog. Breeders at the same time strove to produce a heary-boned breed. In recent years, these exaggerated body and skeleton characters have been largely overcome through wise and careful breeding. The desirable Field Spaniel today is a handsome dog with good balance between height and length. It possesses level-headedness. intelligence, persererance. and a keen nose. Continued breeding for endurance, speed, and agility have made much progress in producing a capable field dog.

The typical Field Spaniel stands about 18 inches at the shoulder and weighs from 35 to 50 pounds. The color is usually black.

The Field Spaniel is almost unknown in Illinois.

Sussex Spaniel.-The Sussex Spaniel is thought to be one of the oldest breeds of land spaniels. Formerly the Sussex was 


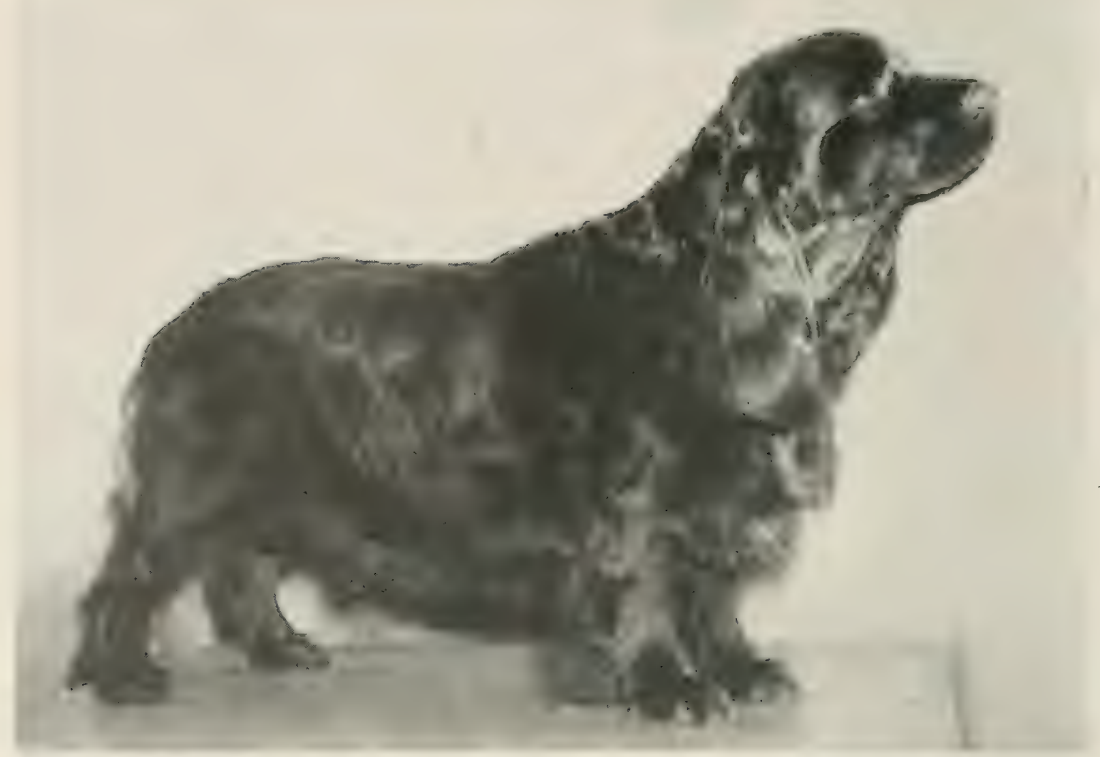

A coat color of rich golden liver is a distinctive mark of the Sussex Spaniel. Dogs of this breed are used in England for small game hunting. but they lack the speed desired by American sportsmen.

a dog of exaggerated body length and shortness of legs. The modern dog possesses good proportions for field work. It is, however, more massive and slower than the Springer or Cocker. In England, it is used for hunting pheasants and other farm game. It is not well known in this country. It is doubtful if there are 10 Sussex Spaniels in Illinois.

The color of the purebred Sussex is a rich golden liver. a distinctive breed characteristic. The body is rather massire and muscular, but should exhibit freedom of motion. Weights vary from 35 to 45 pounds.

\section{The Retrievers}

American Water Spaniel.-The American Water Spaniel for many years has been known to Midwesterners as a familiar companion of the duck hunter. In 1938, this spaniel was recognized as a breed by the Field Dog Stud Book, an adjunct of the Amcrican Field, and, in 1940, it was recognized by the American Kennel Club. 
There are several versions as to where and when this spaniel originated. A similar dog has been known to New England outdoorsmen for many decarles, but the present type dog seems to have evolved in the Middle West. Fairly early in the present

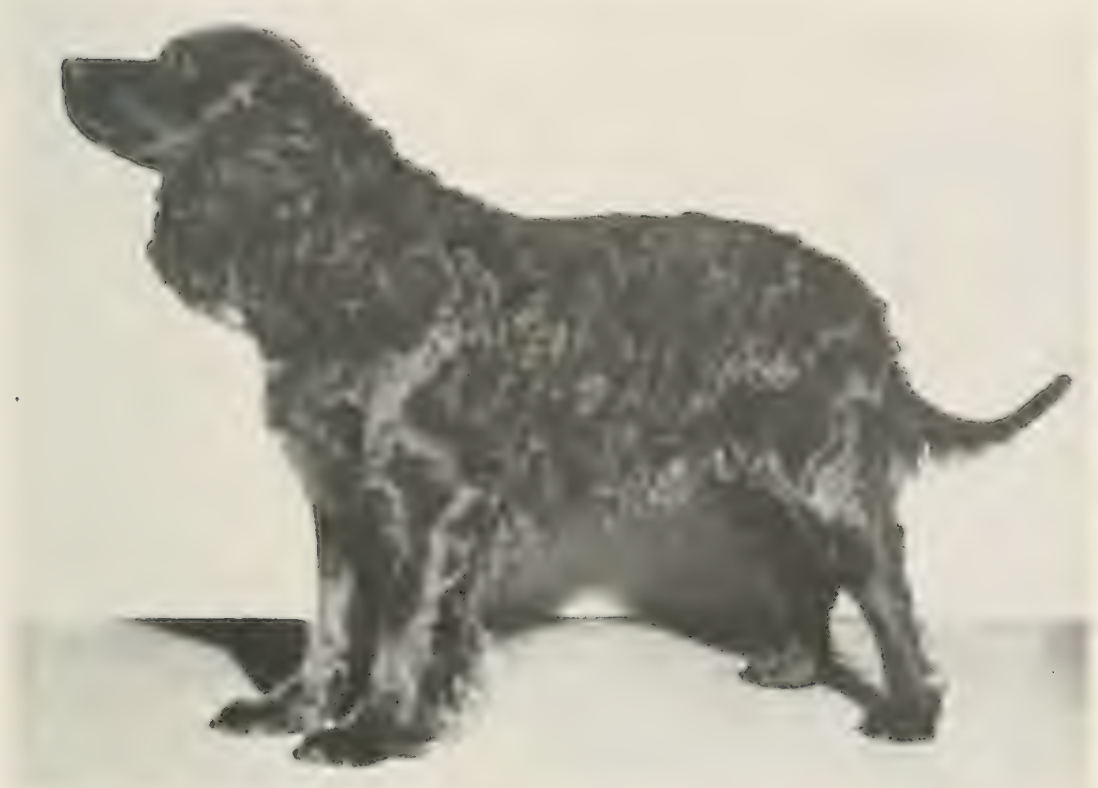

The American Water Spaniel, developed chiefly in the Middle West, is a capable retriever and takes easily to upland game hunting, where its work resembles that of a Springer.

century, American Water Spaniels were well known to hunters in Wisconsin, Illinois, Michigan, and other nearby states.

The American Water Spaniel is best known for its ability as a water retrierer, but owners claim that it deserves to be ranked as a capable all-round hunting dog. It is much at home in both marsh hunting and upland game hunting. On upland game its work resembles that of the Springer Spaniel. It hunts by body scent and "springs" to flush. Its natural retrieving ability here makes it useful in returning crippled and dead game.

As a waterfowl retriever, this dog is praised for its accuracy in marking, its vigor in going after shot game, and its prompt return, as well as its ability as a swimmer. It is said to respond cheerfully to handling and as a breed to possess a tender mouth. 
Obviously, the American Water Spaniel is not of sufficient size to compete on equal terms at all tasks with such powerful dogs as the Chesapeake Bay, and its coat is not water resistant enough to allow it to work comfortably for hours in icy water. Nevertheless, none surpass it in love of the water and willingness to work.

The typical American Water Spaniel is an attractive, mediumsized, active, muscular dog of characteristic spaniel build. It possesses intelligence, an amiable disposition, and a keen nose. It is strong and sturdy and has legs of medium length. In general outline the body should be symmetrical and not too compactly coupled. Its appearance should suggest strength, endurance, and willingness to work.

The coat of the American Water Spaniel should be closely curled or have a marcel effect, and it should be of sufficient density to be of protection against weather, water, and punishing corer. yet not coarse. The legs should have medium-short, curly feather. Acceptable colors are solid liver or dark chocolate; a little white on toes or chest is permissible. Shoulder heights of mature animals may vary from 15 to 18 inches; males may weigh 28 to 45 pounds and females 25 to 40 pounds.

Chesapeake Bay Retriever.-As with most other sporting breeds, there is no complete and authentic record of the derelor)ment of the Chesapeake Bay Retriever. Until the recent recognition of the American Water Spaniel, it held claim to being the only sporting breed to originate in America. The following account of the early history of the Chesapeake is accepted by the American Chesapeake Club as probably true.

In 1807, the American ship, Canton, rescued the crew and cargo of an English brig off the coast of Maryland. Included in the cargo were two Newfoundland puppies, a dog and a bitch. The dog named Sailor and the bitch named Canton. after the rescue ship, were presented to the gentleman who gave hospitality to the shipwrecked crew. Both dogs eventually earned great reputations as retrieving dogs. Sailor, with a dingy red coat. and Canton, a black, were mated with a number of the common nondescript dogs then used for retrieving, thus laying the foundiation of the Chesapeake breed. Whether the two dogs were themselves ever mated is unknown. The claim is sometimes made that out-crosses were later made with other breeds, but this seems to be based entirely on supposition.

By 1885, the Chesapeake Bay breed had become fairly well established and widely known for feats of retrieving in the cold 
and rough water's of Chesapeake Bay. During World War I, further developments in the breed took place, including the now popular "dead grass" color. The Mississippi River valley has long been one of the chief strongholds of this breed.

The Chesapeake Bay Retriever is a powerfully built dog with at short, strong back, a deep and wide chest, and well-dereloped fore and hind quarters. In outline, the Chesapeake should be im-

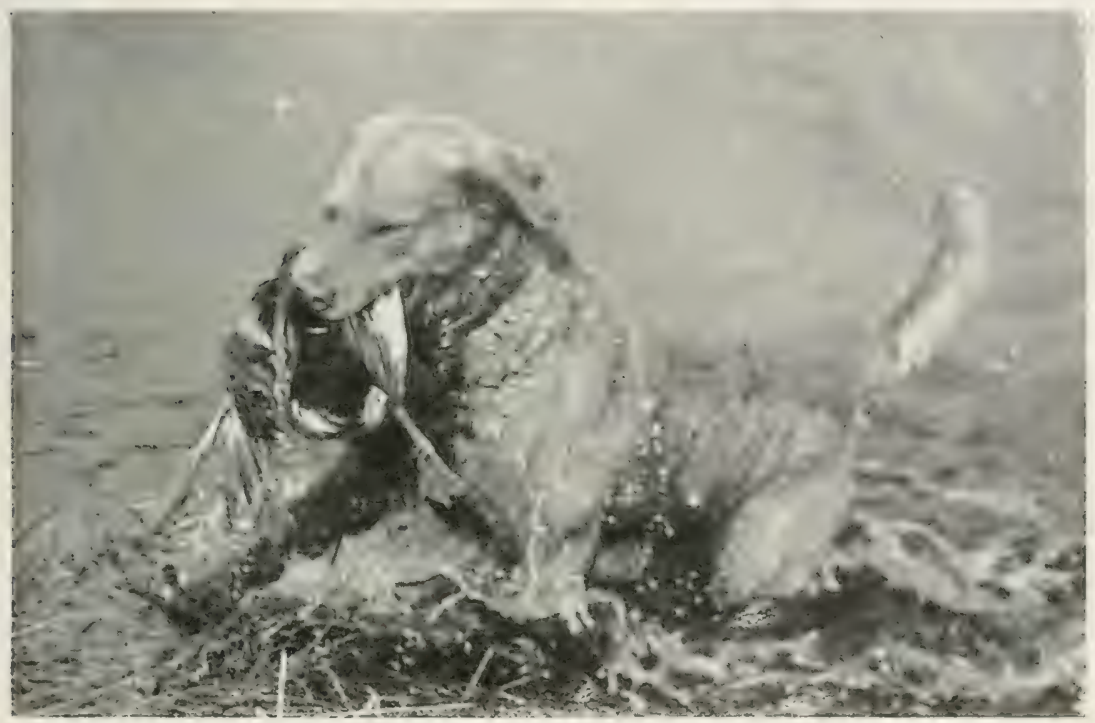

The rugged Chesapeake Bay Retriever is a valuable aid in reducing crippling losses among waterfowl in Illinois. A waterproof coat and powerful frame enable the Chesapeake to work in icy and rough water.

pressive and well balanced. Courage, willingness to work, nose, intelligence, love of the water, and good disposition are qualities that, according to the standard, should be giren primary consideration in the selection and breeding of the Chesapeake Bay Retriever. Special emphasis is placed on quality and texture of coat, as well as color. Acceptable colors vary from dark brown to a faded tan known as "dead grass." The coat should be thick and short, with a dense, fine, woolly undercoat. The oil in the harsh outer coat and the woolly undercoat are of great value in preventing icy water from reaching the dog's skin, and they aid in quick drying. Hair on the face and legs should be short and straight; hair on the shoulder's, neck, back, and loins only should have a tendency to ware (not curl). IIature males stand 
23 to 26 inches at the shoulder and weigh 65 to 75 pounds; females measure 21 to 24 inches and weigh 55 to 65 pounds.

Curly-Coated Retriever.- The Curly-Coat is thought to be one of the oldest breeds of retrievers, although its origin remains an enigma. Like the Flat-Coated Retrierer, it is an English product. It was first shown in an English dog show in 1859, but

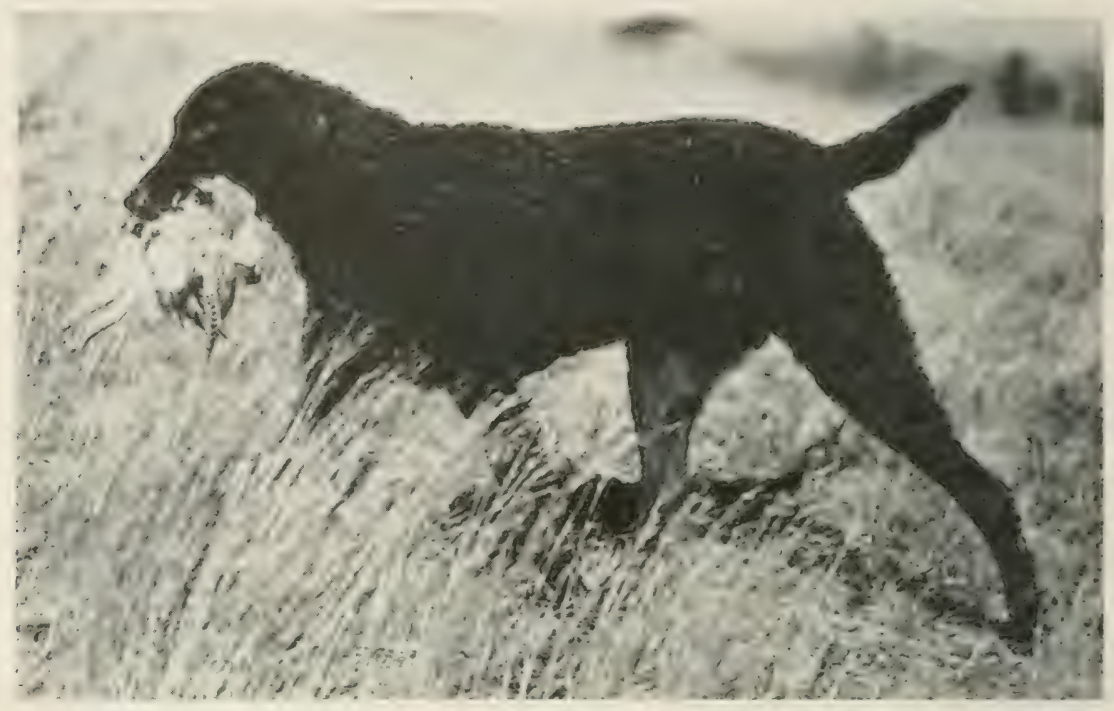

The Curly-Coated Retriever is a capable hunting dog long well linown in the British Isles but is unfamiliar to most Imerican sportsmen.

some time after this Poodle crosses are reported to have been made to give the coat a tighter curl. Curly-Coated Retrierers are rare in the United States.

The Curly-Coated Retriever is a strong, smart, actire, and upstanding dog. Friendly and amenable to training, this dog is said to be a first-class land and water retriever.

The entire coat should be a mass of thick, crisp curls, either wholly black or liver in color. A few white hairs on the chest are not penalized.

Flat-Coated Retriever.-This breed originated in England about a century ago. It has proved to be an excellent worker on waterfowl, marking, retrieving, and delivering in fine style, and a good land retriever on pheasants and other upland game birds. Like the Curly-Coat, this breed is rarely seen in the Lnited States.

The Flat-Coated Retriever is a smart, active, sturdily built 


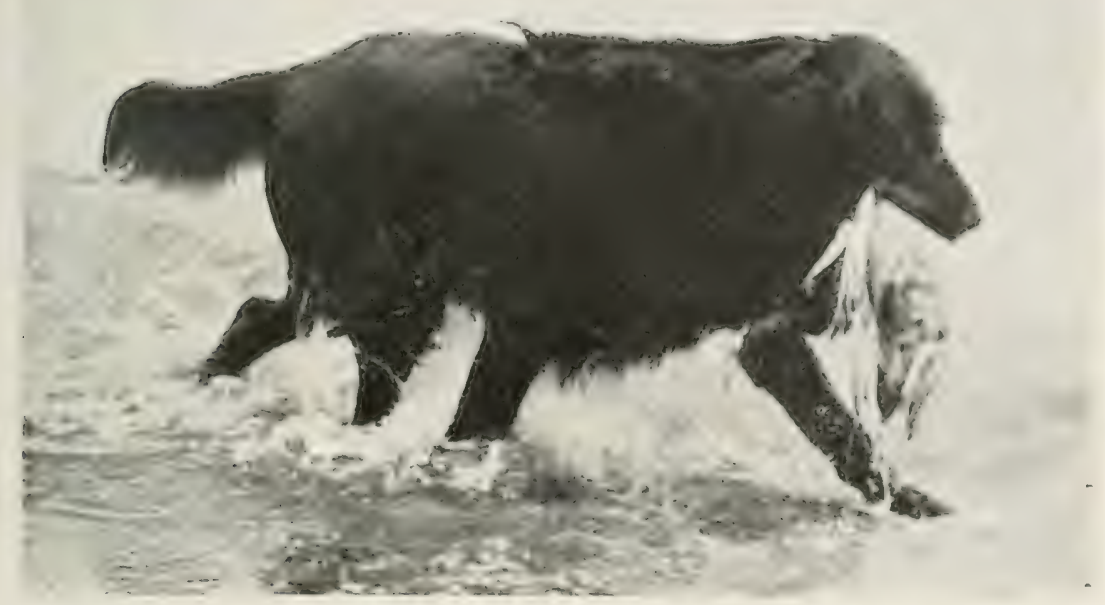

The Flat-Coated Retriever is an English breed that is not well represented in Illinois or elsewhere in the United States.

dog weighing 60 or 70 pounds. The coat should be of fine quality, flat, and dense to afford good protection in water. The color is usually wholly black, but occasionally a bit of some other color is seen, usually white on the chest. Liver color is also acceptable.

Golden Retriever.-The Golden Retriever is a descendant of an old breed of dogs known as trackers, which are native to Asiatic Russia. Russian trackers are huge dogs measuring about 30 inches at the shoulder and often weighing 100 pounds. The breed serves man in a variety of ways in its homeland, among which, it is reported, is to guard isolated flocks of sheep in winter with great steadfastness and courage. According to the American Kennel Club, the circumstances leading to the development of the Golden Retriever breed primarily from tracker stock are as related below.

In 1860, Sir Dudley Marjoribanks watched the performance of a troupe of Russian tracker dogs at a circus in Brighton, England. He was impressed by the intelligence shown by these dogs and, reasoning that this could be put to good use in the field, he purchased the entire troupe of eight dogs and took them to his seat in the Guischan deer forest in Scotland. Here they were bred without out-crossing for 10 years. but there was no game in Scotland suitable to their size, and in about 1870 plans were abandoned to establish the breed in its original form. 


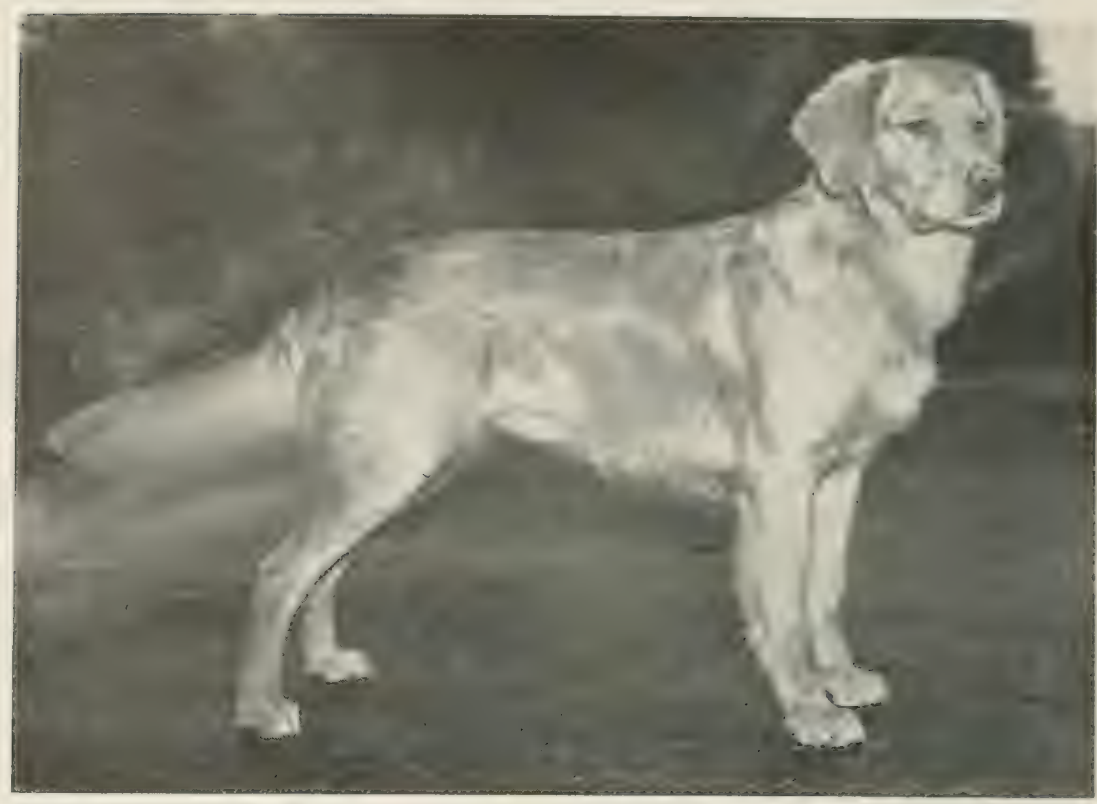

The Golden Retriever is a powerfully built dog with a rich, goldencolored coat. Fine retrievers and agreeable companions, dogs of this breed are gaining in popularity in Illinois and the Middle West.

At this time the Russian trackers were crossed with Bloodhounds. There is no record of crosses with other breeds. and only one generation of Bloodhound crosses is reported, but the descendants appear, on the basis of photographic records and notes, to have soon developed into the present Golden Retrierel type, whose characters included smaller size than the tracker. as well as intensification of scenting ability, refinement, and a slight darkening of the color of the coat.

In this country, Golden Retrievers are found chiefly on the Atlantic seaboard, in the upper Mississippi valley, and on the west coast. They are gaining in popularity in Illinois and the Nidwest.

In general appearance, the typical Golden Retriever is an active, powerful, soundly built dog, of kindly expression. and possessing good, level movement of body and legs. The skull is broad, the chest deep, the body short coupled, and the loins strong. The forelegs are straight, with good bone, and the hindlegs strong and muscular, with well-bent stifles.

The standard calls for a flat or wary coat, with a good. dense. water-resisting undercoat, and a rich golden color, not so dark 
as that of an Irish Setter. Cream color is also acceptable. A ferw white hatrs on the chest are permissible, but white collar, feet, or toes. or blaze should be penalized. Id a al wererhts for mature Golden Retrievers in good hard-working condition alle for dogs 65 to 68 pounds and for bitches 5.5 to 60 pounds. Shoulder hejghts should be for dogs 2:) to 2.1 inches and for bitches 2011.2 io 22.2 inches.

Irish Water Spaniel.-The Irish Water Spanicl has serrecl waterfowl hunters in the Illinois and Mississippi river flywas and elsewhere in the state for many years. The popularity of the Chesaneake. Labrador, and other breeds of retrievers in recent

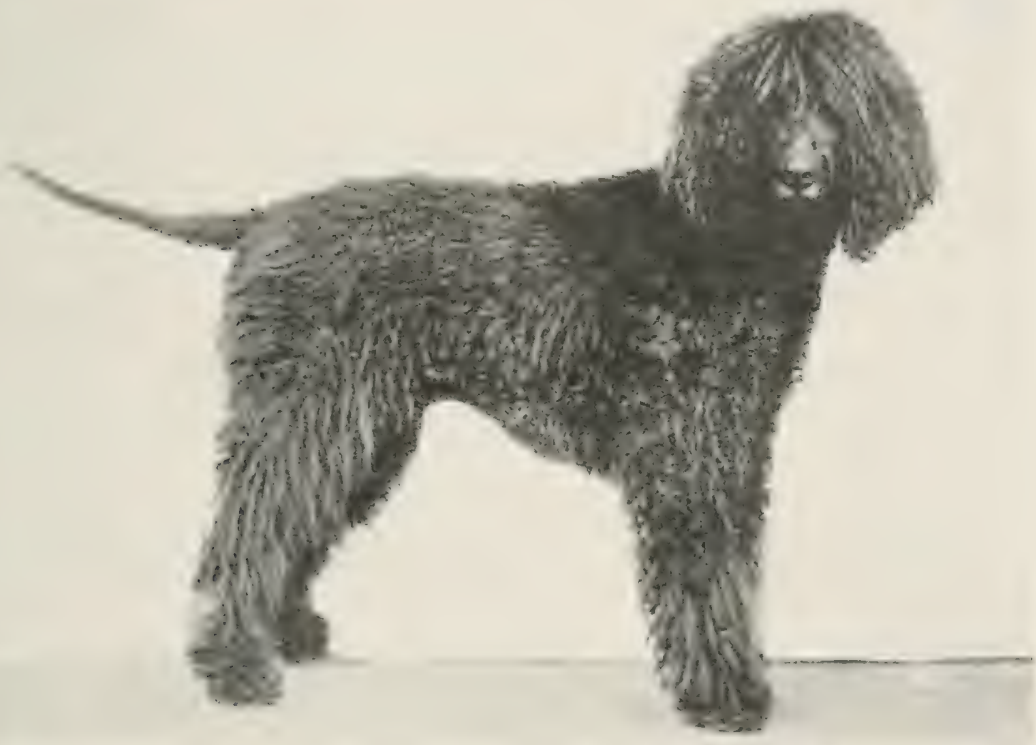

The Irish Water Spaniel is the tallest of the spaniels. The topknot and tapering tail covered with very short hair help to distinguish it from the American Water Spaniel.

rears has overshadowed the Irish Water Spaniel, but a few individuals of this fine breed can be seen along the Illinois and Mississippi.

This quaint-looking product of Erin possesses a water-shedding coat of good quality and he loves the water. Although the Irish Water Spaniel is one of the larger retrievers, he is somewhat less rugged than the Labrador and Chesapeake. 
The general appearance of the Irish Water Spaniel betokens: poodle crosses at some early time in the largely obscure histrory of the breed. It has been suggested, not without truth, that this dog looks as though he had borrowed spare parts from other kinds of dogs. The topknot, a striking characteristic of this bleed. and the round, rather short tail covered with very short hair. a so-called "rat tail," distinguish it from the American Water" Spaniel, whose tail carries a fair amount of feather.

The Irish Water Spaniel is employed to some extent as at land retriever, but its size and curly coat are something of a handicap in thick or thorny cover. It is an excellent worker in marshes, and in the water its all-around ability and willingness to work earn it a high rank among waterfowl hunters.

For show purposes, the color should be deep, pure liver without white, although a white toe does not disqualify. The neck, back, and sides should be covered with tight, crisp curls. Underneath the ribs the hair should be longer. The legs should be abundantly covered with hair that falls in curls or wares. The topknot should fall over between the eyes in peaked form. Nature dogs usually stand 22 to 24 inches and weigh 55 to 65 pounds: bitches usually stand 21 to 23 inches and weigh 45 to 58 pounds.

Labrador Retriever.-The ancestors of this breed were native to Newfoundland rather than Labrador. In 1822, a traveler to Newfoundland wrote of "small water dogs" there that were admirably trained as retrievers in fowling.

Some of these dogs were carried to England by fishermen. and early in the nineteenth century the Second Earl of IIalmsbury, on seeing one, arranged to have a number imported to his kennel in England. Here they soon gained considerable popularity. This dog gradually died out in Newfoundland as a result of a heavy dog tax. The decline of native dogs and the English quarantine law put an end to importation of Labradors to England, and many English breeder's crossed the Labrador with other breeds of retrievers. The Third Earl of Malmsbury is credited with having kept an almost undiluted line of Labradors, thus preserving in large degree the original Labrador characteristics. He states in a letter written in 1887 that he always called his dogs Labradors, and he thus seems to have given the breed its name.

Later, Labrador fanciers, desiring to end the practice of interbreeding, drew up a standard that discouraged crossing with other retrievers. 
The Labrador Retriever should be an exceedingly atctive dog, strongly built and close coupled; it should have a good spring of ribs, and wide, well-developed loin and hindquarters. A keen nose, intelligence, steady nerves, stamina, and an inborn desire to please its master make the Labrador an excellent hunting

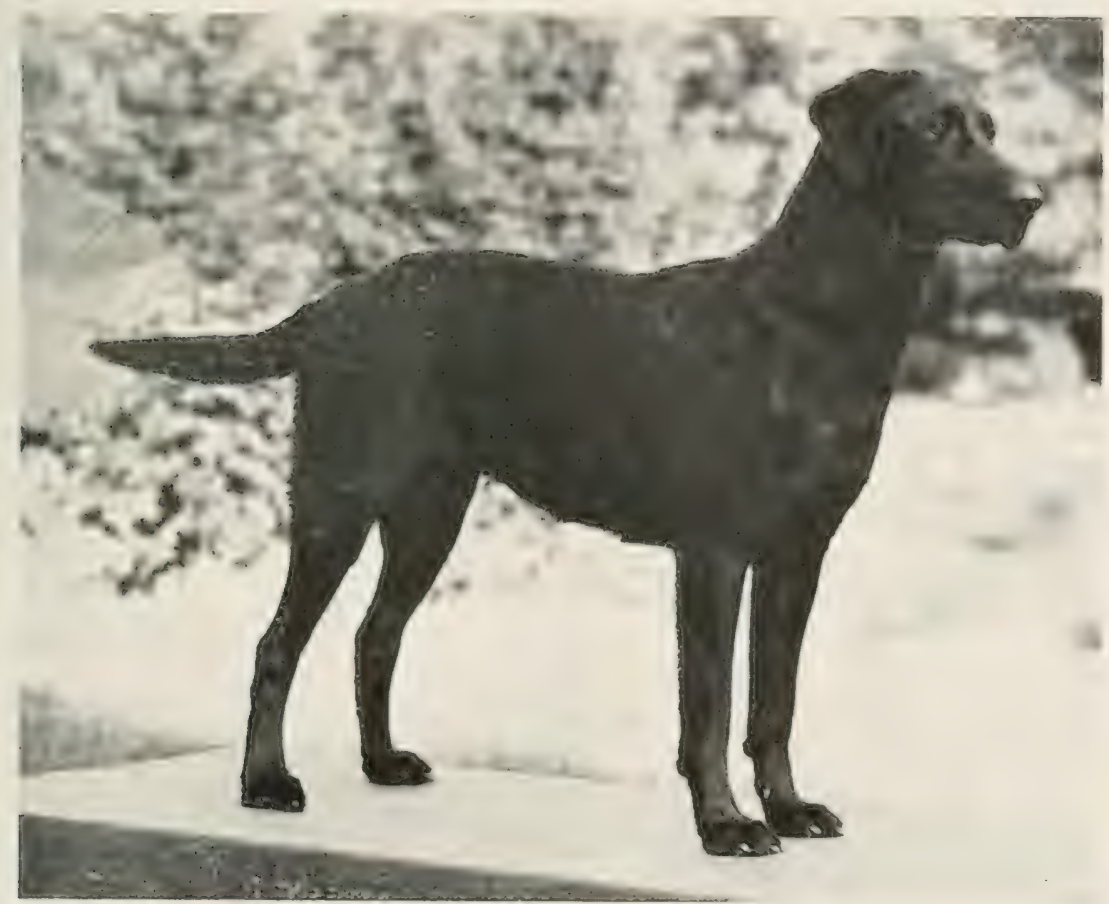

The Labrador is one of our most popular retrievers for both waterfow and upland game. Labradors are strongly built and possess stamina, intelligence, and steady nerves. Black is the usual color for Labradors, but yellow and other colors are permissible.

companion. The eyes of the Labrador, set in a wide skull, should be of medium size and expressive of an active brain and good temper; they may be brown, yellow, or black in color. The jaws should be strong, the nose wide, the nostrils well developed.

The coat character is important; it should be short, rery dense, and without wave, and it should give a fairly hard feeling to the hand. The color is usually black; it should be free from rustiness and any white except possibly a small white spot on the chest. Yellow Labradors are occasionally seen, and other whole colors are permissible. 
Under the standard, dogs should stand $22^{1} .2$ to $24^{1}$. inches and bitches $211 \%$ to $231 \%$ inches. Approximate weights of Labradors in good hard-working condition are dogs 60 to 75 pounds; bitches 55 to 70 pounds.

\section{LITERATURE CITED}

\section{American Kiennel Club}

1947. The complete dog book. Garden City Publishing Co., Inc., Garden City, New York. 753 pp., illus., index.

\section{Becker, Bob}

1945. Retriever, a big hunting asset, makes cripples count in game bag. Ill. Cons. $10(1): 20-4$. Illus.

1947a. Mostly about dogs. Syndicated newspaper column, various dates, in Chicago Sunday Tribune.

"1947b. Bob Becker's dog digest. Paul, Richmond \& Co., Chicago. 1:30 pp., illus.

Bufkin, J. Earl

*1946. Handling your hunting dog. Eighth edition. Ralston Purina Co., St. Louis, Mo. 64 pp., illus.

Carlton, H. W.

*1945. Spaniels: their breaking for sport and field trials. Mile G. Denlinger, Washington, D. C. 126 pp., illus. (Reprint of original published 1915 by Field Press Ltd., London.)

Goodall, Charles S.

1946. The Springer Spaniel is here to stay. Ill. Cons. 11(1\& 2):6-7. 31 illus.

Hawkins, Arthur S., and Frank C. Bellrose

1939. The duck flight and kill along the Illinois River during the fall of 1938. Am. Wildlife 28(4): 178-86. Illus.

\section{Kilbon, Roland}

1947. Born hunter's, the bird dogs. Natl. Geog. Mag. 92(3):369-98. Illus.

\section{Lloyd, Freeman}

1937. Field dogs in action. Natl. Geog. Mag. 71(1):84-108. Illus.

Lytle, Horace

*1934. How to train your bird dog. A. F. Hochwalt Co., Dayton, Ohio. 224 pp., illus.

Moffit, Ella B.

"1937. Elias Vail trains gun dogs. Orange Judd Publishing Co., Inc., New York. 219 pp., illus., index.

Nelson, Urban C., and Gustav Swanson

1941. Losses of crippled game birds. Cons. Volunteer 1(6):41-8.

Randall, Pierce E.

1939. Ringneck pheasant crippling losses. Pa. Game News 10(5):3, 31.

Speelman, S. R., and J. O. Williams

1928. Breeds of dogs. U. S. Dept. Ag. Farm Bul. 1491. 46 pp., 34 figs.

Stringer, Don $\mathbf{H}$.

1946. Beware of the dog racketeer. Here's how he works. Ill. Cons. 11 ( 1 \& 2) : 32-3. Illus.

\section{Stoddard. Herbert L.}

1932. The bobwhite quail: Its habits, preservation and increase. Charles Scribner's Sons, New York. 559 pp., illus., index.

*Publications suggested for use by the amateur trainer. 



\section{Recent Publications}

\section{A.-ILLINOIS NATURAL HISTORY SURVEY BLLLETIV.}

Iolume 22. Article 1.-The Plant Bugs, or Miridae of Illinois. By Harry H. Knigl September, 1941. 234 pp., frontis. + 181 figs, bibliog., index. \$1.25.

Volume 22, Article 2.-Studies of Vorth American Plecoptera, with special reference the fauna of Illinois. By T. H. Frison. Septemher, 19+2. 122 pp.. frontis. + 126 fig bibliog., index. $\$ 1.00$.

Volume 22, Article 6.- Survey of the Illinois Fur Resource. By Louis G. Brown as Lee E. Yeager. September, 1943. 70 pp., frontis. + 33 figs., bibliog. (Bound wi Article 7.)

Volume 22, Article 7.-Illinois Furbearer I)istribution and Income. By. (arl (). Mul September, 1943. 33 pp., frontis. + 24 figs., bibliog. (Bound with Article 6.)

Volume 23, Article 1.-The Caddis Flies, or Trichoptera of Illinois. By Herbert I Ross. August, 1944. 326 pp., frontis. + 961 figs., bibliog., index. $\$ 1.50$.

Volume 23, Article 2.-Duck Populations and Kill. By Frank C. Belloose. Ir. Nosei ber, 1944. 46 pp., frontis. +27 figs., bibliog. 50 cents.

Volume 23, Article 3.-Overfishing in a Small Artificial Lake: ()nized Lake near Alen Illinois. By George W. Bennett. May, 1945. 34 pp., frontis. + 15 figs., bibliog.

V'olume 23, Article 4.-Wetwood of Elms. By J. Cedric Carter. Augrust, 1945. 42 m frontis. +30 figs., bibliog.

Volume 23, Article 5.-Fox Squirrels and Gray Squirrels in Illinois. By Louis ( Brown and Lee E. Yeager. September, 19+5. 88 pp., frontis. + 42 figs., bibliog.

Volume 2t, Article 1.-The Mosquitoes of Iltinois (Diptera. Culicidae). By Herhe H. Ross. August, 1947. 96 pp., frontis. $+18+$ figs., bibliog. 50 cents.

Volume 24, Article 2.-The Leafhoppers, or Cicadellidae, of Illinois (Eurymelina Balcluthinae). By D. M. DeLong. June, 19+8. $280 \mathrm{pp}$. $+51+$ figs., bibliog.. inde $\$ 1.25$.

B.-ILLINOIS NATURAL HISTORY SURVEY CIRCULAR.

34.--Rout the Weeds! Why, When and How. By L. R. Tehon. September, 194 (Fourth printing, with revisions.) 47 pp., color frontis. + 13 figs.

36.-Planting and Care of Shade Trees. By J. E. Davis. September, 1947. (This printing, with additions.) 28 pp., frontis. +20 figs.

41.- How to Recognize and Control Termites in Illinois. By. B. (3. Beruer. Fehruar 1947. 44 pp., frontis. + 32 figs.

\section{C.-ILLINOIS NATURAL HISTORY SURVEY MANLAL.}

2.-Fieldbook of Illinois Land Snails. By Frank Collins Baker. August, 1939. 10e M color frontis. + 170 figs., 8 pls., $\$ 1.00$.

3.-Fieldbook of Native Illinois Shrubs. By Leo R. Tehon. December, 1942. 307 pr + color pls. + 72 figs., glossary, index. \$1.25.

\section{List of available publications, about 700 titles, mailed on request.}

Single copies of It.INoIs N.ITURAL HIstory SURver publications for which no price is linte will be furnished free of charge to indiriduals until the supply becomes low, after which nominal charge may be made. More than one copy of any free publication may be obtaine without cost by educational institutions and ofticial organizations within the state of Illinoi: prices to others on quantity orders of these publications will be quoted upon request.

\section{Address orders and correspondence to the Chief It.inois Natural. History Survey Natural Resources Building, Urbana, Illinois}

Payment in the form of U.S. Post Office money orúer made out to State Treasurer of Illinei Springfield, Illinois, must accompany requests for those puhlications on which a price is set. 



UNIVERSITY OF ILLINOIS-URBANA

570IL6C

C006

CIRCULAR

37-44 1940-51

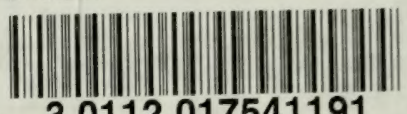
30112017541191 